
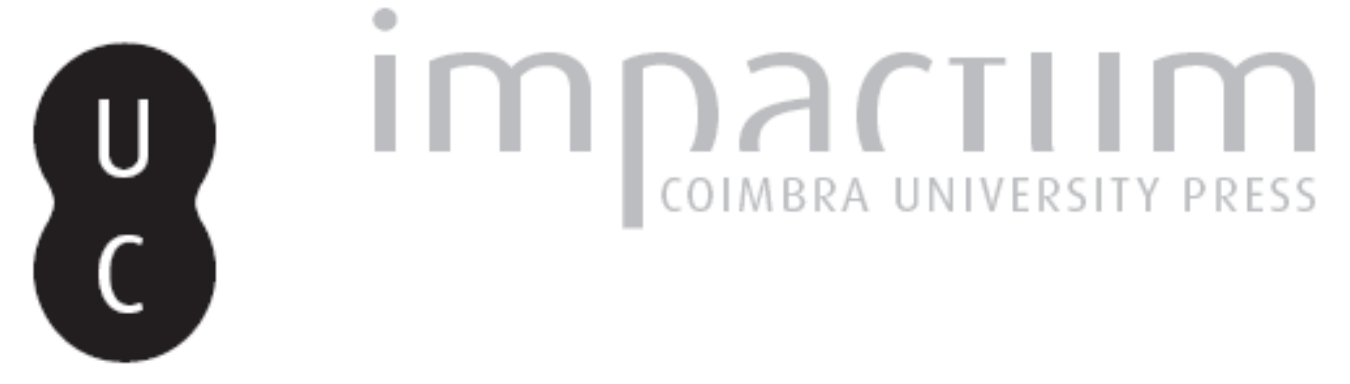

Dipo: ciudad 'tartésico-turdetana' en el valle del Guadiana
Autor(es):
Almagro-Gorbea, Martín; Pau Ripollés, Pere; Rodríguez Martín, F. Germán

Publicado por: Faculdade de Letras da Universidade de Coimbra

URL persistente:

URI:http://hdl.handle.net/10316.2/37819

DOI:

DOI:http://dx.doi.org/10.14195/1647-8657_48_1

Accessed : $\quad$ 26-Apr-2023 07:24:12

A navegação consulta e descarregamento dos títulos inseridos nas Bibliotecas Digitais UC Digitalis, UC Pombalina e UC Impactum, pressupõem a aceitação plena e sem reservas dos Termos e Condições de Uso destas Bibliotecas Digitais, disponíveis em https://digitalis.uc.pt/pt-pt/termos.

Conforme exposto nos referidos Termos e Condições de Uso, o descarregamento de títulos de acesso restrito requer uma licença válida de autorização devendo o utilizador aceder ao(s) documento(s) a partir de um endereço de IP da instituição detentora da supramencionada licença.

Ao utilizador é apenas permitido o descarregamento para uso pessoal, pelo que o emprego do(s) título(s) descarregado(s) para outro fim, designadamente comercial, carece de autorização do respetivo autor ou editor da obra.

Na medida em que todas as obras da UC Digitalis se encontram protegidas pelo Código do Direito de Autor e Direitos Conexos e demais legislação aplicável, toda a cópia, parcial ou total, deste documento, nos casos em que é legalmente admitida, deverá conter ou fazer-se acompanhar por este aviso.

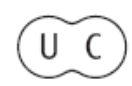


CONIMBRIGA

W.

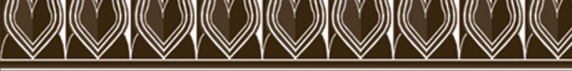

INSTITUTO DE ARQUEOLOGIA

VOLUME XLVIII • 2009

FACULDADE DE LETRAS 
Martín Almagro-Gorbea*, Pere Pau Ripollés**, F. Germán Rodríguez MARTín***

* Universidad Complutense de Madrid e Real Academia de la Historia ; ** Universidad de Valencia; *** Museo Arqueológico Regional

DIPO. CIUDAD 'TARTÉSICO-TURDETANA' EN EL VALLE DEL GUADIANA

"Conimbriga” XLVIII (2009) p. 5-60

Resumen: Los hallazgos de monedas de Dipo en el término de Guadajira, Badajoz, y el estudio territorial del Valle del Guadiana en época orientalizante han permitido localizar esta importante población de la antigua Lusitania. Su origen es una colonia tartésica, paralela y rival de Medellín-Conisturgis, pues ambas controlaban dos ramales paralelos de la 'Vía de la Plata' y la vía de Olisipo a Oretum, que unía todas las colonias periféricas del mundo tartesio septentrional.

El análisis de las referencias a Dipo en la Antigüedad, las discusiones sobre su ubicación, los hallazgos arqueológicos, la estructura topográfica y su importancia estratégica, así como el estudio de la tipología, cronología, dispersión y catálogo de las monedas de Dipo permiten identificar esta ciudad, lo que supone una importante aportación al conocimiento de la estructura territorial de la cuenca del Guadiana y del Suroeste de Hispania en época prerromana.

Abstract: The coins of Dipo found in Guadajira (Badajoz), and the study of the Guadiana Valley in the Orientalizing Period has located this important preroman population of Lusitania. Its origin was a

Conimbriga, 48 (2009) 5-60 
tartesian 'colony', similar to and rival of Medellín-Conisturgis. Both towns controlled two parallel branches of the 'Via de la Plata' and the route from Olisipo to Oretum and Castulo, which connected the peripherical colonies of the northern tartesian world.

The analysis of the classical references of Dipo, the discussions on its location, its archaeological findings, its topography and strategic importance, as well as the study of the typology, chronology, dispersion and catalogue of the coins mint in Dipo, identify definitely this town. It supposes an important contribution to the territorial structure of the Guadiana basin and of Lusitania in preroman times. 


\section{DIPO. CIUDAD ‘TARTÉSICO-TURDETANA’ EN EL VALLE DEL GUADIANA}

\section{Introducción}

La población prerromana de Dippo, una ciudad de origen tartesio a juzgar por la característica terminación de su topónimo, era hasta ahora de situación desconocida. Este hecho ha traído consigo las correspondientes discusiones desde el siglo XIX, hasta que recientes hallazgos numismáticos han permitido localizar con gran probabilidad la ubicación de esta rara ceca y, por consiguiente, el lugar ocupado por esa antigua población prerromana. Este descubrimiento constituye una importante aportación para comprender la estructura territorial de las Vegas del Guadiana y, en un sentido más amplio, de todo el Suroeste de la antigua Hispania, que se ha sumado al reciente estudio sobre Medellín y su identificación con la antigua Conisturgis (Almagro-Gorbea et al. 2008), lo que aconseja publicarlo sin mayor demora.

En efecto, Dipo aparece ubicada en pleno valle del Guadiana, lo que no resulta sorprendente, pues dicha situación ya había sido supuesta por algunos estudiosos y confirma el interés de esa zona dentro del complejo ámbito geopolítico tartésico. Por ello, la localización de la ceca y ciudad de Dippo con datos precisos ofrece una visión mucho mejor de la estructura del territorio del valle del Guadiana desde época orientalizante hasta la fundación de Augusta Emerita, que supuso una profunda reorganización de la estructura territorial del valle del Guadiana. 


\section{Las referencias a Dipo en la Antigüedad}

Las referencias sobre Dipo en las fuentes clásicas son escasas, pues se limitan a una discutida referencia de Livio, otra referencia fragmentaria de Salustio y dos indicaciones en los itinerarios.

La más antigua referencia que existe sobre la población de Dipo es un texto de Livio $(39,30)$ que narra las primeras campañas romanas contra los carpetanos el 185 a.C., en un pasaje que ha sido bastante discutido: Eodem anno in Hispania praetores C. Calpurnius et L. Quinctius, cum primo vere ex hibernis copias, eductas in Baeturia iunxissent, in Carpetaniam, ubi hostium castra erant, progressi sunt, communi animo consilioque parati rem gerere. Haud procul Dipone et Toleto urbibus inter pabulatores pugna orta est, quibus dum utrimque subvenitur a castris, paulatim omnes copiae in aciem eductae sunt.

La segunda referencia a Dipo es una frase de un texto perdido de Salustio (Hist. I,111: et Diponem, validad urbem, multos dies restantem pugnando vicit), texto que hace referencia a una acción de guerra que Maurenbrecher (1967: 48) atribuyó a Metelo, aunque sus circunstancias históricas resultan imprecisas, ya que se trata de un texto fragmentario, si bien su contexto histórico hace suponer que debe corresponder a las luchas del año 80/79 o 79/78 a.C. Finalmente, también se cita a Dipo en el Itinerario Antonino (It.Ant. 418.3) como Dipone y en el Ravenate (IV,44 =314,8), ya con el topónimo corrompido, como Bipone, topónimo que, con seguridad, corresponde a la misma población.

La referencia de Dipo en Livio $(39,30)$ ya fue valorada por Hübner (1903: 1159), quien, con acierto, consideró que esta referencia a Dipo y la de Salustio aludían a la misma ciudad. Sin embargo, esta acertada visión no ha sido posteriormente seguida por otros autores, probablemente por seguir la opinión contraria de A. Schulten (1937: 207), quien consideraba "imposible que se trate de Dipo al Oeste de Emerita; es, por el contrario, otra ciudad del mismo nombre (Hübner, 1903: 1159, confunde ambos lugares)". Por su parte, Tovar (1976: 218), con prudencia, se apartó de Schulten, pero dudaba entre ambas opiniones, pues señaló que: "Es bleibt nach wie vor fraglich, ob das karpetanische Dipo bei Livius tatsächlich ein anderer Ort ist oder ob sich Livius hier geirrt hat", mientras que la Tabula Imperii Romani (J-29: 74, s.v. Dipone) 
excluye sin explicaciones tanto la cita de Livio como también la indiscutida de Salustio.

J. de Alarcão (1973:40), basándose en el desarrollo de la Guerra Sertoriana, señaló que Dipo, Conistorgis y Lacimurgi eran una línea de ataque de Metelo contra Sertorio. Metelo se apoyaría en la línea del Guadiana, a la que desde Olisipo y Caeciliana se llegaba por Dipo (Schulten 1949: 95 s.), pero no se apoyaría en el Guadiana por ser un foso, como señaló Schulten (id., 90), sino porque las gentes de esta zona podían considerarse turdetanos, pueblo entonces ya plenamente romanizado. Desde la línea del Guadiana los caminos de Metelo han quedado indicados por tres topónimos que llevan su nombre: Metellinum, Castra Caecilia y Vicus Caecilius, éste último situado entre el Tajo y la Sierra de Gata, además, acaso, de la Kaíkila (= Caecilia?) de Ptolomeo (II,4,9), quizás situada cerca de Córdoba (Tovar 1974: 182; García Alonso 2003: 47), y de Caeciliana en la costa atlántica, en la zona de la actual Setúbal (Schulten 1949: 91 s. y 95, y mapa), situación que aseguraba la comunicación marítima en retaguardia. Meteló desde el Guadiana se proyectó hacia Castra Caecilia y Vicus Caecilius, en tierras cacereñas, así como hacia Caeciliana, ésta cerca de Setúbal, cuya relación con Metelo ha sido discutida (Guerra 2004: 219).

En 1993, Luis Berrocal (1993: 44, 63) abordó la personalidad de Dipo y su ubicación entre los topónimos del Suroeste de Hispania en su estudio sobre los Célticos. Para este autor Dipo sería el oppidum indígena ya citado por Livio ( $A b U$ r. Con., 39, 30) en la primera incursión romana hacia la Lusitania, fechada en torno al 186 a. C., "situándolo en la Carpetania, quizás por error", aunque en otro lugar (p. 44) señala que "se observa una posible confusión con la ubicación de Dipo, que no puede ser la que se recoge en el Itinerario entre Lobón y Juromenha". Al inicio del decenio de 1990, García Mora (1991: 87 y 91 s.), al estudiar la Guerra de Sartorio, hace una breve referencia al episodio de Dipo (Sal. Hist. I,113), que fecha en el año 78 a.C., pero sin entrar en el tema de la situación de la ciudad ni en lo que representó el episodio de su conquista en el desarrollo de las Guerras Sertorianas tras una lucha que debió ser muy dura, pues parece haber supuesto su destrucción, aunque sí discute con más detalle la ubicación de Castra Caecilia (id., p. 94), Caeciliana y Vicus Caecilius (id., p. 96). 
Años después, Luciano Pérez Vilatela (2000: 176, 196) comenta que algunos manuscritos de Livio ofrecen la forma Hipo, aunque la confrontación con Salustio y con los Itinerarios precisan que la forma original era Dipo. En todo caso, Dipo pudo tener potencialmente una $/ \mathrm{n} /$ final, ya que se declinaba en Latín como tema en - $n$, como indica la forma Diponem (Salust. Hist. I,111) y la Dipone de los itinerarios (IA 418,3).

Pérez Vilatela (ibidem) también señaló con acierto que Dipo y Collippo serían los topónimos en -ipo más septentrionales (Pérez Vilatela 1990: 44 s. y 95) y, al plantearse la identificación histórica de Dipo, la considera la población mencionada por Livio $(39,30)$ en la Carpetania en su narración de la conquista romana de Hispania, "probablemente debido a que era éste el país del que provenía el ejército romano en el 185 a. de J.C.", habiéndose producido la substitución del "lugar en donde" por el "lugar a través del cual se accede", como ocurre a menudo en los Itinerarios. Tras su temprana mención en la campaña del año 185 a. de J.C. de Quinctio Crispino y Calpurnio Pisón, ya no vuelve a ser mencionada de nuevo como punto conflictivo hasta la Guerra Sertoriana, pues según Pérez Vilatela (ibidem), Dipo no se habría inclinado demasiado hacia la causa lusitana, puesto que "se convirtió en una de las cecas romanorepublicanas de Hispania, a partir de 133 a. de J.C.”. En efecto, Dipo pudiera tratarse de uno más de los numerosos casos de ciudades del Suroeste con el mismo nombre que otras de la Celtiberia y zonas afines (Pérez Vilatela, 2000: 108 s.), pero no parece que esto ocurra en el presente caso. Los pretores C. Calpurnio y L. Quinctio, tras haber invernado en la Bética, llevaron sus tropas a la Beturia y de aquí se dirigieron hacia la Carpetania, donde los hispanos tenían sus campamentos de guerra, pues querían combatirlos conjuntamente. En este recorrido, parece lógico que pasaran por el valle del Guadiana, controlado por la ciudad de Dipo. Si se acepta esta lógica interpretación, a esta ciudad correspondería la referencia a la lucha que se inició haud procul Dipone et Toleto urbibus, esto es, no lejos de las ciudades de Dipo y Toledo, en la que vencieron los hispanos, que obligaron a huir a las legiones romanas. Ello lleva a concluir que la Dipo citada por Livio es la que controlaba el paso del Guadiana en el camino desde la Beturia 
a la Carpetania, aunque la falta de precisión en Livio permite pensar en una posible confusión con una segunda batalla que ya habría tenido lugar en el territorio de Toletum, donde, tras la derrota anterior, se impusieron los romanos en la batalla definitiva celebrada en un lugar desconocido junto al Tajo. Sin embargo, todavía cabría una tercera posibilidad, ya menos verosímil, de que también la Toletum citada por Livio no fuera la ciudad carpetana (Ptol. II,6), sino que correspondiera a una población extremeña de nombre semejante, como pudiera ser Tolote (Pérez Vilatela 2000:110), posibilidad que parece mucho menos probable, aunque teóricamente tampoco se deba excluir.

\section{Historiografía sobre las discusiones en torno a la ubicación de Dipo}

Los estudios de la tradición erudita ya se ocuparon de la situación de Dipo basándose en el Itinerario Antonino. En efecto, Dipo ya aparece recogido por el famoso humanista Ambrosio de Morales (Sánchez Madrid, 2002), quien, hacia 1575, en Las Antigüedades de las ciudades de España (1792: 120), al analizar el Iter ab Olisipone Emeritam, sitúa Dipone en Talavera la Real, tradición anticuaria cuyo colofón puede considerarse representado por Ceán Bermúdez (1832: 289), quien, en su Sumario de las antigüedades romanas que hay en España, sitúa Dippo (sic) como octava mansión entre Lisboa y Mérida en Talavera la Real y la considera parte de los Celtas Beturienses, idea que todavía recoge la enciclopedia de Espasa-Calpe (XVIII, s.v.).

A lo largo del siglo XIX prosiguió entre los eruditos e investigadores la discusión sobre la ubicación aproximada de Dipo entre Mérida y Évora. José de Viu (1852:74), siguiendo el Itinerario de Antonino, recoge que había 9 millas de Emerita a Dipone, de ésta a Evandriana otras 12 millas y desde Evandriana hasta Augusta o Pax Augusta (Badajoz), 16 millas, por lo que dedujo que "Dipo debió estar hacia donde ahora la ermita de Perales (en Arroyo de San Serván) y Evandriana donde Talavera la Real", por lo que suponía que quedaba al SW de Mérida y al Sur del Guadiana.

Años después, Eduardo Saavedra (1862: 92), en su Discurso de ingreso a la Real Academia de la Historia, coloca Dipo a la derecha del Guadiana en Portugal en el mapa de las vías romanas de Hispania 
que publica y señala en el texto que debía estar situada "a una legua antes de llegar a Elvas", según las distancias del Itinerario de Antonino. aproximadamente a la altura de Badajoz, opinión que coincide con la seguida posteriormente por otros autores, tanto de su época (Martín Mínguez 1883: 119) como posteriores, como Alarcão, Roldán y, en especial, los numismáticos (vid. infra).

E. Hübner (1893, no 183), al ocuparse de sus monedas, señala que su ubicación era desconocida, situs ignoratur, pero el tipo de moneda de Dipo le llevó a suponer que la ceca estaría en el territorio de Évora (1903:1159), como indican los itinerarios, que la sitúan entre Évora y Mérida, aproximadamente a una legua de Elvas. Schulten, al recoger las referencias de Livio $(39,30)$ y de Salustio $(I, 113)$, siguió a Hübner y también indica que Dipo quedaba entre Emerita y Évora, sin más precisión (Schulten 1935: 205 s.; 1937: 174-175), aunque al referirse a la destrucción de Dipo durante las Guerras Sertoriana el 79 a.C. la sitúa al Este de Badajoz, a 29 millas de Emerita (id., 1949: 95), siendo seguido por otros autores, como Bosch Gimpera y Aguado Bleye (1962: 73), incluso muchos años después, por J. de Francisco (1989: 61), quien textualmente señala que "la Dypon que nos cita Tito Livio no puede ser la Dipo que está enclavada en Lusiania", lo mismo que en la posterior síntesis de Montenegro (1996: 64, n. 80), que sigue a Bosch Gimpera y Aguado Bleye.

Bastantes años después, Navarro del Castillo (1963: 56), en un artículo en el que considera que Lobón era la antigua población de Lyco, es el primero que indica el hallazgo de monedas de Dipo en dicho término municipal, inclinándose por situarla en la zona a $1 \mathrm{~km}$. en dirección a la dehesa de Barbaño, donde existe una importante villa romana (Rodríguez Martín, 1998), aunque no llegó a ofrecer documento alguno y esta referencia, demasiado vaga y no documentada, no llegó a tener eco en los estudios posteriores.

J. de Alarcão (1973: 40, 74 y 82), en su Portugal Romano, indica que se suele situar hacia Elvas, donde no hay hallazgos que lo justifiquen, o en Evora Monte, pues el único indicio es el hallazgo en Juromenha (Concelho de Alandroal), junto al Guadiana, de un miliario. Algunos años después (id., 1988: 221-222) volvió a ocuparse de Dipo, pero sin indicar su situación, y aunque se inclina por Évora Monte (id., I, 
56), señala que es recogida en el Itinerario de Antonino e indica las publicaciones previas de Leite de Vasconcelos (1913: 109, n. 6) y de Roldán (1975: 235), que la había situado en Elvas. De nuevo ha retomado el tema en fechas más recientes (Alarcão 2001), inclinándose de nuevo por situarla en Évora Monte, pero sin ofrecer argumentos concluyentes, aunque discute la nueva interpretación que Gorges y Rodríguez Martín (1999) habían planteado a propósito de la vía de Olisipo a Emerita al publicar un miliario de Magnencio hallado en Torre Águila (Montijo, Badajoz).

Otro autor que se ha ocupado de la ubicación de Dipo en esos mismos años fue J. M. Roldán, en su Itineraria Hispanica (1975: 64 y 235), obra en la que indica que "no es posible localizar con seguridad", siguiendo a Saavedra (op. cit.), aunque se inclina por la zona de Elvas, si bien poco después en una obra general indica la existencia de dos poblaciones con ese nombre (id., 1978: 25).

Ese mismo decenio, Tovar, en el tomo de Iberische Landeskunde dedicado a Lusitania, recoge con cierta extensión las imprecisas referencias existentes sobre Dipo (Tovar 1976: 218-219). En primer lugar, plantea el problema de su identidad con la ciudad carpetana del mismo nombre citada por Livio $(39,30)$, sin decantarse sobre si se trata o no de un error de este autor latino. Igualmente recoge el texto de Salustio (Hist. 1,113) con la cita a Dipo en una acción atribuida a Metelo, de acuerdo con la interpretación tradicional de 1891 de B. Maurenbrecher (1967: 48). Esta Dipo de Salustio la identifica con la de los itinerarios (It. Ant. 418,3; Rav. 314,8), según los cuales se situaría a 12 millas de Ad atrum flumen y 17 de Evandriana. También recoge, finalmente, las opiniones citadas de E. Hübner y de J. de Alarcâo (vid. supra).

Casi un decenio después, Rubio Muñoz (1983: 133) consideró que debía estar próxima a Mérida, en la comarca de Talavera la RealLobón, dado que el Itinerario la sitúa sólo a 26 millas al oeste de Emérita. La referencia a su destrucción probablemente a manos de Metello (Salust., Hist. I,113), "ocurrida tras la campaña del Algarbe, permite situar la fortaleza en el Alto Alentejo o la provincia de Badajoz, dentro de la cuenca del Guadiana, emplazamiento que viene a coincidir, con el deducido del Itinerario, 418,3 y de la Cosmografía de Rávena, 314,8". Aunque también señala las discordancias existentes entre Alarcão (1983: 40 y 74), Roldán (1971: 64) y Rubio Muñoz (1983: 133), Berrocal se 
inclina por situar Dipo bajo la impresionante fortaleza medieval de Juromenha, por la que pasaría la vía de Olisipo a Emerita por Ébora (Heleno 1951; Tovar, 1976: 218-219; Arias 1987: 122).

Fernández Corrales (1987: 54, mapas 1-3), al estudiar El trazado de las vías romanas en Extremadura, la sitúa hacia Talavera la Real según lo que indican las distancias miliarias, pero algunos años más tarde, en la Forma Urbis, este autor recoge las referencias del Itinerario de Antonino (418.3: Dipone) y del Ravenate (314.8: Bipone), pero no las anteriores de Livio y Salustio (Fernández Corrales 1995: 74-75, s. v. "Dipone"), lo que resulta sorprendente. En dicho trabajo, Fernández Corrales (ibidem) la considera una mansio de la vía XII del Itinerario de Antonino de localización incierta entre Evandriana y Ad Atrum Flumen, por lo que no descarta "la posibilidad de que se encuentre en el término municipal de Talavera La Real, en función de las distancias transmitidas", término en el que se señala el hallazgo de monedas de Onuba, Italica y Emerita, pero no de Dipo, según se indica más adelante (Forma Urbis, s. v. "Talavera la Real", p. 150). Por esos mismos años, Dipo no aparece considerada en la obra de Silières (1990a) sobre las vías de comunicación de la Hispania meridional, probablemente por no atribuir su ubicación al importante punto de control viario que ocupa.

Pérez Vilatela (1990: 47), al analizar los topónimos en ipo, la describe como "una de las mayores ciudades de Lusitania prerromana y de época republicana", pero la considera no localizada en su importante obra sobre Lusitania, (2000: 196), en la que concluye que "no creemos probable que estuviese al Este del Anas", por lo que parece sumarse a la tesis de su ubicación en Portugal, que ha resultado incierta.

En fechas posteriores, Villar (2000: 99 s.) vuelve de nuevo a considerar la existencia de dos poblaciones denominadas Dipo, una carpetana y otra lusitana, mientras que $\mathrm{M}^{\mathrm{a}} \mathrm{P}$. García Bellido y C. Blázquez (2001: 111) consideran su ubicación desconocida y Pérez Guijo (2005), al señalar que los romanos fueron derrotados en la Dipo lusitana el 188 a.C., sitúa la población, sin más precisión, entre Mérida y Évora.

La solución a estas largas discusiones se ha resulto en estos últimos años. El uso generalizado de detectores de metal ha debido facilitar la localización de una concentración de monedas de Dipo en terrenos 
cercanos a Talavera la Real, pero ya al Este del río Guadajira, en el término del pueblo del Plan Badajoz al que se dio el nombre de dicho río (Rodríguez Marín y Gorges 2006: 179). Como Dipo es un ceca relativamente rara y con escasa difusión de sus monedas (vid. infra), estos hallazgos numismáticos permitían considerar localizada, con muy alta probabilidad, la ubicación de esta rara ceca y, por consiguiente, la del lugar ocupado por esa antigua población prerromana, hecho que ha permitido profundizar en su situación y significado histórico en el Valle del Guadiana.

\section{La estructura topográfica de Dippo}

La localización de Dippo en el término de Guadajira, Badajoz, ha sido posible gracias a las noticias sobre los hallazgos arqueológicos que aparecían en su término recogidas en estos últimos años por Germán Rodríguez Martín de aficionados y de estudiosos de la zona, entre los que llamaba la atención, como se ha señalado, la reiterada aparición de monedas de Dippo (vid. infra), ceca de acuñación poco abundante y que tuvo escasa dispersión, lo que permitía suponer que Guadajira correspondiera a su ubicación originaria.

La ausencia de trabajos de excavación e incluso de sondeos preliminares en ese lugar impide conocer con la debida precisión la topografía de la población prerromana, que debió estar ubicada en las inmediatas proximidades y bajo el actual pueblo de Guadajira. Ese lugar forma un espolón o península en la convergencia del cauce del río Guadajira, que corre de Sureste a Noroeste, al desembocar por la margen meridional en el Guadiana (fig. 1 y 2). Dicho lugar posee un gran interés estratégico, pues, al mismo tiempo que domina las ricas Vegas Bajas de Guadiana, controla el paso de río por el vado formado por los arrastres del río Guadajira y, por tanto, el camino hacia la Bética (vid. infra).

La topografía del lugar donde se situaba la población de Dipo constituye el extremo occidental de una formación de arcillas terciarias (MME 58-59) cortada por la erosión del cauce fluctuante del Guadiana, por lo que su superficie se eleva unos $50 \mathrm{~m}$. respecto a las inmediatas vegas de la margen izquierda. Esta formación de arcillas forma una especie de macizo que domina las Vegas Bajas del Guadiana y que se extiende unos $5 \mathrm{~km}$., desde la población de Lobón, que ocupa su extremo 
oriental, hasta la de Guadajira, que ocupa el occidental (fig. 1 y 2). En ese extremo occidental, erosionado por el río Guadiana por el Norte y por el Guadajira por el Sureste (fig. 3), el macizo arcilloso ofrece una estructura a modo de espolón con dos pequeñas vaguadas que le dan una forma de península semitriangular, entre el abrupto corte del cauce del Guadiana al Norte y el valle formado por la erosión del Guadajira al Suroeste (fig. 4). La parte más elevada de dicha península queda aproximadamente a $38^{\circ} 51^{\prime} 10^{\prime \prime}$ de latitud Norte y $6^{\circ} 40^{\prime} 40^{\prime \prime}$ de longitud Oeste y ofrece una altura máxima de 232 m.s.n.m., por lo que queda a unos $50 \mathrm{~m}$ sobre el nivel del cauce actual del Guadiana en esa zona, que en la actualidad corre casi $2 \mathrm{~km}$ hacia el Norte a 180 m.s.n.m. (MTNE 776-IV), mientras que la zona septentrional, que avanza hacia el Guadiana, constituye el punto de máximo dominio visual a 211 m.s.n.m. (fig. 3, 4 y 5).

La importancia estratégica de Dipo se explica perfectamente en su marco geográfico, aunque esta zona ha sufrido a lo largo de los siglos importantes transformaciones (Rodríguez Martín 1993; id., 1996), por lo que la visión espacial en la Antigüedad dista bastante de la que se puede apreciar en la actualidad.

No se sabe con exactitud por donde discurriría el cauce y los brazos del Ana a finales de la Edad del Bronce, ya que sus huellas han desaparecido con las parcelación romana en primer lugar y, posteriormente, con las transformaciones de la puesta en marcha del Plan Badajoz, aunque, pese a estas circunstancias adversas, una prospección intensiva podría aclarar algunos de estos interrogantes. Sabemos por el geógrafo Eduardo Hernández Pacheco (1955: 360 s.) que el Guadiana es un río de curso estacional y de fuerte escorrentía, con importantes crecidas en los periodos de lluvias, lo que ha provocado, en un terreno palustre como éste, que cambiase de curso con relativa asiduidad. A la vez, en los períodos de estío, como el propio Hernández Pacheco afirma, el Guadiana queda reducido a charcas en muchos tramos. Por tanto, no podemos seguir manteniendo la idea del caudal del Ana basada en el régimen actual del río, ya que el "nuevo Guadiana" está perfectamente regulado por una amplia red de pantanos, como los del Cijara, La Serena, el Matachel, etc. 
Sin embargo, sí hay constancia aproximada de que en siglos posteriores no debía distar mucho del cauce actual, ya que se puede rastrear el cauce "principal" del río por la posición de las villae romanas localizadas y, sobre todo, por las normas dictadas en época del emperador Vespasiano referentes a la ocupación ilegal de las tierras ribereñas, que habían sido declaradas desde los inicios de la Colonia de Augusta Emerita como públicas. Esta situación, como recogen las fuentes, se solucionó de forma que no agradó ni a los propietarios ni a los demandantes, siendo de interés señalar que casi coincide Dipo (fig. 20) con la pértica de la centuriación romana de Emerita (Georges y Rodríguez Marín 2006: 187, fig. 3).

El límite primigenio de las tierras de subcesivae quedó marcado por medio de dos calzadas, una en cada margen del Ana: la vía XII del Itineario de Antonino, por la margen izquierda, y la XIV y XV, por la derecha. Esta situación y el hallazgo en excavación de un miliario en la villa de Torre Águila permiten saber que la calzada pasaba por los bajos de Lobón, entre la milla 16 y 17, es decir, por la zona de vega de aproximandamente un kilómetro, donde el río no podía llegar en su máxima crecida. En la zona de Guadajira, no cabe suponer que se aproximara a ella el Guadiana, ya que las villas situadas en su ribera marcan perfectamente su trazado. Es precisamente en la villa de Pesquero, en Pueblonuevo del Guadiana, ubicada en la margen derecha frente a Guadajira, donde el río ha ido socavando la propia villa.

Este paisaje del Ana en Lobón debió ir cambiando paulatinamente o en una de sus múltiples crecidas, tendiendo cada vez más a aproximarse al pueblo. Parece ser que entre los siglos VIII y IX, como hemos podido comprobar en la villa de Torre Águila (Rodríguez Martín 1993), el río hace un cambio de curso más brusco, de tal modo que si en los primeros siglos la villa se encontraba en la margen izquierda, a partir de esas fechas pasa al margen derecho, aunque llegaba a ocupar la primitiva calzada en las etapas de grandes crecidas. En el caso de Lobón, el fenómeno resultante es la aproximación cada vez más marcada a las partes bajas del pueblo, situación que obligó a un cambio en el trazado de la antigua calzada (vía XII), que a partir de esos momentos pasó a transcurrir por los altos de Lobón para dirigirse por la planicie superior hasta el Guadajira, punto esencial y de control, en todo momento, de 
este río, afluente que desembocaba en el período romano y posterior, aproximadamente, a $1 \mathrm{~km}$. de los cerros del Cotorrillo, nombre con el que se conocía al lugar donde se levanta el actual pueblo de colonización de Guadajira.

La situación tan privilegiada del actual pueblo de Guadajira, así como la presencia de hallazgos del Bronce Final y del Período Orientalizante, con estructuras tanto de tipo urbano (hoy destruidas al levantar nuevas viviendas), como de necrópolis, permiten afirmar que el lugar fue siempre un importante punto de control. Cierto es que ambos extremos de la meseta (Guadajira y Lobón) siguen facies similares, con mayor preponderancia, en un primer momento, de la occidental (Guadajira) y a partir del siglo IV a.C. de la oriental (Lobón). Sin embargo, ambas siguen un ritmo paralelo a lo largo de la Antigüedad, como ponen de manifiesto los materiales recogidos en ambos lugares. Será a partir del cambio del curso del río Guadiana, expuesto unas líneas más arriba, cuando Lobón consiga un desarrollo mucho mayor, como lo atestigua la presencia de un castillo levantado en época islámica, hoy destruido, y la ubicación a partir de esas fechas del nuevo trazado vial, que cada vez se aleja más del cerro del Cotorrillo, como evidencia el propio trazado de la antigua carretera nacional $\mathrm{V}$, que pasaba por los bajos del nuevo pueblo de colonización. Por tanto, sin poder precisar en el tiempo, pero con bastantes visos de probabilidad, el nuevo cambio de río y el auge tomado por Lobón como punto estratégico y de control, llevó a una paulatina desaparición del lugar donde debió ubicarse la primitiva Dipo. Abandono que culmina con la creación a finales de los cuarenta del siglo XX del pueblo de colonización de Guadajira.

\section{Los hallazgos arqueológicos}

Bajo el promontorio o espolón más saliente y extremo situado al Noroeste y justo encima de las vega del Guadiana (fig. 5), sobre un lugar denominado El Cuco, es donde se han realizado los más importantes hallazgos, datados desde la Edad del Bronce hasta época romana (vid. infra). Dicho promontorio mide tan sólo unos $200 \mathrm{~m}$ de Norte a Sur por $100 \mathrm{~m}$ de Este a Oeste en su anchura máxima y avanza en forma de lengua destacándose del resto de la península entre una 
abrupta caída hacia el valle del Guadajira y una vaguada que lo separa del resto del macizo que domina esa parte de las Vegas del Guadiana (fig. 3, 4 y 5).

Este estratégico lugar debió ser ocupado por la población prerromana de Dipo, quizás como acrópolis, aunque la falta de excavaciones impide contar con indicios más evidentes. Es seguro el hallazgo de algún fragmento campaniforme y de monedas antiguas en la zona, como una de Salacia (fig. 6a) aparecida en la calle de la Orden, en el suroeste del actual casco urbano de la población, a $38^{\circ} 51^{\prime}$ ' $02^{\prime \prime}$ Norte y $6^{\circ} 40^{\prime} 57^{\prime \prime}$ Este. Sin embargo, también hay que tener en cuenta que los rebajes de tierra que se realizaron para construir la población de Guadajira dentro del llamado "Plan Badajoz" han debido destruir niveles arqueológicos, que en parte fueron transportados a la vega para mejorar su carácter palustre, según confirmación oral de las gentes que vivieron en los cortijos de la zona antes y durante la construcción del pueblo de colonización en los años 1960, aunque falta documentación sobre las fuertes transformaciones sufridas en toda esa zona (Jerez Linde 2002: 13), que se vió afectada por remociones de tierras ocurridas en esas fechas (fig. 7).

Además de la citada moneda de Salacia, es de interés señalar la aparición algo más al Sur, en las ladera meridionales de la población (fig. 8), de una tumba con una urna de tipo turdetano con su cuenco como tapadera (fig. 9), fechable en los siglo III-II a.C. (José Manuel Jerez Linde, comunicación personal, 19.4.2008), en una zona ocupada ya por enterramientos del inicio de la Edad del Bronce (Hurtado 1985). Esta tumba de incineración confirmaría la existencia de un hábitat prerromano de tradición turdetana sobre el cerro en espolón que domina la confluencia del Guadajira con el Guadiana que actualmente ocupa el pueblo de Guadajira (fig. 3 y 4). Más interesante son algunos hallazgos procedentes del lugar denominado "El Cuco", situado en la Vega del Guadiana al pié del cerro y en la margen derecha del pueblo de Colonización (fig. 1 y 4). En dicho lugar, de unas $5 \mathrm{Ha}$., han aparecido, además de diversas monedas de la ceca de Dipo (vid. infra), numerosos materiales arqueológicos de interés, los más antiguos de los cuales se remontan al Periodo Orientalizante. Además de numerosas cerámicas a torno grises orientalizantes, destaca un fragmento de plato ático atribuido al Pintor de Londres B-76 (fig. 10), fechado hacia el 
570-560 a.C. (Jiménez Ávila y Ortega 2004: 15 s. y 68 s.), así como otro fragmento de cerámica con una figura humana, quizás alada, bajo cenefa de cable (fig. 11), que cabe fechar antes del 600 a.C. al ser de tipo 'Medellín' (Torres 2008). También se esa zona proceden algunos fragmentos de cerámicas áticas de barniz negro (fig. 12), que documentan la continuidad de la población en el siglo IV a.C. (Jiménez Ávila y Ortega 2004: 18 y fig. $14,5$ y $15,2-3)$.

Igualmente, en esa zona han aparecido objetos de bronce de interés. Uno es una palmeta de un asa de tipo 'ancla' (fig. 13), de las que ya se conocía algún ejemplar en Hispania (Almagro 1943), aunque esta pieza de Dipo debe considerarse una imitación de un oinochoe arcaico probablemente etrusco (Jacobsthal y Langsdorff 1929: 93 s.; Vegas 1957; Hill 1958: 196 s.), más que griego (Hill 1958; Stibbe 2000: 27 s.), a juzgar por la forma plana de la palmeta con las lengüetas separadas por simples líneas incisas. Otra pieza importante son dos asas de manos de 'braserillo' (fig. 14, a), de tipo orientalizante a juzgar por las líneas en las muñecas (Cuadrado 1956: 57, fig. 1-4; Prada 1986; Jiménez Ávila 2002: fig. 96), así como un resorte de fíbula de tipo Alcores o Acebuchal (fig. 14, b), fechable a inicios del siglo VI a.C. (Ruiz Delgado 1989), y dos fíbulas anulares hispánicas, una ellas de tipo orientalizante de arco de alambre (fig. 14, c), tipo 9 de Cuadrado (1963: 17), que en Medellín se fecha c. 575-475 a.C. (Torres 2008a: 532 s.) y otra de charnela (fig. 14, d), de tipo 4 de Cuadrado (1957: fig. 5), ya del siglo $\mathrm{V}$ avanzado o IV a.C., un brazalete en forma de cinta plana con los extremos esféricos (fig. 14, e), variante de forma desconocida en Medellín (Torres 2008b), por lo que no se puede excluir una fecha post-orientalizante, y un colgante amorcillado de 'cesto' (fig. 14, f), característicos de guerreros celtas de tradición atlántica y cuya fecha se sitúa hacia el siglo V a.C. (del Amo 1978), como los lusitanos (Pérez Vilatela 2000: 125). Este conjunto de materiales se completa con una terracota que parece representar un felino con la cabeza y las patas rotas (fig. 15, a), por lo que su adscripción estilística es difícil, aunque recuerda algunos exvotos similares del santuario de Corvo (Maia 2008: fig. 4), y una fusayola casi esférica con decoración incisa (fig. 16, b), que puede atribuirse a la Cultura de los Oppida de Extremadura (Berrocal 2003: fig. 9).

Los materiales de "El Cuco" han sido considerados por Jiménez Ávila y Ortega (2004), como procedentes de una necrópolis del Periodo 
Orientalizante Reciente, que estaría situada próxima al cauce del Guadiana, por lo que sería prácticamente contemporánea de la de Medellín (AlmagroGorbea et al. 2007-2008), pues se fechan, como los objetos de metal, en los siglos VI al IV a.C., aunque la aparición en esa zona de monedas de Dipo y las fuertes remociones sufridas por los terrenos al adecuarlos para el plan de regadío de las Vegas Bajas del Guadiana (fig. 7) dejan abierta la posibilidad de que pudieran proceder de una parte destruida del poblado situado en el cerro. Además, también ha aparecida a unos $200 \mathrm{~m}$. más al Este una moneda de Dipo (fig. 17, a), que confirmaría el posible origen urbano de esos materiales. Por último, el panorama de los hallazgos de esta zona se completa con los materiales recogidos en el extremo suroeste de Guadajira, actualmente sin urbanizar y dedicado a tierras de labor (J. M. Jerez Linde, comunicación personal, 19.4.2008), situado sobre la confluencia del valle del río Guadajira con el vado al Sur y las vegas del Guadiana al norte del posible asentamiento de la población, a $38^{\circ} 50^{\prime} 48^{\prime \prime}$ Norte y $6^{\circ} 40^{\prime} 07^{\prime \prime}$ Este, lugar en el que han aparecido monedas de Castulo $\left(C N H\right.$, p. 335, $\mathrm{n}^{\circ} 38$; García Bellido 1982: no 301-412), Obulco (Arévalo 1999: serie VA) y Carbula (Almodóvar del Río, Córdoba; $\mathrm{CNH}$ p. 365, nº 3), que indican la continuidad de las relaciones comerciales con la Bética de un punto tan estratégico a inicios del siglo I a.C. (fig. 6, b-d).

\section{Dipo, una población tartesia en el Valle del Guadiana}

La identificación del emplazamiento de Dipo permite comprender su importancia geo-estratégica en el Valle del Guadiana, aunque la población resulta prácticamente desconocida al no haberse podido realizar excavaciones. Sin embargo, junto a los materiales orientalizantes, existen diversos indicios de que esta población debe considerarse una fundación o "colonia" tartesia, a juzgar por lo que documenta su topónimo, que ofrece una interesante información complementaria, pues se relaciona con la serie bien estudiada de poblaciones tartesias con topónimos en ipo (Untermann 1961: 34, mapa 16; Villar 2000: 85 s.; Torres 2002: 324 s., fig. XIII,6).

El tamaño y características urbanas de Dipo son desconocidas, ya que su solar parece haber sido muy arrasado al realizar la colonización agrícola del Plan Badajoz hacia 1960 (fig. 7). Sin embargo, este estratégico 
lugar ya debió ser habitado en la Edad del Bronce, como evidencian tres sepulturas de cámara halladas al sur del pueblo actual, junto a la carretera de acceso (fig. 8), que contenían cerámicas de tipo Atalaya-Santa Vitoria (Hurtado 1985; id., 1995: 77, fig. 8), y en el altozano que debió ocupar la ciudad, dominando las Vegas del Guadiana y el río Guadajira, también se ha hallado un fragmento de vaso campaniforme y una muñequera (José Manuel Jerez Linde, comunicación personal, 19.4.2008),

Dipo debe considerarse, en principio, una población de origen orientalizante similar a Conisturgis-Medellín y Lacimurgi en la 'línea' del Guadiana (vid. infra, fig. 19), como confirma su característico topónimo tartésico en -ipo, que se considera un apelativo con significado de "ciudad" (Villar 2000: 387), pues este sintagma siempre aparece asociado a nombres de ciudades, salvo en el hidrónimo Callipous $<*$ Callippo (Villar 2000: 90), aunque este caso podría explicarse por haber recibido dicho río el nombre de la población por la que pasaba. Por ello, la hipótesis de que ipo signifique "ciudad" o "población" en tartésico puede aceptarse sin dificultad (Correa 1994: 339; Villar 2000: 90 y 117 s.), lo que ayuda a interpretar la historia de Dipo. Más problemático es el posible origen anatólico de este elemento, ya valorado por Hubschmid (1960) y seguido por Villar (2000: 109), por lo que se trataría de un término que quizás hubiera llegado hasta Hispania con los movimientos de gentes del Bronce Final relacionados con los llamados "Pueblos del Mar", sin excluir otras posibilidades.

Luciano Pérez Vilatela $(2000: 176,196)$ ya observó que Dipo y Collippo son los topónimos en -ipo más septentrionales conocidos (Villar 2000: 87 s.). Sin embargo, a Dipo y Collippo hay que añadir Lacipaea, en las proximidades de Medellín, pero de ubicación muy discutida (Fita 1894: 94-95; Rosso de Luna 1912; Mélida 1925: 371; Tovar 1974: 208; Díaz et al. 1986; Rosco y Téllez 1986; Fernández Corrales 1987: 69 s.; Madruga y Salas 1995: 347 s.; TIR J-29: 97; Olivares 2002: 41-42, 249), y Lippos, situada ya en la Meseta Norte al Sur de Salamanca (Almagro-Gorbea et al. 2008). Además, en la cuenca del Guadiana, a los topónimos citados se deben añadir Iulipa, en Zalamea de la Serena (CIL II, p. 326 s.; Tovar 1974: 94 s.; Plinio III,10; ItAnt.416,1; Rav. 315,9; quizás Ptol. II,4,9; García Alonso 2003: 54 s.) y con estos topónimos se podría relacionar, con ciertas reservas, 
Sisapo, en la zona minera de Almadén (Strab. III,2,3; Plin. Nh. XXXIII,118 y 121; Ptol. II,6,58; Tovar 1974: 96 s.; TIR, J-30, 301 s.; García Alonso 2003). Ya en la zona atlántica, junto a Collipo, en San Sebastião de Freixo, Leiria, en la Estremadura portuguesa (Plin. IV,133; TIR J-29: 65), hay que incluir Olisippo, Lisboa (Str. III,3,1; Plin. IV,116; Mela III,76; Ptol. II,5,3; ItAnt 416,4; TIR J-29: 118 s.) y Callipo-Cantnipo/Bevipo, en Alcácer do Sal (Ptol II,5,2: TIR J-29: 50; Faria 1989: 79; id. 1992: 40-41; id. 1995: 144 s.). Pero el interés de este conjunto de topónimos en ipo extendidos por áreas periféricas del mundo tartésico es que corresponden a poblaciones que conformaban una auténtica colonización tartesia (Torres 2005; Almagro-Gorbea et al. 2008a, p. 1055s.).

Villar (2000: 87 s.) ha realizado una exhaustiva recopilación de casi 50 topónimos de esta serie, caracterizados por estar formados por un elemento ipo, que se concentran en Andalucía Occidental, pero que se extienden por todo el Suroeste de la Península Ibérica hasta el Tajo (fig. 18). Dichos topónimos se pueden clasificar en tres subseries, según la forma en que aparece dicho elemento en ipo (Villar 2000: 105).

Unos pocos casos, entre los que se encuentra Dipo, se caracterizan porque dicho elemento va precedido de un simple 'prefijo', como ocurre en otros cuatro topónimos (fig. 18): Laepia, en Lepe, Huelva (Plin. III,15), Lippos, en Valverde de Valdecasa, Salamanca (ItAnt. 434,2), Saepo, en el Cerro de la Botinera, Algodonales, Cádiz (Plin. III,14) y Aipora, ceca de ubicación incierta, quizás en Évora, Cádiz (García Bellido y Blázquez 2001, II: 22 s.), aunque la lectura es dudosa y podría ser Anaipora (Villar 2000: 101), en cuyo caso no pertenecería a este subserie, si bien Villar plantea alguna reserva sobre estos topónimos en ipo más sencillos del grupo de Dipo. Sin embargo, no puede aceptarse la interpretación de Villar (ibidem) sobre la existencia de dos poblaciones distintas con el topónimo Dipo, una en la vía de Olisipo a Emerita (ceca; ItAnt. 418,3; Sall. I,113) y otra la que cita Livio $(39,30)$, pues se trata de una interpretación errónea del impreciso texto de Livio, que ha hecho que algunos autores sitúen erróneamente Dipo en la Carpetania, pues se trata con toda probabilidad de esta misma población del Guadiana tal como se ha indicado (vid. supra). 
La segunda subserie de topónimos en ipo es la más numerosa y en ella dicho elemento también aparece como segundo miembro de compuesto, pero precedido por un "prefijo". Estos topónimos en ipo son Acinippo, Ronda la Vieja, Málaga (Plin. III.14; Ptol. II,4,15, ceca); Baesippo, Barbate, Cádiz (Mela II,96; Plin. III,7,15; Ptol. II,434; ItAnt. 408,1); Baicipo, Vejer de la Frontera, Cádiz (ceca), Basilippo, Cerro del Cincho, Arahal, Sevilla (ItAnt. 410,1; Rav. 316,13); Bevipo?, Alcácer do Sal, Portugal (Faria 1989: 79; id. 1992: 40-41; Guerra 1999: 338); Belippo, lugar incierto de Cádiz (Plin. III,15); Blacippo (Plin. III,15); Callipous (Ptol. II,5,3); Cantnipo (ceca); Cedripo, cerca de Estepa? (CIL II,1444); Collippo (Plin. IV.133; CIL II,5332); Ilipa (Str. III,5,9; Plin. III,11; Rav. 314,17; ceca); Ilipla (ceca); Ilipula Magna (Plin. III,10); Ilipula Minor (Plin. III,12); Irippo, Oeste de Andalucía (ceca); Iulipa, Zalamea de la Serena (CIL II, p. 326 s.; Tovar 1974: 94 s.); Lacilbula (ceca; CIL II 1342; Ptol. II,3,9); Lacipea, Almadenejos, Almadén (ItAnt. 438,4); Lacipo, Cortijo de Alechipe, Casares (Ptol. II,4,9; Mela II,94); Olisipo (Plin. IV, 116; ItAnt. 416); Orippo (ceca); Ostippo, Estepa, Sevilla (Plin. III,12; ItAnt. 411,3; Rav. 316, 16); Serippo, Andalucía (Plin. III, 14); Serpa (ItAnt. 426,6; Rav. 306,6); Sisipo (ceca); Usaepo, Cortijo de la Fantasía, Cortes de la Frontera (Plin. III, 15) y Ventipo (Plin. III,12).

La tercera serie ya se aparta más de la forma que ofrece Dipo, pues ipo aparece como primer elemento del compuesto. Esta serie está representada por 11 ejemplos: Epora, Montoso, Córdoba (Plin. III,10), Ipagrum, Aguilar de la Frontera (ItAnt. 412,4; Rav. 315,18), Ipolcobulcula, Cabeza Baja de Encina Hermosa, Locubín, Jaén (CIL II,1651), Iponuba, Cerro del Minguillar, Baena (CIL II,166=5465), Ipora, de localización aún incierta (ceca), Iporca, Constantina, Sevilla (CIL II,1046), Ipsca, Cortijo de Íscar, Castro del Río, Córdoba (CIL II,1572), Ipses (ceca, Vila Velha, Alvor), Iptuci, Prado del Rey, Cádiz (Plin. III,15; ceca; CIL II,1923) e Ituci, Aldea de Tejada, Escacena del Campo, Huelva (Plin. III,12; ceca; ItAnt.; Ap. Ib. 67), aunque debió haber al menos dos poblaciones denominadas Ituci.

Un análisis de la dispersión de estos topónimos en ipo (fig. 18) permite apreciar que su "zona nuclear" se concentran en Andalucía Occidental, en especial al Sur del Guadalquivir y a ambos lados del Genil, aunque, sobretodo, desde este río hacia el Oeste hasta el 
Guadalquivir, que constituye la zona "nuclear A" de Villar (2000: 104106, mapa), que coincide con el área nuclear de la cultura tartésica (Torres 2002: fig. VII,2, 4 y 10; VIII, 24, 27, 29, 31 y 33; etc.). También aparece un número significativo, aunque menor, al Este del Genil, siempre al Sur del Guadalquivir, zona que Villar denomina "nuclear B" (ibidem) y que se caracteriza porque todos los casos conocidos corresponden a la subserie en la que ipo aparece al inicio del topónimo.

Fuera de estas dos áreas hay algunos otros casos que Villar (ibidem) ha considerado "de expansión secundaria". Dicha expansión comprendería los topónimos en ipo que aparecen al occidente del Guadalquivir, entre los que resulta muy interesante la presencia de algunos a lo largo de la costa atlántica portuguesa, concentrados en las desembocaduras del Sado (Callippo/Cantnipo/Bevipo?) y del Tajo (Olisipo), aunque Collipo se sitúa en la Estremadura portuguesa, ya al Norte de este río (fig. 18). Pero también aparecen por los territorios de la cuenca del Guadiana, como evidencian las poblaciones de Dipo, Iulipa y Lacipaea, e, incluso, existe el posible caso de Lippos que rebasa hacia el Norte el Tajo y el Sistema Central. Además, es de interés que en esta última zona la mayoría de los topónimos son simples, de formación similar a Dipo, lo que hace suponer que se crearan en circunstancias parecidas y, probablemente, contemporáneas (fig. 18). Si a este hecho se añade que todos estos topónimos ofrecen una situación periférica y mucha menor densidad respecto a la zona nuclear, se puede deducir, como ya observó Villar ( $i b i d$.), que deben proceder de gentes originarias de la zona nuclear tartésica, "la nuclear A" del topónimo, es decir, la situada entre Guadalquivir, Genil y Golfo de Cádiz, lo que indicaría el carácter de "asentamientos o colonias" tartésicas de todos estos topónimos en ipo situados en áreas periféricas.

La población de la antigua Dipo no se ha podido excavar y, en consecuencia, sus características urbanas son desconocidas. Sin embargo, su origen orientalizante queda constatado por los materiales hallados (fig. 10-16) y su emplazamiento estratégico (fig. 1-5), confirmado por su importancia historia y por haber acuñado moneda en el siglo II e inicios del I a.C. (Villalonga 1994: 509; Faria 1995: 146 s.; Barnett et al. 1992: 403; vid. infra, fig. 25-29), todo lo cual indica que debió constituir un importante núcleo urbano del Valle del Guadiana. 
La identificación de Dipo es de gran importancia para reconstruir los territorios de las ciudades-estado del Valle del Guadiana y, en concreto, el extenso territorio que debió controlar esta ciudad (fig. 19). En una zona relativamente homogénea como es el Valle del Guadiana, un primer método de análisis, hasta cierto punto objetivo para precisar los límites teóricos entre los principales oppida y yacimientos prerromanos, es utilizar las líneas de equidistancia de tipo Christaler para formar polígonos de Thiessen, aunque dicha aproximación resulta poco adecuada a la realidad geográfica. Por ello, para aproximarse objetivamente al tamaño real de los territorios en cuestión, se deberían valorar y ponderar otros factores, como el tamaño superficial de las correspondientes poblaciones centrales, desconocidos en la mayoría de los casos, y las características geográficas del territorio.

Si se pretende una aproximación a la estructura territorial de época orientalizante (fig. 19), el primer hecho evidente, tal como indica la estructura viaria (vid. infra, fig. 21), es que las poblaciones principales del Valle del Guadiana se alineaban a intervalos bastante regulares a lo largo del río para aprovechar sus feraces tierras, como ya se observó hace años (AlmagroGorbea 1990: fig. 98-99, fig. 12). En consecuencia, desde el Periodo Orientalizante, el Valle del Guadiana aparece dividido en 4 o 5 grandes unidades territoriales o "reinos" (fig. 19), que pueden identificarse con el oppidum asentado en el Cerro de la Mesa, bajo la actual alcazaba de Badajoz (Berrocal 2008), la población ahora identificada como Dipo, Metellinum, que correspondía a la antigua Conisturgis (Almagro-Gorbea et al. 2008a) y Lacimurgi (Sáez 1990; Aguilar et al., 1993), ésta ya en su extremo oriental y fuera de la zona de las Vegas del Guadiana. En consecuencia, el descubrimiento de Dipo ha permitido precisar el esquema anterior (Almagro-Gorbea 1990: fig. 12), pues esta ciudad debe ocupar el estratégico papel que se atribuía a Lobón, situada en su proximidad y con importantes hallazgos arqueológicos (Kukahn 1966; Jiménez Ávila y Ortega 2004), aunque no ofrece una situación estratégica tan destacada.

En consecuencia, el territorio de Dipo quedaría enmarcado entre el oppidum del Cerro de la Mesa en el que se asienta la Alcazaba de Badajoz (Berrocal 2008) por el Oeste y el territorio de Conisturgis-Medellín por el Este. Este marco permite reconstruir de forma hipotética el territorio de 
Dipo con cierta precisión. Por el Este, debió extenderse hasta El Turunuelo (Jiménez Ávila 1997: 144 s.), que parece haber sido un palacio-fortín situado a casi $20 \mathrm{~km}$. al Este de Dipo, a unos $11 \mathrm{~km}$ al Oeste de Mérida y a más de $35 \mathrm{~km}$ de Medellín, por lo tanto, fuera del territorio de esta última ciudad, cuya frontera todavía en época romana se situaba en Alange; además, El Turuñuelo coincide prácticamente con la mansio de Evandriana en la milla IX de la vía de Emerita a Olisipo, lo que pudiera no ser casualidad (fig. 20), sino una consecuencia de la 'fosilización' de ese límite. Por el Oeste, cabe plantear como hipótesis que llegara hasta la Alcazaba de Badajoz, situada a $24 \mathrm{~km}$ de Dipo y cuyas $5.5 \mathrm{Ha}$ de superficie (Berrocal 1994; id. 2008) permiten pensar que quizás fuera una población 'satélite' que protegería la frontera occidental del Valle del Guadiana. Por el Norte debía abarcar todas las extensas Vegas Bajas del Guadiana y es posible que llegara hasta la ermita de Nuestra Señora de Bótoa, la antigua Budua (Tovar 1974: 222; TIR J-29: 47), cuyo nombre lusitano permite plantear que fuera un santuario limítrofe, como el de Ataecina en Santa Lucía de El Trampal (Abascal 1995; $i d$. 2002), que también parece situado en un punto fronterizo del territorio de Medellín-Conisturgis (Almagro-Gorbea et al. 2008a, p. 1022). Además, Budua controlaba la vía que por el río Zapatón conducía hacia Aliseda, a una distancia de casi $30 \mathrm{~km}$. de Dipo, lo que supondría que su territorio incluía todas las Vegas Bajas del Guadiana. Por el Sur sus límites quedan más inciertos, pero debía limitar con el territorio de Vama, ubicada en Salvatierra de Barros (Ptol. II,4,11; Tovar 1974:175; TIR J-29, p. 160 s.; García Alonso 2003: 81 s.), que era la ciudad más septentrional de la Baeturia Celtica y que ya queda situada a $39 \mathrm{~km}$ de Dipo, por lo que el límite territorial debió estar bastante más próximo a esta población, probablemente por la zona de La Albuera y Solana de los Barros, situadas a unos $15 \mathrm{~km}$. del Guadiana, que ya marcan la transición hacia la comarca de Los Barros perteneciente a la Beturia.

Esta estructura territorial deja suponer que las poblaciones de Dipo y de Conisturgis-Medellín en el Valle del Guadiana debían ser paralelas pero rivales, tanto en el control de la Vía de la Plata como en la vía transversal Este-Oeste, sin contar los posibles problemas limítrofes, aunque, en todo caso, la supremacía política en la cuenca del Guadiana parece haberla ostentato Conisturgis-Medellín, la capital de los conios (Strab. III,2,2) y la población más importante del Guadiana desde el Periodo Orientalizante 
(Almagro-Gorbea et al. 2008a), importancia que debió mantener en la II Guerra Púnica durante la presencia en estos territorios de Magón el 210 a.C. (Pol. X,7,4; fig. 22) y tal como confirma la temprana presencia de Roma a juzgar por un as del 209 a.C. (Crawford 1974, $n^{\circ} 88,3$ b), hallado en Medellín (Martín Bravo 1995:142; Haba 1998:155, lám. I,2).

Dipo aparece citada por primera vez al enfrentarse a Roma en la acción bélica del 185 a.C., mientras que pocos años después, ConisturgisMedellín aparece como una ciudad pro-romana en el Valle del Guadiana (Almagro-Gorbea et al. 2008a:1033s), pues resulta evidente la postura prorromana de Medellín, que pasó a ser la base romana de operaciones contra los lusitanos situados más al Norte, por ser un punto de control seguro de las vías hacia Toletum y hacia Corduba, lo que explicaría que $Q$. Caecilius Metellus fundara en ella el 79 a.C. Caecilia Metellinum (Galsterer 1971: 14; Tovar 1976: 231 s.; Haba 1998: 406 s.; Guerra 2004: 219 s.), cambiando el nombre de Conisturgis que hasta entonces había tenido (Almagro-Gorbea et al.2008). Este cambio de nombre se explicaría porque la antigua población conia de Conisturgis, quizás también con una colonia tartesia (AlmagroGorbea et al. 2008a), debió permanecer aliada de Roma dada su profunda vinculación a la Turdetania.

Por el contrario, Dipo, su ciudad rival en el Valle del Guadiana desde el Periodo Orientalizante, por su ubicación, por su territorio y por su control de las vías de comunicación, puede considerarse una población orientalizante paralela a Medellín, habitada, como ésta última, por gentes de origen tartesio, aunque rodeada de poblaciones celtas y celtizadas, tanto por el Norte como por su limítrofe meridional en la Beturia, lo que pudo suponer verse cada vez más imbuida en una creciente celtización y, tras su toma por Sertorio, no sabemos si por la fuerza o, más bien, de forma pacífica, fue destruida por Metelo y se convirtió en una simple mansión de vía romana.

En todo caso, la existencia de ambas poblaciones, Dipo y ConisturgisMedellín, permite comprender que el Valle del Guadiana en el Periodo Orientalizante debió estar estructurado probablemente en torno a estas dos importantes ciudades-estado (fig. 19), con sus amplios territorios y con otras poblaciones menores más o menos 'satélites' en su entorno, ambas, con gran probabilidad, con una sociedad urbana y un sistema político de tipo tartésico, como el documentado en Medellín (Almagro-Gorbea et al. 2008a). 


\section{La situación de Dipo y las vías de comunicación del Valle del Guadiana}

La identificación de Dipo en Guadajira ha permitido comprender su situación estratégica y el papel que debió tener como una de las más importantes poblaciones tartesias del Valle del Guadiana (Almagro-Gorbea et al. 2008). La población de Dipo debía constituir un estratégico cruce de vías de comunicación desde el Periodo Orientalizante que merece ser analizado con atención, pues este hecho confirma su importancia estratégica en las comunicaciones del Valle del Guadiana, paralela y, probablemente rival, de Medellín (fig. 21).

Dipo controlaba un cruce de la mayor importancia en el sistema de vías prerromanas que comunicaba todos los territorios del Suroeste de la Península Ibérica (Almagro-Gorbea 1977: 5; id. et al. 2008), entre la llamada "Vía de la Plata" en sentido Sur-Norte, que enlazaba el Golfo de Cádiz y el Valle del Guadalquivir con la Meseta Norte a través de Extremadura, y la vía transversal en sentido Oeste-Este, que desde el Atlántico alcanzaba el Levante (fig. 21). Este armazón viario prerromano daría lugar, siglos después, a las principales vías romanas (Roldán 1971 y 1975; Fernández Corrales 1987; Sillières 1990; Haba 1998: 357 s.; Alarcão 2006) y ha perdurado en parte hasta nuestros días en la red de cañadas ganaderas (García Martín 1990).

En efecto, Dipo, además de controlar la vía Este-Oeste citada, controlaba también un importante vado del Guadiana en dirección NorteSur, en el que debe considerarse como ramal más occidental de la "Vía de la Plata", que corría paralelo al que pasaba por Medellín (AlmagroGorbea et al. 2008). Esta vía arrancaba del Golfo de Cádiz y, tras pasar por Hasta Regia y Carmo, subía hacia la Baja Extremadura y penetraba después en la Penillanura Cacereña (Almagro-Gorbea 1977: 204 s.; Martín Bravo 1999: 121 s.), desde la que proseguía hacia la Meseta Norte (Almagro-Gorbea, 2005). La importancia de Dipo y de su vado del Guadiana dependía de su situación junto al río Guadajira, que enlazaba hacia el Sur con el citado ramal occidental de la "Vía de la Plata". El origen de esta vía en el Periodo Orientalizante parecen confirmarlo los diversos topónimos prerromanos que la jalonan, como Iporca, en Constantina, Sevilla (CIL II,1046; Tovar 1974: 180), que debía controlar el acceso a 
Sierra Morena, y, ya en tierras pacenses, Curgia/Curiga, en Monesterio (TIR J-29: 73; García Alonso 2003: 78), Lacunis, hacia Fuente de Cantos (TIR J-29: 97) y Ugultunia o Contributa Iulia Ugultina, en Medina de las Torres (TIR J-29: 67; García Alonso 2003: 79), de donde procede una importante figura de bronce orientalizante de Smiting God (AlmagroGorbea 1977: 250 s., lám. 52,a-b), mientras que atravesando la Baeturia por Arucci y la posterior Turobriga llegaba hasta Onuba y también, por Serpa, permitía alcanzar con Laccobriga y las poblaciones del Algarbe. Este ramal de la Vía de la Plata ofrecía la misma importancia en dirección Norte, pues alcanzaba, con más facilidad si cabe, la Penillanura Cacereña, zona de cruce de comunicaciones desde el Norte de Extremadura para alcanzar la Meseta Norte. Tras cruzar el Tajo por Turmogium (Alconétar), se podía utilizar la falla de Plasencia para dirigirse hacia Abula o el puerto de Béjar hacia Salmantica (Gil Montes y Álvarez Rojas, 1988), tramo donde estaba situada Lippo, en Valverde de Valdecasa (ItAnt. 434,2), otra población de topónimo tartesio (vid. infra), situada ya en el borde de la Meseta Norte en la zona meridional de Salamanca, mientras que la Meseta Sur se alcanzaba sin dificultad atravesando el puerto de Miravete y prosiguiendo por Augustobriga, en Talavera La Vieja, población de origen orientalizante (Jiménez Ávila (ed.) 2006), hasta el territorio de Toletum (fig. 21).

Dipo, además de controlar el ramal occidental de la Vía de la Plata, también controlaba otra importante vía, la que de Este a Oeste recorría todo el Valle del Guadiana desde las ciudades marítimas del Atlántico de origen colonial tartesio hasta enlazar con el Levante a través de la Vía Heraclea (Maluquer 1985; Almagro-Gorbea et al. 2008).

Esta vía, por el Oeste, partía desde el Atlántico con dos ramales. El más meridional saldría de *Cantipo-Salacia (Alcácer do Sal) y por Evora alcanzaba el Guadiana en el oppidum de Badajoz (Berrocal 2008), desde donde enlazaba directamente con Dipo. El ramal más septentrional partiría desde Olisippo (Lisboa) y Collippo, en San Sebastião de Freixo, en la Estremadura portuguesa (Alarcão 2006), debía cruzar el Tajo por Scallabis, Santarem, población de nombre prerromano de etimología celta (García Alonso 2003: 110) con niveles orientalizantes desde fines del siglo VIII a.C. (TIR J-29: 145; Arruda 2002; Tavares da Silva 2005: 751 s.) y alcanzaba el Valle del Guadiana por Budua (Ntra. Sra. de Bótoa, al norte de Badajoz), uniéndose ambos ramales en Dipo. Desde esta 
población, proseguía hacia el Este hasta Conisturgis-Medellín, principal ciudad de los Conios y de toda la cuenca del Guadiana (Strab. III,2,2; Almagro-Gorbea et al. 2008), desde la que proseguiría por Lacimurgi y Mirobriga hasta la región minera de Sisapo, para proseguir hacia Oretum y enlazar con la vía de Castulo a Toletum o descender hacia Castulo y enlazar en esta ciudad con la Vía Heraclea y, por ella, alcanzar el Mediterráneo en el Levante o en el Sureste (fig. 21).

La importancia de esta vía desde el Periodo Orientalizante se confirma de nuevo en la II Guerra Púnica (fig. 22), cuando pasó a ser la vía estratégica de comunicación entre los tres ejércitos púnicos que controlaban Hispania el 210 a.C., tras la muerte de Escipión el año anterior (Liv. XXV, 32-36). Según refiere Polibio (X,7,4), el ejército de Asdrúbal, hijo de Giscón, estaba en la Lusitania en la desembocadura del Tajo, que cabe identificar con la zona de Olisipo; el ejército de Magón estaba con los conios, a la altura de las Columnas de Hércules, lo que cabe identificar con la zona de Dipo y Conisturgis, la posterior Metellinum, en el Valle del Guadiana; finalmente, el ejército de Asdrúbal luchaba con los carpetanos, por lo que las tres zonas citadas quedaban comunicadas por esta estratégica vía Oeste-Este. Estos datos concuerdan con los que ofrece Tito Livio (XXVI,20,6), según el cual los generales cartagineses se separaron para invernar y mientras Asdrúbal Giscón lo hizo próximo al Océano y Gades, Magón se quedó in mediterranea maxime supra Castulonensem saltum, esto es, por encima de Sierra Morena, y Asdrúbal, el hijo de Amílcar, ya lo hizo, según Livio, cerca de Sagunto (fig. 22).

La importancia estratégica de Dipo como centro de control de esta vía se confirma de nuevo pocos años después, el 185 a.C., al inicio de la conquista romana, cuando a ella se enfrentaron, al parecer con poca fortuna, los pretores C. Calpurnio Pisón y L. Quinctio Crispino, quienes, tras haber invernado en la Bética, atacaron Dipo al pasar desde la Beturia por Extremadura para penetrar por primera vez en la Carpetania por la vía mencionada (Liv. 39,30) y atacar a los hispanos que debían tener en el territorio de Toletum sus campamentos de guerra, pues ambos pretores querían combatirlos conjuntamente. Este recorrido exigía atravesar el valle del Guadiana y pasar por la ciudad de Dipo, lo que confirma que esta población controlaba, junto con Conisturgis-Medellín, el paso del Guadiana en este estratégico camino que iba desde el Atlántico y desde la Beturia hasta la Carpetania (fig. 22). 
No hay noticias posteriores de Dipo durante las Guerras Lusitanas, aunque esta población debió seguir siendo una ciudad importante, pues acuñó moneda a fines del siglo II hasta el inicio de las Guerras Sertorianas (Villalonga 1994: 509; Faria 1995: 146 s.; Barnett et al. 1992: 403; vid. infra, § 9), cuando parecen haber cesado las acuñaciones (Faria 1995: 146 s.), pues Q. Caecilio Metelo debió destruirla hacia el 79 a.C. según referiría el episodio fragmentario de Salustio (Hist. frg. I,113), poco antes de reunirse con sus legiones en Conisturgis-Medellín, población que en esas fechas hacía tiempo que era el cuartel de invierno de las tropas romanas (Ap. $I b$. 56-57; Ap. Ib. 58; id., 68), probablemente por ser la principal ciudad aliada del Roma en el Guadiana, lo que explica que, a partir de entonces, pasara a denominarse Caecilia Metellinum (Ptol. II,5,6; Plin. N.h. IV,117; Schulten 1937, p. 173 s.; García Mora 1993, p. 389; Haba 1998: 406 s.; Guerra 2004, p. 219 s.), lo que evidencia que se había convertido, definitivamente, en el punto clave para el control de las vías del Guadiana (fig. 23). Estos episodios de las Guerras Sertorianas confirman la importancia estratégica de este ramal de la Vía de la Plata que Metelo reforzó al fundar Castra Caecilia el 75 a.C. (Ulbert 1984), precisamente como punto de control de esta vía. En efecto, hace años ya observó Alarcão (1973: 40) que Dipo, Lacimurgi y la entonces desconocida Conisturgis (Tovar 1976: 209; TIR J-29: 66), que pasó a ser Metellinum (Alarcão 2001, p. 311 y 337; Almagro-Gorbea et al. 2008a), constituían la línea de ataque de Metelo contra Sertorio, desde la que Metelo proyectó un segundo escalón constituido por Castra Caecilia y Vicus Caecilius en tierras cacereñas, mientras que debió establecer el de Caeciliana cerca de Setúbal, seguramente para asegurar su retaguardia marítima. Es precisamente en estas luchas cuando Salustio menciona a Dipo como validam urbem $(\mathrm{I}, 113)$, aunque la ciudad debió quedar destruida en esta guerra, tras la que desaparece como entidad urbana, pues cesan sus emisiones (Faria 1995: 147), a pesar de haber sido la única ciudad del Guadiana que había acuñado moneda (vid. supra), por lo que, desde entonces, quedó reducida a una simple mansión en la vía Olisipo a Augusta Emerita (fig. 19), curiosamente en práctica coincidencia con la pertiga de la centuriación de Emerita (Rodríguez Marín y Gorges 2006: 187, fig. 3), aunque en época romana apenas aparece citada por los itinerarios (It. Ant. 418,3; Rav. 314,8), si bien su topónimo guardaba la memoria de su antiguo origen orientalizante (fig. 20). 
Todo lo expuesto indica que, hasta su destrucción en las Guerras Sertorianas, Dipo ocupaba una privilegiada posición en las fértiles Vegas Bajas del Guadiana y controlaba un importante vado de este río en una posición semejante a la que ocupaba Medellín en las Vegas Altas, por lo que ambos núcleos urbanos estructuraban el territorio del Guadiana como puntos de control comercial y estratégico de las más importantes vías de comunicación del Suroeste de la Península Ibérica, tanto con las regiones costeras del Golfo de Cádiz como del Atlántico y con las ricas zonas mineras y ganaderas del Occidente de Hispania a través de la "Vía de la Plata" y de los restantes ramales transversales. Esta interesante estructura de comunicaciones, junto a las magníficas condiciones agropecuarias de la Vega Baja del Guadiana, explican la acertada elección del asentamiento de Dipo y la importancia de esta ciudad y su territorio en época prerromana.

\section{Las monedas de Dipo \\ Los estudios numismáticos sobre Dipo}

Las monedas de Dipo no son muy habituales. No fue una ceca que tuviera un gran volumen de producción, por lo que sus monedas no resultan frecuentes en las colecciones ni tampoco en los hallazgos numismáticos. Además, destaca la gran tosquedad del grabado de los cuños, hasta el punto de que no es segura la interpretación del tipo del reverso, si bien la lectura del letrero con el topónimo nunca ha planteado problemas.

Las emisiones de Dipo las dio a conocer Delgado (1857: 9), cuando catalogó la colección de monedas perteneciente al diplomático sueco G. D. Lorichs, con el propósito de ser vendida. Años más tarde, en su obra Nuevo Método (1871: 132-137) se detuvo un poco más en el análisis de esta ceca, reubicando en ella piezas mal leídas y descritas de obras anteriores. Identificó en el anverso una cabeza cubierta con un casco, adornado con una cimera marcada por una línea de puntos; la mala calidad del grabado le hizo pensar en la posibilidad de que quisieran imitar el perfil de un ave de rapiña (Delgado 1871: 134-135). El reverso lo describió como una cornucopia, discutiendo las identificaciones anteriores como carcaj o aljaba, que habían sido propuestas por Sestini 
(1818) siguendo O'Cruley, argumentando que este tipo de objeto no podía tener un perfil curvo.

La consideró localizada en Portugal, en las cercanías de Elvas, con una argumentación basada en su mención en los textos, especialmente en el Itinerario Antonino (Delgado 1871: 136-137). Delgado introdujo en el catálogo un tipo con la leyenda retrógrada (1871: $\left.135, \mathrm{n}^{\circ} 7\right)$, aunque no lo ilustró por no tener ningún dibujo auténtico a la vista, a pesar de que había descrito así la moneda de la Colección Lorichs (Delgado 1857: 9; SNG Stockholm 187); todo hace pensar que Delgado no estaba muy seguro de su existencia. De hecho sólo ha aparecido uno hasta ahora, aunque la irregularidad y el peculiar trazado de los signos dan problemas de lectura.

Zóbel de Zangróniz (1880: 185-187) poco añadió a lo que ya se sabía sobre Dipo, ya que trata esta ceca dentro de la explicación general sobre las de la Ulterior, que agrupó por distritos, colocando a Dipo dentro del Myrtilense. Propuso su localización cerca de Elvas (Portugal), sobre la base de su mención en textos clásicos, en especial en el Ravennate y en el Itinerario Antonino.

Vives y Escudero, en la Moneda Hispánica, incluyó a Dipo como ceca $8^{\mathrm{a}}$ del $5^{\circ}$ grupo que denominó como "Vario" entre las monedas de la Serie Undécima o Latinobéticas (1926: 67 y 105). Según Vives, de esta ceca sólo se conocen "monedas bárbaras, de arte tan degenerado, que apenas se sabe qué tipos se quisieron representar, sobre todo en el reverso, que tiene algo que puede ser una cornucopia; el día que aparezca una moneda de la $1^{\mathrm{a}}$ emisión, se saldrá de esta y otras dudas, como son lectura de epígrafe, etc". Esa $1^{\text {a }}$ emisión ha sido identificada (cat. 1a), pero su calidad no es tan buena como se esperaba. El valor acuñado sería el as, en el que identificó una cabeza varonil, de arte muy bárbaro, en el anverso, y una posible cornucopia tendida en el reverso. Ilustró dos piezas, una del I.V.D.J., procedente de la Colección Sánchez de la Cotera (Id., lám. XVC, $\mathrm{n}^{\mathrm{o}} 1$ ), y otra considerada como variante de arte y de módulo menor, también de la antigua Colección Sánchez de la Cotera (Id., lám. XVC, $\mathrm{n}^{\mathrm{o}} 2$ ).

En 1950, Antonio Beltrán (1950: 374), consideró a Dipo un ceca "en situación insegura, cerca de Elvas" con cabeza muy tosca y en el reverso cornucopia y el nombre de la ceca, que habría acuñado grandes y medianos bronces, siguiendo a Vives (op. cit.). 
Gil Farrés (1966: 350, fig. 77, $\mathrm{n}^{\circ}$ 1271-1272) hizo referencia a la ceca como ubicada en la zona de Elvas (1966: 276-279, fig. 67), en todo caso, en la margen derecha del Guadiana. Identificó las denominaciones como dupondio y as (id., 283, 296) y las incluyó entre las cecas de clasificación dudosa entre el 67 y el 44 a.C. (id., 294). La identificación de los tipos fue la tradicional, una cabeza humana muy tosca y una cornucopia horizontal, con la leyenda DIPO debajo.

En el libro Numismática ibérica, Guadán (1969) no dedicó atención a esta ceca, pero de las tablas en las que expuso de forma resumida la producción de la zona en la que la localizó se desprende que distinguió dos grupos de acuñaciones, uno pesado (Vives 115-1) que incluyó en su período 3 (206-133 a.C.) y otro más ligero que supuso semiuncial que lo enmarcó en su período 4 (133-105 a.C.), pero del que no dio ninguna indicación que permita identificar el tipo al que se refiere (Guadán 1969: 128 y 134). En su libro La moneda Ibérica (1980: 237, $\mathrm{n}^{\mathrm{o}}$ 914) se desdijo de todo lo anterior, lo cual supuso un retroceso, ya que introdujo bastantes errores. Así, unificó toda la producción, datándola desde el año 100 y la época de Augusto. Con poco acierto describió la figura del reverso como una "embarcación fluvial hacia la derecha" y, además, dijo leer la leyenda MVN DIPO en el reverso, lo cual fue una invención.

En el año 1974, M. Beltrán Lloris publicó un estudio sobre las monedas aparecidas en el yacimiento de Cáceres el Viejo (Cáceres), de las que cuatro de ellas fueron acuñadas en Dipo. Eran los únicos hallazgos conocidos hasta el momento, lo que le brindó una buena ocasión para examinar y actualizar el conocimiento de este tipo de acuñaciones. En cuanto a los tipos optó por identificar en el anverso una cabeza con casco con cimera y en el reverso una cornucopia. Dividió toda la producción conocida en seis grupos, cuyos criterios no explica. En cuanto a la rudeza de los tipos se hace eco de la idea de Vives de que hace falta que aparezcan monedas de buen arte y ante la pregunta que se plantea de si las piezas de arte bárbaro fueron las únicas que se acuñaron o formaron la segunda parte de la vida de la ceca, podemos contestar que no debió haber nada de mejor calidad que los cuños de las monedas con leyenda DIPPO (cat. 1a). Finalmente dedicó atención a la localización de la ceca, recogiendo los argumentos hasta entonces propuestos, basados 
en los itinerarios de caminos y en las fuentes literarias, sin decidirse por la ubicación tradicional en las proximidades de Elvas (Portugal) o por la más reciente de Roldán (1971: 155) en Talana, al sur de Badajoz.

Villaronga (1979: 144 y 155, fig. 392) incluyó a Dipo entre las emisiones de la Ulterior del siglo II a.C., y la situó en Portugal, hacia Elvas y Portalegre. Describió las acuñaciones como toscas, de peso uncial de c. 21,91 gr. (21 ejemplares), con cabeza viril y cornucopia tendida, y debajo la leyenda de la ceca. Guadán (1980: 237, nº 914), unificó toda la producción del taller en un solo tipo, que incluyó en el período entre el 100 a.C. y la época de Augusto. El anverso lo describió como "Cabeza masculina hacia la derecha, de arte muy bárbaro y casi irreconocible. Gráfila de puntos" y el reverso como "Embarcación de tipo fluvial hacia la derecha. Debajo y en cartela, leyenda latina MVN DIPO. Gráfila de puntos gruesos y separados". Sin duda, tanto la identificación de la figura del reverso como de la leyenda fueron incorrectas.

El Corpus de Villaronga (1994: 403) dedicó una introducción muy corta a esta ceca, en la que sólo comentó la posibilidad de que estuviera localizada en Portalegre (Portugal), un poco más al norte que la mayor parte de las ubicaciones propuestas, pero la ordenación que presenta revela la idea que tiene sobre ella. Aunque no se justifica en el libro, es probable que el peso medio de las monedas sea lo que le llevó a fechar la acuñación de estas piezas en la primera mitad del siglo II a.C., una época quizás demasiado temprana. Consideró toda la producción como una emisión en la que las monedas con igual tipología y peso más reducido ( $\mathrm{CNH} 403 / 3)$ las calificó de semis.

En 1995 se ocupó de la ceca de Dipo Antonio Marques de Faria, quien la consideró situada en Portugal siguiendo a la mayor parte de los numismáticos y aludiendo a la propuesta de J. de Alarcão (1988a, 56), de situarla en Évora Monte (Estremoz). En los anversos identificó una tosca cabeza masculina sin atributos y en los reversos, una cornucopia que, en la mayoría de los ejemplares, muestra dos apéndices laterales en forma de losange, que Faria (id., 147) interpretó como imitaciones toscas de racimos de uvas, como los que suelen ornamentar las cornucopias de las monedas de Valentia (Ripollés Alegre 1988: 5). La diferencia de peso que se atestigua entre las distintas monedas la vinculó con la calidad de las acuñaciones y no creyó que las más ligeras deban 
considerarse como semis. La fecha de inicio de la ceca la dedujo Faria del tipo del reverso, que consideró inspirado en las monedas de Valentia del último cuarto del siglo II a.C. (Ripollés, 1988: 63-64), cronología que confirmarían las cuatro monedas de Dipo aparecidas en el campamento romano de Cáceres el Viejo (Hildebrandt, 1984, 264), cuya fecha de abandono se sitúa en c. 95-93 a.C. (Beltrán, 1973-1974, 292293) o c. 80 a.C. (Hildebrandt, 1984, 278-280, 297), lo que le llevó a fechar los ases de Dipo a fines del siglo II a.C. o en las primeras décadas del I a.C.

Un dato complementario que manejó en esta discusión fue una supuesta reacuñación de un bronce de Dipo (Faria, 1987: 26) sobre una pieza atribuida a Castulo ( $\mathrm{CNH} 339 / 70)$. No obstante, discrepamos de la interpretación de esta reacuñación, ya que creemos que se trata de una pieza de Dipo que fue reacuñada por Castulo. Estamos de acuerdo en la identidad de las cecas involucradas, pero vemos que los diseños de Castulo sólo han modificado parcialmente la pieza de Dipo, porque el cuño móvil ejerció la presión sólo en una parte del cospel. En el anverso de Dipo se aprecian algunas letras y parte de los labios y la barbilla del retrato de Castulo y en el reverso parte del manto de Europa y la parte de detrás del toro. Esta nueva identificación cambia sustancialmente las cosas, porque ya no es necesario forzar la antigüedad de la pieza de Castulo ni proponer una cronología del siglo I para la producción de Dipo.

También Ripollès ha aceptado implícitamente la ubicación numismática tradicional de Dipo en la zona de Portugal (CNH, p. 403), localización que se mantiene en obras posteriores como el Catálogo de la Real Academia de la Historia (Ripollés y Abascal 2000: 92, mapa 3), que ofrece 2 ejemplares de 10,81 y 16,25 gr, este último fragmentado (id., $\mathrm{n}^{\mathrm{0}} 410$ y 411) y otra del Catálogo de las Monedas Hispánicas de la Bibliotèque nacional de France (Ripollés 2005, n 510), de 16,50 gr.

Chaves Tristán (1998: 280-281), en su capítulo sobre las amonedaciones de las cecas latinas de la Hispania Ulterior, publicó un completo estado de la cuestión sobre esta ceca. Aludió a la supuesta localización en Elvas (Portugal), siguiendo la opinión mayoritaria, y definió las características tipológicas de las monedas con detalle, identificando el tipo de reverso como una cornucopia de la que salen dos apéndices que terminan en un rombo con un punto en medio, 
admitiendo la posibilidad, siguiendo a Faria, de que estén representando racimos de uva simplificados. Puso en cuestión que realmente se trate de una emisión formada por dos denominaciones y propuso la posibilidad de que fueran dos emisiones distintas y que hubiesen sido emitidas en momentos diferentes, lo que en su opinión justificaría el uso de los mismos diseños, pero con pesos más ligeros. La separación de la producción en dos emisiones le permitió proponer que las piezas más pesadas pudieron haberse acuñado en el siglo II a.C. y la emisión más ligera en un momento "avanzado" del siglo I a.C. La fecha final está mediatizada por la aceptación de la supuesta reacuñación de Dipo sobre Castulo.

García-Bellido y Blázquez (DCPH II, 111-112) consideran que la localización de Dipo es incierta y dan cuenta de todas las opciones propuestas, Evora Monte, Elvas, Juromenha, Talavera la Real o la Carpetania. La producción monetaria la agrupan en dos denominaciones, duplos y unidades, para las que proponen una cronología posterior a Sila sobre la base de los hallazgos en Castra Caecilia y de la reacuñación de Dipo sobre una pieza de Castulo con reverso Europa sobre un toro, pero ya hemos comentado que esa reacuñación lo es de Castulo sobre Dipo, por lo que este dato no puede admitirse en la argumentación. En cuanto a las leyendas, advierten que en algunos ejemplares la inicial del topónimo pudiera ser una $\mathrm{B}$, pero esta posibilidad fue rechazada por Faria (2003: 219), aduciendo que no se conoce ninguna moneda con la leyenda BIPO, y nosotros tampoco la hemos visto en las piezas que hemos examinado, por lo que creemos que esa lectura es inexistente. Sobre los tipos que utilizaron, en el anverso señalan la existencia de un retrato masculino con cimera o con un halo formado por un semicírculo de puntos; el tipo de reverso lo encuentran más difícil de identificar, aunque en los duplos proponen con dudas que sea una cornucopia y en las unidades afirman que lo es.

\section{Los tipos}

En el anverso muestran un retrato masculino muy tosco, que desde la parte superior hasta la nuca va rodeado por un semicírculo de puntos. Esto ha motivado que se interprete como que el retrato lleva casco del 
que el semicírculo de puntos sería la cimera (Delgado 1871: 134; M. Beltrán Lloris 1974: 289; DCPH II, p. 111). En algunas monedas bien conservadas se aprecian pequeños puntos globulares y trazos alargados en la cabeza que podrían representar mechones, por lo que no es seguro que la cabeza vaya cubierta con un casco. En algún cuño (cat. 1c), el semicírculo de puntos termina detrás de la cabeza con tres de ellos formando un triángulo. El estilo de los retratos es rudo desde el principio $\mathrm{y}$, conforme avanza el tiempo, ahonda todavía más en el esquematismo y la deficiente ejecución del grabado. De todos los cuños conocidos, los que presumiblemente llevan la leyenda de reverso DIกกO (cat. 1a) son los que alcanzaron un mayor nivel de calidad, lo cual, unido a su singular leyenda, permite proponer que éstas fueran las primeras monedas acuñadas por la ciudad; estas monedas son las que Vives (1924:105) esperaba que aparecieran algún día y que aclararan las dudas sobre sus tipos y epigrafía, porque todas las que conocía eran de estilo bárbaro, pero está bien claro que las expectativas de mejora en el diseño y factura no se han cumplido. La única diferencia apreciable en los anversos es la corona vegetal esquematizada que rodea al retrato en la última emisión (cat. 2; $\mathrm{CNH} 2$ ).

Por lo que respecta al reverso, compartimos las dudas que siempre se han manifestado sobre la identificación del objeto representado. La cornucopia ha sido la opción por la que se han inclinado la mayor parte de los investigadores que se han ocupado de las monedas de Dipo (véase supra el apartado Los estudios numismáticos sobre Dipo). Admitir que se trata de una cornucopia implica aceptar un elevado grado de esquematización de las figuras, ya que incluye dentro de este tipo de objeto una forma que resulta bastante anómala, por cuanto carece de los frutos que normalmente asoman por su boca, aunque en algunos cuños, especialmente del tipo cat. 2 ( $\mathrm{CNH} 2$ ), se aprecian unas líneas que salen de la parte central de ella. No obstante, si tenemos en cuenta que también es bastante esquemático el retrato del anverso, entonces hay que considerar esta posibilidad, aunque la decoración de compartimentos cuadrados que muestra en algunos cuños no parece que sea la más adecuada para una cornucopia. Tampoco la esquematización en forma romboidal de lo que normalmente se ha considerado un racimo de uva parece que sea la que cabría esperar. Así pues, aunque es probable que el objeto representado sea una cornucopia, existen argumentos que 
introducen dudas para aceptar sin reservas esta identificación. La enigmática decoración de rectángulos y líneas, que es visible en reversos del tipo cat. 1c, con leyenda DIUO, nos ha llevado a encontrar una cierta similitud con la que muestran algunas vainas de puñal, aunque la curvatura que presenta el objeto no acaba de apoyar esta posibilidad (véase dos ejemplos en Quesada 1997: 280, fig 164, IV y VI).

La figura del reverso también ha sido identificada como una aljaba o carcaj. Fue propuesta por O`Crouley y Sestini, pero Delgado (1871: 136) discrepó de esta identificación alegando que una aljaba no podía tener un perfil curvo. Recientemente, Gómes (1998: 39-42) ha vuelto a proponer la idea de que se trata de una aljaba. No nos parece desatinada la alegación de Delgado y descartamos la posibilidad de que lo sea.

\section{Metrología}

Los pesos de las monedas son muy irregulares, en consonancia con el escaso cuidado puesto en la elaboración de los cuños y en el proceso de acuñación. Del examen de la muestra que hemos recopilado se desprende que los tipos $C N H 1$ y 3 (cat. 1) constituyen dos o más emisiones, entendidas éstas como momentos de acuñación separados en el tiempo, y que las monedas del tipo $\mathrm{CNH} 2$ (cat. 2) forman una nueva emisión diferenciada de las anteriores, siendo probablemente la última que acuñó la ciudad.

La existencia de monedas con los mismos diseños (CNH 1 y 3 ) (cat. 1), pero con pesos muy dispares ha motivado que hayan sido consideradas bien como una emisión con dos tipos de denominaciones, unidades y mitades (CNH: 403) o duplos y unidades (DCPH II: 111112), o bien como dos emisiones acuñadas en momentos diferentes, la primera con un peso medio uncial y la segunda con uno superior al semiuncial (Guadán 1969; Chaves 1998: 281, con dudas). Villaronga distinguió los tipos 1 y 3 con criterios de módulo y peso. Pero el problema que se plantea es si los criterios para hacer esta distinción son suficientes y adecuados para decidir qué monedas pertenecen a un tipo y cuáles al otro, ya que no se ha publicado un estudio de cuños. Efectivamente el conjunto de monedas recopiladas muestra dos concentraciones, aunque no lo suficientemente numerosas y claras, sobre todo en lo que respecta 
a la más ligera ( $C N H 3$; cat. 1c), que sugieren la existencia de dos poblaciones de monedas, una más pesada que estaría articulada en torno a un peso medio de $23,71 \mathrm{~g}$ (cat. 1a, b) y otra más ligera en torno a 16,37 g (cat. 1c, d). Esta posibilidad parece estar avalada por el hecho de que las monedas con leyenda DINO son generalmente más pesadas que las que muestran la leyenda DIUO y un retrato de ejecución más grosera, con tres o dos puntos detrás de la cabeza, al final de la línea semicircular de puntos. Pero no es menos cierto que en ambos grupos existen monedas que invaden el margen de pesos en los que se encuadran cada uno de ellos. Así, las monedas más pesadas del grupo cat. 1c $(\mathrm{CNH} 3)$ lo son más que las más ligeras del grupo cat. 1a-b $(\mathrm{CNH} 1)$.

En consecuencia tendríamos un primer grupo de monedas, resultado de la producción de varios cuños de anverso y de reverso, con un peso casi uncial ( $\mathrm{CNH}$ 1) (cat. 1a-b), con el que la ciudad comenzó sus emisiones y que podríamos conceptuar como unidades; dentro de este grupo la acuñación se iniciaría con los cuños de las monedas cat. 1a. Le seguiría un segundo grupo, a nuestro entender también de unidades, que mantuvo sin modificación los tipos anteriores, pero acuñado con un peso medio más ligero, que parece concentrarse en torno a 16,37 g (cat. 1c). El grupo de piezas que muestra la cornucopia tendida a dcha. (cat. 1d) debería, probablemente, relacionarse con el grupo 1c si tenemos en cuenta el peso medio y la decoración de compartimentos rectangulares y líneas de la cornucopia. Y finalmente un tercer grupo, de peso semiuncial (14,33 g), que reuniría las piezas del tipo $C N H 2$, que son fácilmente reconocibles porque muestran un retrato dentro de una corona vegetal esquemática, la cornucopia está orientada a derecha y con una forma diferente, así como por llevar la leyendaDInO sin cartela. Continuarían siendo unidades, aunque desconocemos cómo serían valoradas en relación con las anteriores que pudieran quedar en circulación.

Esta ordenación sería a grandes rasgos la que pensamos que mejor encaja con la información disponible. Las monedas del tipo cat. 1c ( $\mathrm{CNH}$ 3) no serían contemporáneas de cat. 1a-b (CNH 1), sino consecutivas, sin que probablemente hubiese pasado mucho tiempo entre el cese de una y el inicio de la otra; en realidad pensamos que $\mathrm{CNH} 3$ es la sucesión de $C N H$ 1, en la que se ha disminuido su peso estándar. Distinto es el 
caso de cat. 2 ( $C N H 2)$ que pudo ser la última emisión acuñada por la ciudad. Está bastante desvinculada estilísticamente de cat. 1a-b ( $\mathrm{CNH}$ 1 ), su peso es más reducido y tampoco guarda relación con cat. 1c-d $(\mathrm{CNH} 3)$, mientras que entre cat. 1a-b y $1 \mathrm{c}-\mathrm{d}(\mathrm{CNH} 1 \mathrm{y} 3)$ parece que se dé una mayor proximidad de estilo y de fabricación.

\section{Leyendas}

La mala calidad de los cuños empleados, así como la deficiente conservación de la mayoría de las monedas ha dificultado la lectura de sus leyendas. Estas circunstancias han favorecido la tendencia a repasar y reavivar las figuras y la leyenda de un buen número de monedas, lo que ha hecho que éstas sean inservibles para el estudio de las leyendas y de los cuños. Aunque todavía subsisten dudas, en la muestra reunida hemos identificado con desigual seguridad cuatro tipos distintos.

1.DIRPO, dentro de una cartela. Esta leyenda la encontramos en las monedas del tipo cat. 1a. Las cinco piezas identificadas aportan desigual información por su deficiente estado de conservación. La moneda ANE 4-5/1959, lote 73 (=cat. 1a-2) es en la que mejor se aprecia esta leyenda y en el resto o no es posible o hay dificultades para ello. La pieza IVDJ 2291 (= cat 1a-1) comparte el cuño de anverso con la anterior y posiblemente también el de reverso, aunque no estamos seguros, porque las partes mejor conservadas en cada una no coinciden lo suficiente. En ella no es visible la parte central, por haber un hueco en la superficie del metal, pero la distancia a la que se encuentran las letras inicial y final sugieren la existencia de dos letras P. La geminación de la P no resulta anómala, como ya hace tiempo señaló Delgado (1871: 137), ya que la labial en otras ciudades cuyo topónimo incluye el final ipo, en ocasiones también lo escriben con una o con dos P, como Orippo, Baicipo o Ventipo (Villar 2000: 87-89).

2. DInO, dentro de una cartela o sin ella. Es la forma más usual de nombrar a la ciudad en las leyendas. La encontramos en algunos cuños del tipo cat. $1 \mathrm{~b}(\mathrm{CNH} 1)$, dentro de una cartela, y en los de cat. 2 ( $\mathrm{CNH}$ 2), sin cartela.

3.DIUO, dentro de una cartela. Es la única variante que puede señalarse, además de la retrógrada, pues el resto de ellas no es seguro 
que existan y es probable que se trate de malas lecturas derivadas de su mala conservación o ser producto de manipulaciones y retoques actuales, como es el caso de la pieza IVDJ 2295.

4. उखाप Esta leyenda retrógrada la hemos podido leer sólo en una pieza (cat. 1d-59). Posiblemente se trata de un error del grabador, pues la cornucopia está tendida a derecha, cuando la posición en las primeras emisiones es a la izquierda. Nada importante en un contexto en el que las monedas son de mala calidad artística y de fabricación y en el que la capacidad de lectura de sus usuarios debió ser bastante limitada.

La leyenda DINกO /DInOcorresponde a un topónimo que contiene el elemento ipo precedido de un prefijo (Villar 2000: 87-118, con un amplio comentario sobre topónimos con el elemento ipo). De acuerdo con la ordenación que proponemos, la consonante labial P se utilizó en primer lugar geminada e inmediatamente después de forma simple, que es, como ha visto Villar, la que predomina en la epigrafía; de ser cierta esta ordenación, su secuencia favorecería la evolución ippo > ipo, en un proceso de simplificación que podría estar representando dos momentos fonológicos distintos (Villar 2000: 88). Sobre el significado de este topónimo, Villar (2000: 115-117) se inclina por la hipótesis tradicional que considera que ipo pudo ser un apelativo que significara ciudad en la lengua que creó este tipo de sintagma toponímico.

\section{La dispersión de las monedas}

La producción monetaria de Dipo fue limitada. El número de cuños que se utilizaron fue escaso y estimamos que para la totalidad de la producción no debieron utilizarse más de 8 ó 9 de anverso. Esta es una estimación que más o menos coincide con los 11 cuños que propuso Villaronga para toda su producción (Villaronga 1990: 23), lo cual justifica la rareza de monedas de las que se conoce su procedencia. No obstante, los hallazgos conocidos se encuentran localizados en un área bastante delimitada (fig. 24). Una pieza del tipo cat. 1d procede de Hornachuelos (Ribera del Fresno, Badajoz) (Jiménez Ávila 1990: nº 137) y cuatro de los tipos cat. 1b-c del campamento de Cáceres el Viejo (Cáceres) (Beltrán Lloris 1974). 
Esta relativa escasez de hallazgos, si bien no ha contribuido a dar prelación a ninguna de las localizaciones propuestas, sí, al menos, ha reforzado la seguridad de que la ciudad de Dipo se encontraba en la actual Extremadura, sin poder precisar en qué lado del río Guadiana, aunque los hallazgos conocidos abogan por la parte española. Dentro de esta tremenda escasez, los recientes hallazgos de monedas documentados por Germán Rodríguez Martín y José Manuel Jerez Linde cobran una especial relevancia y permiten, junto con otros argumentos, proponer su localización en la zona que en la actualidad ocupa el pueblo de Guadajira (Badajoz), construido sobre el solar de la población originaria de Dipo (vid. supra).

A continuación, se ofrecen los hallazgos hasta ahora localizados de monedas de Dipo, todos los cuales apuntan a la ubicación propuesta para Dipo en Guadajira, Badajoz (fig. 24):

1 El Cuco, Guadajira (Badajoz). Noticias del hallazgo en esa zona de la Vega situada debajo del pueblo de Guadajira de unas 10 monedas en fechas distintas (G. Rodríguez Martín, comunicación personal, 2007).

2 Villa romana de las Vegas de "Pedro Franco", situada cerca de "El Cuco", pero algo más al Este, Guadajira, Badajoz, a $38^{\circ} 51^{\prime} 28^{\prime \prime}$ Norte y 6 40 ' 42" Este (fig. 17 y José Manuel Jerez Linde, comunicación personal, 19.4.2008).

3 Iglesia de Lobón, Badajoz. "La mayor parte de la numismática de la ceca de Dipo ha surgido en las tierras de Lobón (puede tratarse del lugar citado como $\mathrm{n}^{\circ} 1$ ), ... las obras de la iglesia arrojaron elementos... numismáticos... de la mítica Dipo..." (http://www.laguia.es/poblacion.php/provincia-Badajoz/poblacion-lobon/donde5083).

4 Lobón (Badajoz). En su territorio y alrededores se han localizado gruesas y pesadas monedas con cara y cornucopia muy rústicas y el epígrafe DIPO (http:// www.celtiberia.net/verrespuesta.asp?idp=9010; aunque puede tratarse del lugar citado como $\mathrm{n}^{\circ}$ 1) (fig. 17b)

5 Almendralejo (Badajoz): 1 moneda (Rodríguez Casanova 2007: 227)

6 Hornachuelos (Badajoz): 1 moneda (Jiménez Ávila 1990: 55, nº 137, de 10,80 gr.; Rodríguez Casanova 2007: 227)

7 Olivenza, Badajoz: noticia imprecisa (http://www.celtiberia.net verres puesta.asp?idp=9010).

8 Badajoz: noticia imprecisa (http://www.celtiberia.net/verrespuesta.asp?idp=9010 parece otra referencia más imprecisa del $\left.\mathrm{n}^{\circ} 1\right)$.

9 Vegas Bajas del Guadiana (Badajoz): noticia imprecisa (http://www.celtiberia.net/ verrespuesta.asp?idp $=9010$, puede ser otra referencia imprecisa del lugar citado como $\left.\mathrm{n}^{\circ} 1\right)$.

10 Elvas, Portugal: noticia imprecisa (http://www.celtiberia.net/verrespuesta. asp?idp=9010). 
11 En el oppidum prerromano de Segobia, Elvas, Portugal, se encontraron numerosas monedas de cobre con la leyenda Dippo: (http://www.celtiberia.net/ verrespuesta.asp?idp $=9010$ ).

12 Campo Maior (Portugal): noticia imprecisa (http://www.celtiberia.net/ verrespuesta.asp?idp $=9010)$

13 Estena (Sierra de San Pedro, Cáceres): noticia imprecisa (http://www.celtiberia.net/ verrespuesta.asp?idp $=9010$ ).

14 Campamento de Cáceres el Viejo: 4 monedas (Hildebrandt 1984: 264).

\section{Cronología}

El argumento más determinante a la hora de establecer la cronología de la producción de Dipo descansa sobre el hallazgo de cuatro monedas en el yacimiento de Cáceres el Viejo, identificado como el campamento de Castra Caecilia. Las cuatro piezas son una buena representación de Dipo. La pieza Beltrán Lloris 225 pertenece al tipo cat. $1 \mathrm{~b}(\mathrm{CNH} 1)$. $\mathrm{La} \mathrm{n}^{\mathrm{o}} 226$ corresponde a un cuño evolucionado del tipo anterior. La $\mathrm{n}^{\circ} 227$ es una variante, posiblemente consecuencia de un error de grabado, ya que la cornucopia está dispuesta en dirección contraria a como se había hecho hasta ahora (cat. 1d). Por último la ${ }^{\circ}$ 228 es un cuño tardío dentro del grupo cat. 1c ( $\mathrm{CNH} 3)$, que se caracteriza por un anverso que muestra un grabado más grotesco y un reverso con un trazado anómalo de la leyenda toponímica en la forma DIUO y la cornucopia decorada.

Del tipo cat. $2(\mathrm{CNH} 2)$ no han aparecido monedas en Cáceres el Viejo, lo cual podría interpretarse como que todavía no habían sido acuñadas, aunque el hecho de que todas las monedas de este tipo puedan proceder de una sola pareja de cuños (esa es la impresión que tenemos) debilita esa argumentación. No hay inconveniente en admitir que ya se habían acuñado y que no han aparecido porque simplemente no llegaron; pero tampoco lo hay para pensar lo contrario, que sean posteriores. Ambas posibilidades son admisibles mientras no contemos con datos más seguros.

Por tanto, la secuencia que proponemos, basada en el aspecto de las monedas (grabado, peso, módulo y forma de los flanes) y en los hallazgos de Cáceres el Viejo, es la de considerar las monedas del tipo cat. 1a-d (CNH 1) como el grupo con el que se inició la acuñación en Dipo. Dentro de este grupo las primeras monedas acuñadas fueron 
posiblemente las que llevan el topónimo con la forma DInกO (cat. 1a); de hecho, son las piezas que se fabricaron con los mejores cuños de todos los que Dipo utilizó a lo largo de su producción. Seguidamente se acuñaron las piezas del tipo cat. $1 \mathrm{~b}$, similares a las que ilustran $\mathrm{CNH} 1 \mathrm{o}$ Vives 115-1. La producción continuó, quizás con alguna interrupción, con cuños de peor calidad, especialmente visible en el retrato (cat. 1c), como la pieza ilustrada en $\mathrm{CNH} 3$. Por último, creemos que se emitió el tipo cat. $2(\mathrm{CNH} 2)$, que con respecto a las acuñaciones anteriores introdujo algunos detalles menores, como la corona vegetal o la leyenda sin cartela, que consideramos suficientes para considerarla desvinculada de las anteriores.

Si proponer una ordenación de las emisiones de Dipo es complejo, bastante más es dar una cronología absoluta, aunque sea aproximada. Las dataciones sugeridas han sido la primera mitad del siglo II a.C. por Villaronga (1994: 403); de los hallazgos de Cáceres el Viejo, Hildebrand ha propuesto los años 155/146 - 116/91 a.C. para las piezas del tipo cat. 1 b y 141-116 a.C. para las del tipo cat 1c-d (Hildebrandt 1985: 291292, cataloga dos monedas como tipo Vives 115-2, pero de ese tipo de piezas no ha aparecido ninguna, por lo que debe referirse a la monedas del tipo cat. 1c-d); Faria sugiere el período comprendido entre fines del siglo II a.C. e inicios del I a.C. (Faria 1995: 147; Faria 2003: 219); el siglo II a.C. y un momento avanzado del siglo I a.C. ha sido la propuesta de Chaves (1998: 281) para cada una de las dos emisiones que supone que existieron; por último, García-Bellido y Blázquez (DCPH II: 111112) se inclinan por los comienzos del siglo I a.C. Las cronologías más bajas están mediatizadas por una supuesta reacuñación de Dipo sobre una pieza de Castulo con reverso Europa sobre toro, que por su ausencia entre los hallazgos del yacimiento Cáceres el Viejo, cabe la posibilidad de que fuera emitido en época post-sertoriana. Pero como ya hemos comentado anteriormente, no creemos que la reacuñación haya sido bien identificada y pensamos que es justo al revés, que se trata de una reacuñación de Castulo sobre Dipo.

Sobre las reacuñaciones reposan algunos argumentos cronológicos de las monedas de Dipo, pero tenemos la impresión de que hemos aceptado fácilmente lo que debería haberse examinado mejor, y hasta dudamos de la fiabilidad de las reacuñaciones que hasta ahora han sido publicadas y recogidas en los diferentes estudios, entre ellos el que uno 
de nosotros publicó (Ripollès 1995: 289-296). La de Murtili sobre Dipo (S de C 612), que Chaves (1998: 281) atribuye al IVDJ, no la hemos identificado en el catálogo de la colección y tampoco lo hicieron GarcíaBellido y García (1986), y dudamos que lo sea, dado que más parece que esté doblemente acuñada. La otra reacuñación, la de Dipo sobre una pieza de Castulo, según Faria (1987), pero identificada y publicada inicialmente como sobre Untikesken por Cardoso y Salgado (1987 = Gomes 1998: 40), creemos que no ha sido bien identificada, ya que, contrariamente, creemos que se trata de una reacuñación de Castulo sobre una pieza de Dipo. Nuestra impresión es que las emisiones de Dipo pudieron iniciarse en la segunda mitad del siglo II a.C., quizás en su último cuarto y perduraron durante el siglo I a.C., siendo posible que las monedas del tipo cat. $2(=\mathrm{CNH} 2)$ fueran post-sertorianas, aunque los datos disponibles no lo hacen necesario.

Catálogo ${ }^{1}$ (fig. 25-29)

Fines del siglo II - inicios del I a.C.

1. AE. Unidad. $34-28 \mathrm{~mm}$. 20,56 g (52 ejemplares). $C N H$, p. $403, \mathrm{n}^{\circ} 1$, 3. Vives, lám. CXV, 1.

Anv. Cabeza masculina, a dcha.; con un semicírcculo de puntos que se inicia sobre la cabeza y termina a la altura de la nuca.

Rev. Cornucopia, tumbada a izq.; debajo, en cartela, leyenda DIก DIROoDIUO.

a. Leyenda DInกO en cartela y cornucopia a izq. $34 \mathrm{~mm}$. 26,88 g (4 ejemplares)

$1 *$ IVDJ 2291. 27,57 g, $7 \mathrm{~h}$.

2* ANE 4-5/1959, lote 73 (= S de C 220).

3* Ex col. Vila Casas (archivo Villaronga). 25,2 g, $12 \mathrm{~h}$.

4* Col. J. Rodrigues Marinho (Lisboa) (= Gomes 1998: 40, n 2.02), 30,14 g (archivo A. M. Faria 10).

5 Ex col. Martínez Bilbao (archivo Villaronga). 24,60 g.

\footnotetext{
${ }^{1}$ Agradecemos la colaboración prestada por L. Villaronga, A. M. Faria, C. Marcos, P. Otero, M. Campo en la confección de este catálogo. También agradecemos de forma general a todos los colegas y coleccionistas que nos han facilitado información.
} 
b. Leyenda DINO en cartela y cornucopia a izq. $34-30 \mathrm{~mm}$. 23,71 g (23 ejemplares).

6* IVDJ 2290. 33,93 g, 7 h. (= $S$ de C $219=$ Vives, lám. CXV, $1=$ DCPH II, 112, 1' -1$)$.

7* Vico 13/11/1997, lote 40. 23,20 g (=CNH, p. 403, no 1).

$8 *$ Col. G. Cores (Madrid). 22,2 g, 8 h.

9* Aureo 7/3/2001, lote 188. 17,82 g.

10* BM ex Buckler (1914). 31,04 g, 4 h (= SNG BM 1650)

11 SNG Cop 124. 20,39 g, $11 \mathrm{~h}$.

12 Ex col. Cardim (archivo Villaronga). 28,20 g, $3 \mathrm{~h}$.

13 FNMT. 25,907 g, $5 \mathrm{~h}$.

14 Herrero 3/1987, lote 64. 30,97 g.

15 Ex col. Domenech (archivo Villaronga). 22,3 g 3 h. El cospel está incompleto.

16 Ex col. Serra (archivo Villaronga). 17,10 g, 6 h. La leyenda del reverso ha sido retocada.

17 M. Cáceres, hallada en Cáceres del Viejo, 23,12 g (= M. Beltrán 1974: 225 = Hildebrant 1984: 137).

18 M. Cáceres, hallada en Cáceres del Viejo, 15,76 g (= M. Beltrán 1974: 226 = Hildebrant 1984: 139).

19* Vico 10/6/2004, lote 32 (=Aureo 3/3/2004, lote 1141). 40,05 g. $20 *$ Col. Privada (archivo A. M. Faria 6).

21* Aureo 18/10/1994, lote 46. 19,83 g.

22* BM ex Baldwin (1956). 22,50 g, $12 \mathrm{~h}$ (= SNG BM 1651).

$23 * S$ de C 222. $22 \mathrm{~g}$ (= GMI 914) (foto archivo A. M. Faria 5).

24* Pliego 7/3/2001, lote 70. 22,28 g.

25 Vico 16/3/1999, lote 26. 16,80 g.

26 Aureo 28/5/2002, lote 104 (= Aureo 28/4/2004, lote $2275=$ Aureo $15-16 / 12 / 2004$, lote 3226). $21,29 \mathrm{~g}$.

27 Herrero 4/4/2002, lote 28. 26,04 g.

28 ANS HSA 1001.1.23651 (ex Cervera). 19,13 g, $11 \mathrm{~h}$.

c. Leyenda DIUO en cartela y cornucopia a izq. $16,47 \mathrm{~g}$ (25 ejemplares: $\mathrm{c}+\mathrm{d}) .34-28 \mathrm{~mm}$.

29* FNMT. 22,83 g, $3 \mathrm{~h}$.

30* Royal Coin Cabinet, Estocolmo, ex Lorich. 21,47, 7 h. (= SNG Stockholm 187). 
31 MAN 2.6363. $14 \mathrm{~g}$.

32* $S$ de C 221 (= IVDJ 2293).

33* IVDJ 2294. 13,73 g, $6 \mathrm{~h}$.

34 Herrero 19/5/2005, lote 50. 28,61 g.

35 MAN 2.6361. 15,33 g. Da la impresión de que se reacuñó sobre una pieza de Obulco.

36 MAN 2.6359. 21,19 g.

37* Col. Privada. Barcelona.

$38 *$ Col. Privada (archivo A. M. Faria 7).

39 MAN 2.6360. 13,79 g.

40 Herrero 9/6/2004, lote 51. 19,42 g. La figura y la leyenda del reverso parecen haber sido reavivados.

41 Pliego 22/4/2004, lote 117. 21,21 g.

42 Aureo 21/10/1997, lote 961. 17,47 g.

43 Aureo 30/4/2008, lote 2133. 13,81 g.

44* Aureo 5/3/2003, lote 1043. 17,79 g.

45 Villaronga 1994: 403, $\mathrm{n}^{\circ} 3.13,43 \mathrm{~g}$.

46 Herrero 17/10/1991, lote 26. 13,78 g.

47 Herrero 15/11/2006, lote 37. 18,60 g. La leyenda parece haber sido retocada.

48 Aureo 26/4/2006, lote 2144. 11,48 g.

49 Aureo 21/10/1997, lote 962. 13,03 g.

50 BnF ex Seymour de Ricci (= BnF 510). 16,50, - h.

51 Aureo 21/10/1997, lote 958.

52 Aureo 26/1/1999, lote 295. 13,64 g.

53 M. Cáceres, hallada en Cáceres del Viejo, 22,38 g (= M. Beltrán 1974: 228 = Hildebrant 1984: 140).

54 Jiménez 1990: nº 137. 10,80 g, 4 h. Hallada en Hornachuelos (Ribera del Fresno, Badajoz).

d. Variante cornucopia a dcha. $16,47 \mathrm{~g}$ (25 ejemplares: $\mathrm{c}+\mathrm{d}) .32-31$ $\mathrm{mm}$.

Se conocen por lo menos dos o tres cuños de reverso que parecen tener la leyenda grabada de distinta forma.

55* Aureo 20/1/1998, lote 489. 14,99 g.

$56^{*}$ Aureo 21/5/1998, lote 262. 13,75 g.

$57 *$ IVDJ 2292. $19,82 \mathrm{~g}$.

Conimbriga, 48 (2009) 5-60 
58 M. Cáceres, hallada en Cáceres del Viejo. 15,15 g (= M. Beltrán 1974: 227 = Hildebrant 1984: 138). La última letra de la leyenda es una O.

59* Cardoso, Salgado 1987: 1-5 (= Gomes 1998: 40, nº 1.04). 13,21 g. Es una reacuñación de Castulo (aunque no lleva topónimo se atribuye a esta ciudad) (CNH 339/70) sobre una pieza de Dipo. En el anverso, sobre el cuello del retrato, se aprecian las letras VL F y parte de los labios y la barbilla del retrato de Castulo y en el reverso, sobre el extremo apuntado de la cornucopia, parte del manto de Europa y la parte trasera del toro. En esta moneda la leyenda es retrógrada: गबाप.

\section{Sin determinar}

Magerit-Segura-Vico 17/12/1981, lote 576. 25,80 g (ex Cardim).

RAH 410. 10,81 g.

RAH 411. 16,25 g (fragmentada), $3 \mathrm{~h}$.

MAN 2.6362. 19,90 g.

2. $A E$. Unidad. $14,33 \mathrm{~g}$ (10 ejemplares). 31-29 mm. $C N H$, p. $403, \mathrm{n}^{\circ} 2$. Vives, lám. CXV, 2.

Anv. Cabeza masculina, a dcha.; dentro de una corona vegetal estilizada. Rev. Cornucopia, tumbada a dcha.; debajo, sin cartela, leyendaDInO; dentro de una corona vegetal estilizada.

60* Glasgow, colección Hunterian (= MacDonald 1905: 668, nº 1). 16,72 g.

61* Ex col. Ramón Vidal Quadras 744.

62* Col J. Rodrigues Marinho (Lisboa). 12,50 g (archivo A. M. Faria $9)$.

63 Aureo 21/10/1997, lote 960. 11,63 g.

64 Col. Privada (archivo A. M. Faria 4).

65 MAN 2.6364. 9,69 g.

66 S de C 223 (= Vives, lám. CXV, 2).

67 IVDJ 2297. 9,41 g (perforada y con falta de metal).

68 ANS 1001.1.23615 (ex Cervera). 16,61 g, 6 h.

69* $C N H$, p. $403, \mathrm{n}^{\circ} 2$.

70 Aureo 21/10/1997, lote 959.

71 Pliego 22/4/2004, lote 118. 12,11 g.

72 Aureo 16-17/2/2003, lote 3230A. 15,75 g. 
73 Aureo 7/3/2001, lote 189. 18,52 g.

74 Ex col. Cardim (archivo Villaronga). 15,7 g, $3 \mathrm{~h}$.

75 FNMT. 14,034 g, 6 h.

\section{BIBLIOGRAFÍA}

Abascal, J. M., 1995: "Las inscripciones latinas de Santa Lucía del Trampal (Alcuéscar. Cáceres) y el culto de Ataecina en Hispania”, Archivo Español de Arqueología 68: 31-105.

Abascal, J. M., 2002: “Ataecina”, Religiões da Lusitania. Loquuntur saxa (catálogo de la exposición), Lisboa: 53-60.

Aguilar Sáenz, A., Guichard, P. y Lefebvre, S., 1993: "La ciudad antigua de Lacimurga y su entorno rural", Studia Historica. Historia Antigua 10-11: 109-130.

Alarcão, J. De, 1973: Portugal Romano, Lisboa.

Alarcão, J. De, 1983: Portugal romano ${ }^{3}$, Lisboa.

Alarcão, J. DE, 1988: O Domínio Romano em Portugal, Lisboa.

Alarcão, J. DE, 1988a: Roman Portugal, vol. I: Introduction. Warminster.

Alarcão, J. DE, 2001: “A Localização de Dipo e Evandriana”, Al-Madan, II série, 10: 39-42.

AlarCÃO, J. DE, 2006: "Notas de arqueologia, epigrafia e toponímia, IV", Revista portuguesa de arqueologia, 9,1: 131-148.

Alfaro, C., Arévalo, A., Campo, M., Chaves, F., Domínguez, A. y Ripollés, P. P., 1998: Historia monetaria de Hispania antigua, Madrid.

Almagro, M., 1943: Un nuevo bronce griego hallado en España, Ampurias 5: 251-252.

Almagro-Gorbea, M., 1977: El Bronce Final y el Período Orientalizante en Extremadura (Biblioteca Praehistorica Hispana 14), Madrid.

Almagro-Gorbea, M., 1990: "El Periodo Orientalizante en Extremadura", La Cultura Tartésica y Extremadura (Cuadernos Emeritenses 2) Mérida: 85125.

Almagro-Gorbea, M., 2005: "La Vía de la Plata en la Prehistoria", Anas 18, 2005: 29-43.

Almagro-Gorbea, M., Jiménez, J., Lorrio, A., Mederos, A. y Torres, M., 2006: La necrópolis de Medellín. I, La excavación y sus hallazgos (Biblioteca Archaeologica Hispana 26,1), Madrid.

Almagro-Gorbea, M., Lorrio, A., Mederos, A. y Torres, M., 2008: La necrópolis de Medellín. II-III, Estudios e interpretación de los hallazgos (Biblioteca Archaeologica Hispana 26,2-3), Madrid. 
Amo, M. DEL., 1978: "El Castañuelo: un poblado céltico en la provincia de Huelva”, Huelva arqueológica, 4: 299-342.

Arévalo, A., 1999: La ciudad de Obulco. Sus emisiones monetales, Guadalajara.

AriAs, G., 1987: Repertorio de caminos de la Hispania romana, La Línea.

Arias, G., 2004: "Mapa-Índice de vías romanas y caminos milenarios de Hispania. Revisión de enero de 2004", Anexo de "El Miliario Extravagante $n^{\circ} 72$ ", Cortes de la Frontera.

Arruda, A. M., 2002: Los fenicios en Portugal. Fenicios e indígenas en el centro y sur de Portugal (siglos VIII-VI a.C.) (Cuadernos de Arqueología Mediterránea 5-6). Barcelona.

Beltrán Lloris, M., 1974: "Problemas de arqueología cacereña: El campamento romano de Cáceres Viejo (Cáceres). Estudio numismático". Numisma 120-131: 255-310.

Beltrán Martínez, A.: 1950. Curso de Numismática: Numismática Antigua. Cartagena.

Berrocal Rangel, L., 1993: Los Pueblos Célticos del Suroeste de la Península Ibérica (Complutum Extra 2), Madrid.

Berrocal RANGel, L., 1994: "El oppidum de Badajoz. Ocupaciones prehistóricas en La Alcazaba", en Almagro-Gorbea, M. y Martín, A.M. ' (eds.), Castros y oppida en Extremadura (Complutum Extra 4), Madrid: 143-187.

Berrocal Rangel, L., 2003: "El instrumental textil en Cancho Roano: consideraciones sobre sus fusayolas, pesas y telares", S. Celestino (ed.), El palacio-santuario de Cancho Roano IX, Badajoz: 213-297.

Berrocal Rangel, L., 2008: "El oppidum de Badajoz en época postorientalizante", J. Jiménez Ávila (ed.), Sidereum Ana I. El Río Guadiana en época post-orientalizante. Madrid: 177-183.

$B n F=$ véase Ripollès, P. P. 2005.

Bosch Gimpera, P. y Aguado Bleye, P., 1962: "La conquista de Hispania por Roma”, en R. Menéndez Pidal, Historia de España, II, Madrid.

Cardoso, J. L. y SAlgado, J., 1987: "Moeda de Dipo inedita reacunhada sobre asse de Undicesce", Numisma [Lisboa], 1987: 1-5.

Carrasco Serrano, G., 1995: “Comunicaciones romanas del ámbito provincial de Toledo en las antiguas fuentes itinerarias", en Espacio, tiempo y forma, II, Historia Antigua 8: 299-313.

CeÁn Bermúdez, A., 1832: Sumario de las antigüedades romanas que hay en España, Madrid.

Chaves, F., 1994: La colección numismática de la Universidad de Sevilla, Sevilla. 
Chaves, F., 1998: "Amonedación de las cecas latinas de la Hispania Ulterior". En C. Alfaro et alii, Historia Monetaria de Hispania Antigua. Madrid: 233-317.

$C N H=$ Véase Villaronga, 1994.

Correa, J. A., 1994: "El topónimo Ilipa", Homenaje al Profesor Presedo, Sevilla: 333-340.

Crawford, M., 1994: Roman Republic Coinage, Cambridge.

CuADRADO, E., 1956: "Los recipientes rituales metálicos llamados braserillos púnicos", Archivo Español de Arqueología, 29:53-84.

CuADRADO, E., 1957: "La fíbula anular hispánica y sus problemas, Zephyrus 8: $5-76$.

Cuadrado, E., 1963: Precedentes y prototipos de la fibula anular hispánica (Trabajos de Prehistoria 7), Madrid.

CuAdRADO, E., 1966: Repertorio de los recipientes rituales de asas de manos en la Península Ibérica (Trabajos de Prehistoria 21), Madrid.

$D C P H=$ Véase García-Bellido y Blázquez, 2001.

Delgado, A., 1857: Catalogue des monnaies et des médailles antiques, du moyen age et des temps modernes, en or, en argent et en bronze, composant le cabinet numismatique de feu Mr. Gustave Daniel de Lorichs. Madrid.

Delgado, A., 1871: Nuevo método de clasificación de las medallas autónomas de España, vol. I. Sevilla.

Díaz, P., Rio-Miranda, J. y Rosco Madruga, J., 1986: “Aportaciones a la epigrafía y arqueología de la Provincia de Cáceres", Epigrafía publicada en la revista BIGCValdeobispo, desde 1981 a $\left.1986 \mathrm{n}^{\circ} 1-16\right), \mathrm{n}^{\circ} 5$. http:// caparra.es/archivospdf/N.\%200\%20-\%201995.pdf

Díaz y Pérez, N., 2005: Historia de Talavera la Real. Villa de la provincia de Badajoz por -, Valladolid.

s.a., s.f., 1975 (reed.): s.v. Dipo, Enciclopedia universal ilustrada europeoamericana de Espasa-Calpe, XVIII,1, Madrid: 1386.

Faria, A. M. DE, 1989: "A numária de *Cantipo", Conimbriga 28: 71-99.

FARIA, A. M. DE, 1992: "Ainda sobre o nome prerromano de Alcácer do Sal", Vispasca 1: 39-48.

FARIA, A. M. DE, 1995: "Moedas da época romana cunhadas em territorio actualmente portugués", en M ${ }^{\mathrm{a}}$. P. García Bellido y R. M. Sobral (eds.), $L a$ Moneda Hispánica. Ciudad y territorio (Anejos de Archivo Español de Arqueología XIV), Madrid: 143-153.

FariA, A. M. DE, 1998a: Recensión de la obra de Alfaro, C., Arévalo, A., Campo, M., Chaves, F., Domínguez, A., y Ripollés, P. P., Historia monetaria de Hispania antigua, Madrid, 1998, en Revista Portuguesa de Arqueologia, 1,2:241-256.

Conimbriga, 48 (2009) 5-60 
Faria, A. M. DE, 2003. “Crónica de onomástica paleo-hispânica (5)”, Rev. Port. de Arq. 6, 1: 211-234.

Fernández Corrales, J. M., 1987: El trazado de las vías romanas en Extremadura, Universidad de Extremadura. Madrid.

Fernández Corrales, J. M., 1995: "Dipone”, Tabula Imperii Romani, Hoja J29: Lisboa. Emerita-Scallabis-Pax Ivlia-Gades, Madrid: 74-75.

FitA, F., 1894: "Excursiones epigráficas", Boletín de la Real Academia de la Historia XXV: 43-166.

FrancisCo, J. DE, 1989: Conquista y romanización de Lusitania, Salamanca.

GALSTERER, H., 1971: Untersuchungen zum Römischen Städtewesen auf der Iberischen Halbinsel (Madrider Forchungen 8), Berlín.

García Alonso, J. L., 2003: La Península Ibérica en la Geografía de Claudio Ptolomeo (Anejos de Veleia 19). Vitoria.

García Martín, P., 1990: El patrimonio cultural de las Cañadas Reales. Valladolid.

García Mora, F., 1991: Un episodio de la Hispania republicana. La Guerra de Sertorio: Planteamientos iniciales, Granada.

García Mora, F., 1993: "Sertorio frente a Metelo (79-78 a.C.)", II Congreso Peninsular de Historia Antigua, Coimbra: 375-398.

GarcíA, J. A., 1875: Historia de Talavera la Real. Villa de la provincia de Badajoz, Madrid.

GARCíA-BELlido, Ma P., 1982: Las monedas de Cástulo con escritura indígena. Historia numismática de una ciudad minera, Barcelona

García-Bellido, Ma P. y BlázQuez, C., 2001: Diccionario de cecas y pueblos hispánicos con una introducción a la numismática antigua de la Península Ibérica, I-II, Madrid.

García-Bellido, Ma . P. y García de Figuerola, M. 1986: Álbum de la antigua colección Sánchez de la Cotera de moneda ibero-romana. Madrid.

Gil FArrés, O., 1966: La moneda hispánica en la Edad Antigua, Madrid.

Gil Montes, J. y Álvarez Rojas, A., 1988: “Aproximación al estudio de las vías de comunicación en el primer milenio antes de Cristo en Extremadura", Trabajos de Prehistoria, 45, 1988: 305-316.

Ginés Hernández, M., 1879: Historia de Talavera la Real. Villa de la Provincia de Badajoz, Madrid.

Gomes, A. 1998: Moedas do território português antes da fundaçao da nacionalidade (hispano-romanas). Lisboa.

Gorges, J.-G. y Rodríguez Martín, F. G., 1999: "Un nouveau milliaire de Magnence en Hispanie. La borne de Torre Águila (Montijo, Badajoz): épigraphie et territoire", en Économie et territoire en Lusitanie romaine. Madrid: 241-262. 
Gorges, J.-G. y RodríGuez Martín, F. G., 2000: “Voies romaines, propriétés et propriétaires à l'ouest de Mérida: problèmes d'occupation du sol en moyenne vallée du Guadiana sous le Haut-Empire". Sociedad y cultura en Lusitania romana. IV Mesa Redonda Internacional. (Serie Estudios Portugueses, 13), Mérida: 101-153.

Gorges, J.-G. y Rodríguez Martín, F. G., 2004: "De Lusitania en Bétique. Regina et le réseau routier romain entre Sierra Morena et Guadiana", en J.G. Gorges, E. Cerrillo, y T. Nogales (eds.), Las comunicaciones. V Mesa Redonda Internacional sobre Lusitania romana, Madrid: 61-108.

GuAdÁn, A. M. 1969: Numismática ibérica e ibero-romana. Madrid.

Guadán, A. M. 1980: La Moneda ibérica. Catálogo de Numismática ibérica e ibero romana, Madrid.

GuerrA, A., 2004: “Caepiana: uma revalidação crítica do problema da sua localisação e enquadramento histórico", Revista Portuguesa de Arqueología 7,2: 217-235.

HabA, S., 1998: Medellín romano. La Colonia Metellinensis y su territorio, Badajoz.

Heleno, M., 1951: “Arqueología de Elvas, Noticia preliminar”, O Arqueólogo Português, n.s. II, 1: 83-93.

Hernández Pacheco, E., 1955: Fisiografía del Solar Hispano, Madrid.

Hildebrandt, H. J. 1984: "Die Münzen aus Caceres el Viejo", en G. Ulbert, Caceres el Viejo. Madrider Beiträge, 11: Mainz: 257-297.

Hitl, D. K., 1958: A Class of Bronze Handles of the Archaic and Classical Periods, American Journal of Archaleology, 62,2: 193-201.

HüBner, E., 1893: Monumenta linguae Ibericae, Berlin.

HÜBNER, E., 1903: s.v. "Dipo", Realencyclopädie der klassischen Altertumswissenschaft, IX, Stuttgart: col. 1159.

Hubschmit, J., 1960: Mediterrane Substrate, mit besondere Berücksichtigung des Baskischen un der west-östlichen Sparchbeziehungen (Romanica Helvetica 70), Bern.

Hurtado, V., 1985: "La excavación de una sepultura circular de la Edad del Bronce en Guadajira (Badajoz)", Homenaje a Cánovas Pesini. Badajoz: 25-35.

Hurtado, V., 1995: "Interpretación sobre la dinámica cultural de la cuenca media del Guadiana del IV al II milenio a.C.", Homenaje a M. Gil-Mascarell (Extremadura Arqueológica V). Mérida: 53-80.

IVDJ = véase Ruiz Trapero, 2000.

Jacobsthal, P. y LANSDorfF, A., 1929: Die Bronzeschnabelkannen, ein Beitrag zur Geschichte des vorrömischen Imports nördlich der Alpen, Berlín.

Conimbriga, 48 (2009) 5-60 
Jerez Linde, J. M., 2002: "Prospecciones arqueológicas en la villa romana de "La Tiesa" (Lobón, Badajoz). Las cerámicas", Revista de Estudios Extremeños 58,1: 11-29.

Jiménez Ávila, J., 1990: Estudio numismático del poblado de Hornachuelos (Ribera del Fresno, Badajoz) (Arqueología Extremeña 4), Badajoz.

Jiménez ÁvilA, F. J., 1997: “Cancho Roano y los complejos monumentales del Guadiana”, Complutum 8: 141-159.

JimÉnez Ávila, F. J., 2002: La toréutica orientalizante en la Península Ibérica (Bibliotheca Archaeologica Hispana 16), Madrid.

JimÉnez Ávila, F. J. y ORTEGA, J., 2004: La cerámica griega en Extremadura (Cuadernos Emeritenses 23), Mérida.

JimÉnez Ávila, F. J. (ed.), 2006: El conjunto orientalizante de Talavera la Vieja (Cáceres) (Memorias de Arqueología Extremeña 5), Mérida.

KuKAHN, E., 1966: "Una caja funeraria ibérica con representaciones en relieve", IX Congreso Nacional de Arqueología, Valladolid-1965, Zaragoza: 293295.

MacDonald, G., 1905: Catalogue of Greek Coins in the Hunterian Collection, University of Glasgow. III. Further Asia, Northern Africa, Western Europe. Glasgow.

Madruga, J. V. y Salas Martín, J., 1995: “A propósito de teónimos indígenas en el conventus Emeritensis", Espacio, Tiempo y Forma, Serie II, 8: 331355.

Maia, Ma García Pereira, 2008: "Reflexões sobre os complexos arquitectónicos de Neves-Corvo, na região central do Baixo Alentejo, em Portugal", J. Jiménez Ávila (ed.), Sidereum Ana I. El río Guadiana en época postorientalizante (Anejos de Archivo Español de Arqueología 46), Mérida: 353-364.

Maluquer de Motes, J., 1985: "Notes sobre les relacions comerciales entre la conca del Guadiana i Andalucia en els darrers temps de la civilització tartéssica". Pyrenae 21: 11-22.

Martín Bravo, A. Ma , 1995: "Dracmas aparecidas en castros de la provincia de Cáceres", Ma . P. García Bellido y R. M. Sobral, La Moneda Hispánica: ciudad y territorio (Anejos del Archivo Español de Arqueología XIV), Madrid: 139-142 .

Martín Bravo, A. Ma ., 1999: Los orígenes de Lusitania. El I milenio a.C. en la Alta Extremadura (Biblioteca Archaeologica Hispana 2), Madrid.

Maurenbrecher, B., (ed.), 1891: C. Sallusti Crispi Historiarum reliquiae (reed. 1967), Stuttgart.

MÉlidA, J. R., 1925: Catálogo Monumental de España. Badajoz, Madrid. 
Montenegro, A., 1996: "La conquista de Hispania por Roma”, en R. Menéndez Pidal (ed.), Historia de España, II (reed.), Madrid: 3-192.

Morales, A. DE, 1972: Las antigüedades de las ciudades de España que van nombradas en la corónica con la averiguación de sus sitios y nombres antiguos..., Madrid.

Morente y Cejo, Da M. Ma Del Rocío 1908: Geografía, topografía é historia de Talavera la Real, Provincia de Badajoz por -, Badajoz, Uceda Hermanos.

MGE 58-59: Mapa Metalogenético de España 1:200.000. Villareal-Badajoz, Madrid, 1974.

MTNE 776-IV: Mapa Topográfico Nacional de España 1:25.000. 776-IV. Montijo, Madrid, 2003.

Navarro del Castillo, V., 1963: "El pueblo Lyco (Lobón) a través de la historia", Revista de Estudios Extremeños 19,1: 51-99.

NuñEz, P., 1873: Opúsculo de la Historia general de Talavera la Real villa de la provincia de Badajoz, Madrid.

Olivares, J. C., 2002: Los dioses de la Hispania céltica (Bibliotheca Archaeolgica Hispana 15), Madrid.

Pérez Guijo, S., 2001: "La Beturia: definición, límites, etnias y organización territorial”, Florentia Iliberritana. Revista de estudios de antigüedad clásica, 12: 315-349.

PÉrez GuiJo, S., 2005: "El progreso de la integración de la Beturia Túrdula en la provincia Hispania Ulterior Betica", Memorias de Historia Antigua 2122: 105-121.

Pérez Vilatela, L., 1990: La ciudad romana de Acinipo, Ronda.

Pérez Vilatela, L., 2000: Lusitania. Historia y Etnología (Bibliotheca Archaeologica Hispana 6), Madrid.

PRADA M. DE, 1986: "Nuevas aportaciones al repertorio de los recipientes rituales metálicos con 'asas de manos' en la Península Ibérica”, Trabajos de Prehistoria 43, 1986: 99-142.

Quesada, F. 1997: El armamento ibérico. Montagnac.

$R A H=$ Véase Ripollès y Abascal, 2000.

Ripollès, P. P. 1988. La ceca de Valentia. (Estudis Numismàtics Valencians 2). Valencia.

Ripollés, P. P., 2005: Monedas hispánicas de la Bibliotèque national de France (Bibliotheca Numismatica Hispana 1), Madrid.

Ripollès, P. P. y Abascal, J. M., 2000: Monedas hispánicas. Catálogo de la Real Academia de la Historia, Madrid.

Rivero, C. M ${ }^{\mathrm{a}}$ DEL, 1912: La colección de monedas ibéricas del Museo Arqueológico Nacional. Monedas de la Ulterior, Madrid. 
Rodríguez Casanova, I., 2007: "Noticia de un as de Sekaisa con contramarca de Asido procedente de Almendralejo (Badajoz)", Documenta \& Instrumenta 5: 211-228.

Rodríguez Martín, F. G., 1993: Arqueología de la Villa romana de Torre Águila [tesis doctoral inédita], Cáceres 1993.

Rodríguez Martín, F. G., 1998: “La villa romana de Torre Águila (Barbaño, Badajoz) a partir del siglo IV d.C. Consideraciones generales", Congreso Internacional la Hispania de Teodosio, Segovia-Coca, 2, Salamanca: $697-$ $-711$.

Rodríguez Martín, F. G., 1999: "Los asentamientos rurales romanos y su posible distribución en la cuenca media del Guadiana”, en J.-G. Gotees y F. G. Rodríguez Martín (eds.), Économie et territoire en Lusitanie romaine, Madrid: 121-134.

Rodríguez Martín, F. G. y Gorges, J.-G., 2006: "La estructura del paisaje antiguo en el territorio emeritense en el Alto Imperio: El ejemplo del valle medio del Guadiana", Arqueología Espacial 26: 171-192.

RoldÁn, J. M., 1971: Iter ab Emerita Asturicam. El camino de la Plata, Salamanca.

RoldÁn, J. M., 1975: Itineraria Hispanica. Fuentes antiguas para el estudio de las vías romanas en la Península Ibérica. Valladolid.

RoldÁn, J. M., 1978: Historia de España, Madrid (Cátedra).

Rosco, J. y Téllez, L., 1986: ¿Lacipea ubicada?, en C. Chaparro (ed.), Primeras Jornadas sobre manifestaciones religiosas de la Lusitania, Cáceres: 133$-134$.

Roso de LunA, M., 1912: "Las vías romanas del Nordeste de Mérida”. Boletín de la Real Academia de la Historia LX: 373-379.

Rubio Muñoz, A., 1983: Datos para el estudio del poblamiento rural romano en las Vegas Bajas del Guadiana (Memoria de Licenciatura de la Universidad de Extremadura), Cáceres.

Ruiz Delgado, M. Mª., 1989: Fíbulas Protohistóricas en el Sur de la Península Ibérica, Sevilla.

Ruiz Trapero, M., 2000: Las monedas hispánicas del Instituto Valencia de Don Juan. Madrid.

$S$ de $C=$ Véase García-Bellido y García de Figuerola, 1986 .

SaAvedra, E., 1862 (reed. 1914): Discursos leídos ante la Real Academia de la Historia en la recepción pública de Don Eduardo Saavedra y Moragas el 28 de Diciembre de 1862, Madrid.

SÁez FernÁndez, P., 1990: "Estudio sobre una inscripción catastral colindante con Lacimurgi", Habis 21: 205-227. 
SÁnchez Abal, J. L. y García Jiménez, S., 1988: "La ceca de Tanusia”, I Congreso Peninsular de Historia Antigua, II, Santiago de Compostela: 149190.

SÁnchez Madrid, S., 2002: Arqueología y Humanismo. Ambrosio de Morales. Córdoba.

Schulten, A., 1935: Las guerras del 237-154 a. de J.C. (Fontes Hispaniae Antiquae III), Barcelona.

Schulten, A., 1937: Las guerras del 154-72 a. de J.C. (Fontes Hispaniae Antiquae IV), Barcelona.

Schulten, A., 1949: Sertorio, Barcelona.

Sestini, D., 1818: Descrizione delle medaglie Ispane appartenenti alla Lusitania, alla Betica e alla Tarragonense che si conservano nel Museo Hedervariano, Florencia.

Sillières, P., 1990: "Voies romaines et limites de provinces et de cités en Lusitanie", Les villes de la Lusitanie romaine, Paris: 77-88.

Sillières, P., 1990a: Les voies de communication de l'Hispanie Méridionale, Paris.

SNG BM= Purefoy, P. B., Meadows, A., 2002: Sylloge Nummorum Graecorum. The British Museum. Part 2: Spain. Londres: The British Museum Press.

SNG Cop = Jenkins, G. K., 1979: Sylloge Nummorum Graecorum. The Royal Collection of Coins and Medals. Danish National Museum. Spain - Gaul. Copenhagen.

SNG Stockholm = Ripollès, P. P., 2003: Sylloge Nummorum Graecorum. Sweden II. The collection of the Royal Coin Cabinet. Nacional Museum of Economy. Stockholm. Part 6: The G. D. Lorichs collection. Estocolmo: The Royal Academy of Letters History and Antiquities.

Stibbe, C., 2000: Sons of Hephaistos. Aspects of the Archaic Greek Bronze Industry, Rome.

TAVARES DA Silva, C., 2005: “A presença fenícia e o processo de orientalização nos estúarios do Tejo e Sado”, F. J. Jiménez Ávila y S. Celestino (coords.), El periodo orientalizante: Actas del III Simposio Internacional de Arqueología de Mérida, Protohistoria del Mediterráneo Occidental (Anejos de Archivo Español de Arqueología 35), Madrid: 749-765.

TIR J-29: Tabula Imperii Romani. Hoja J-29: Lisboa. Emerita - Scallabis Pax Iulia - Gades. Madrid, 1995.

TIR J-30: Tabula Imperii Romani. Hoja J-30: Valencia. Madrid, 2002.

Torres, M., 2002: Tartessos (Biblioteca Archaeologica Hispana 14). Madrid.

Torres, M., 2005: “Una colonización tartésica en en el interfluvio Tajo-Sado durante la Primera Edad del Hierro?”, Revista Portuguesa de Arqueología 8,2: 193-213.

Conimbriga, 48 (2009) 5-60 
Torres, M., 2008: “Cerámica tipo Medellín”, Almagro-Gorbea et al. 2008: 724733.

Torres, M., 2008b: "Fíbulas", Almagro-Gorbea et al. 2008: 529-535.

Torres, M., 2008a: "Brazaletes”, Almagro-Gorbea et al. 2008: 537-540.

Tovar, A., 1974: Iberische Landeskunde, II-1. Baetica, Baden-Baden.

Tovar, A., 1976: Iberische Landeskunde, II,2. Lusitanien, Baden-Baden.

UlBert, T., 1984: Cáceres el Viejo. Ein spätrepublukanisches Legionslager in Spanisch-Extremadura (Madrider Beiträge 11), Mainz.

Untermann, J., 1961: Sprachräume und Sprachbegegungen im vorrömischen Hispaniens, Wiesbaden.

Vasconcelos, J. Leite de, 1913: Religiões da Lusitania III, Lisboa.

Vegas, M., 1957: “Asas de oinokoes de bronce etruscos del Museo de Barcelona”, Cuadernos de Trabajos de la Escuela Española de Historia y Arqueología en Roma 9: 77-94.

VILlaR, F., 2000: Indoeuropeos y no indoeuropeos en la Hispania prerromana: las poblaciones y las lenguas prerromanas de Andalucía, Cataluña y Aragón según la información que nos proporciona la toponimia. Salamanca.

Villaronga, L., 1979: Numismática Antigua de Hispania. Barcelona.

VillarongA, L., 1990: "Assaig-balanç dels volums de les emissions monetàries de bronze a la Península Ibèrica”, Acta Numismática 20, 1990, pp. 19-35.

Villaronga, L., 1994: Corpus Nummum Hispaniae ante Augusto Aetatem, Madrid.

Villaronga, L., 2004: Numismática antiga de la Península Ibérica, Barcelona.

VIU, J. DE, 1852: Extremadura. Colección de sus inscripciones y monumentos, seguidas de reflexiones importantes, sobre lo pasado, lo presente y lo porvenir de estas provincias, Madrid ( $\left.2^{\mathrm{a}} \mathrm{ed}.\right)$.

Vives = Vives y Escudero, A., 1924-1926: La Moneda Hispánica, I-II, Madrid.

Zóbel, J., 1880: Estudio histórico de la moneda antigua española. Madrid. 
EsT. I

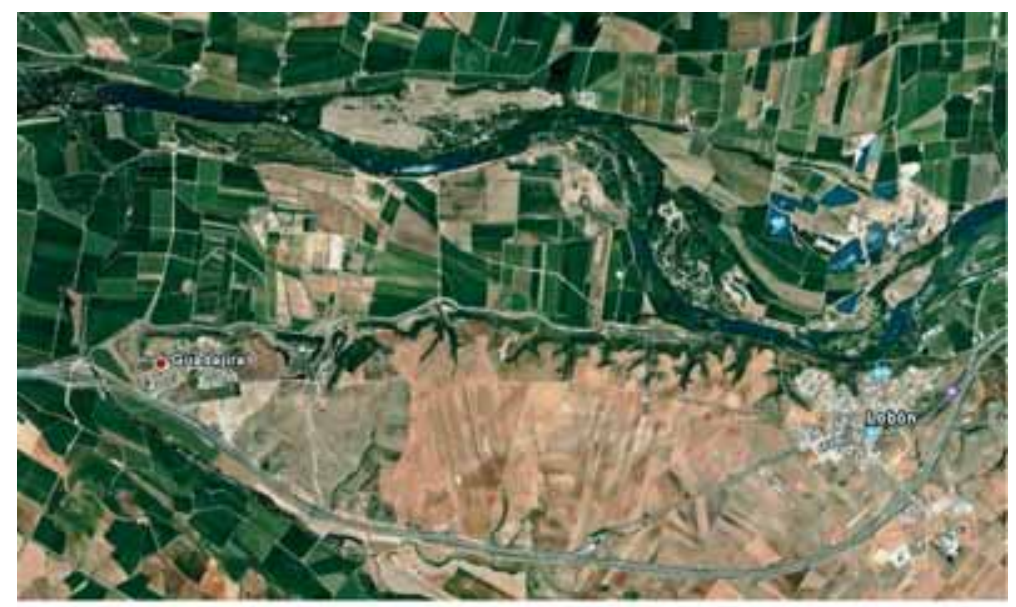

FIG. 1 - Plataforma terciaria de Lobón-Guadajira dominando la Vega Baja del Guadiana (Foto Google Earth a 6500 m.s.n.m.).

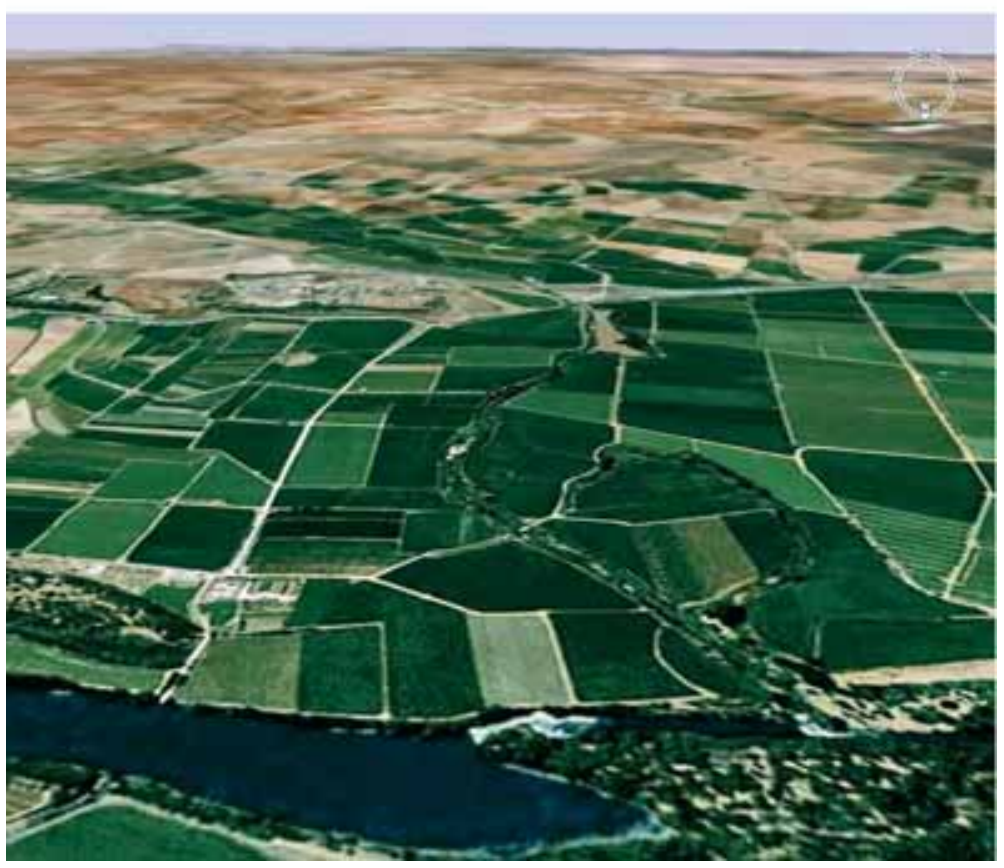

FIG. 2 - Vista aérea oblicua de la zona ocupada por la antigua Dipo desde el Norte (Foto Google Earth a 1000 m.s.n.m.). 
Est. II

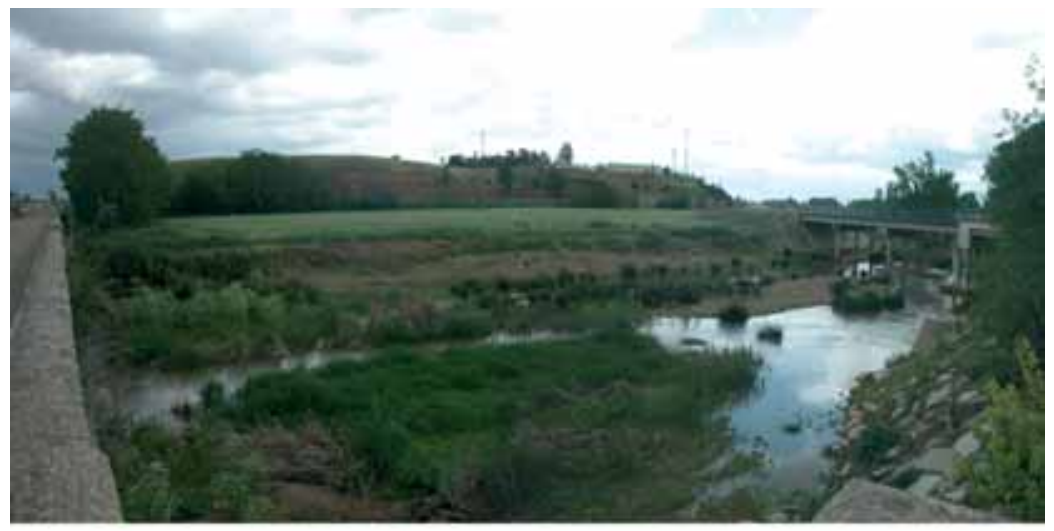

Fig. 3 - Plataforma ocupada por la antigua Dipo desde el lado occidental del río Guadajira.

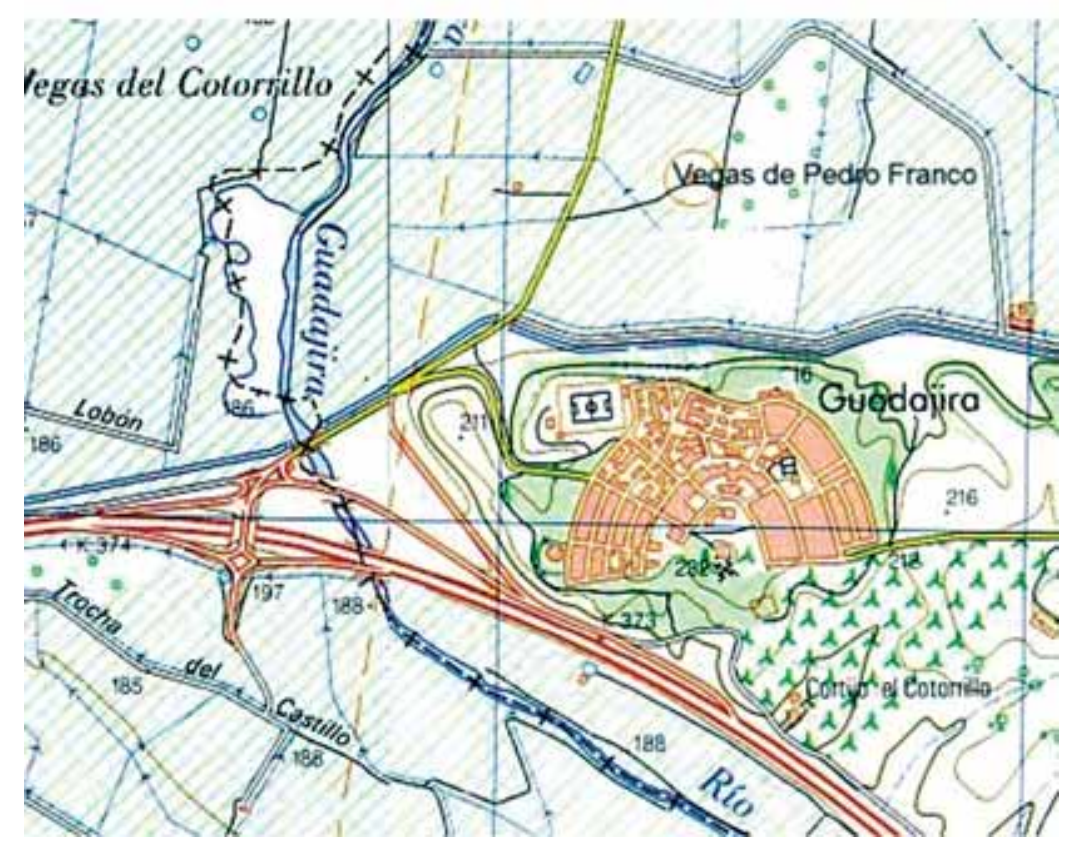

FIG. 4 - Planta de la zona ocupada por la antigua Dipo, según el mapa 1:50.000. 


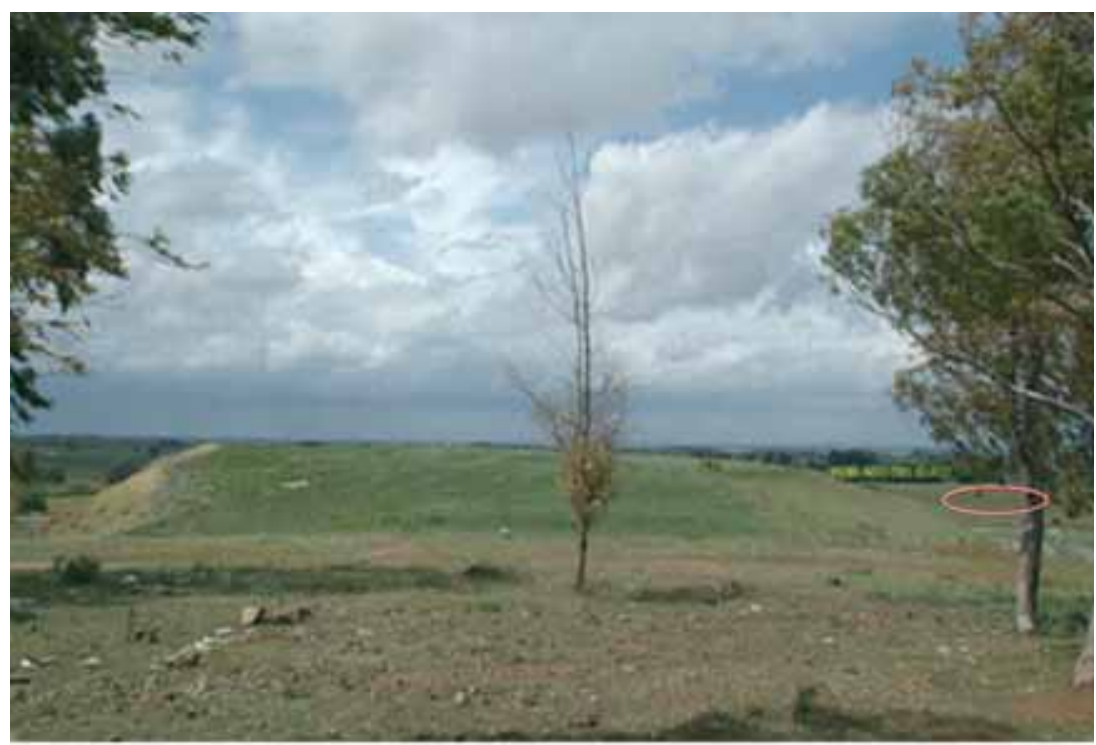

FIG. 5 - Espolón hacia el Guadiana de la zona ocupada por la antigua Dipo, con el lugar de hallazgo de restos arqueológicos señalado.
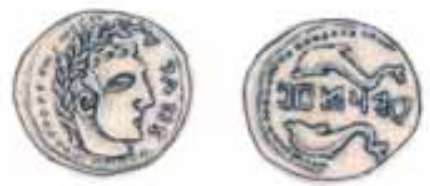

a

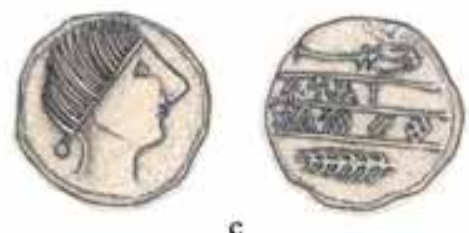

c

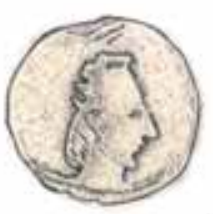

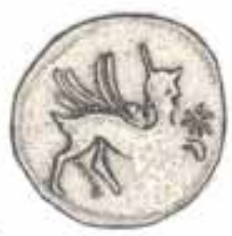

b

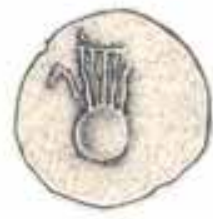

d

FIG. 6 - a-d. Monedas de Salacia, Castulo, Obulco y Carbula halladas en Guadajira (según J. M. Jerez Linde). 
Est. IV

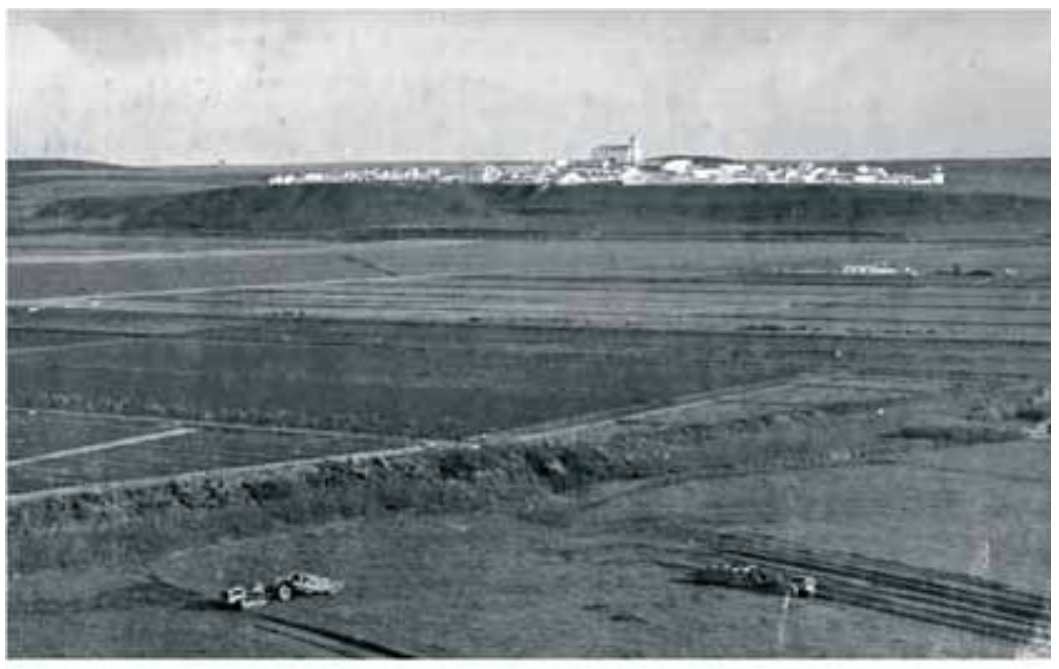

FIG. 7 - Remociones de tierras en la Vega del Guadiana con el pueblo de Guadajira al fondo, hacia 1960 (Foto Consejería de Agricultura de la Junta de Extremadura).

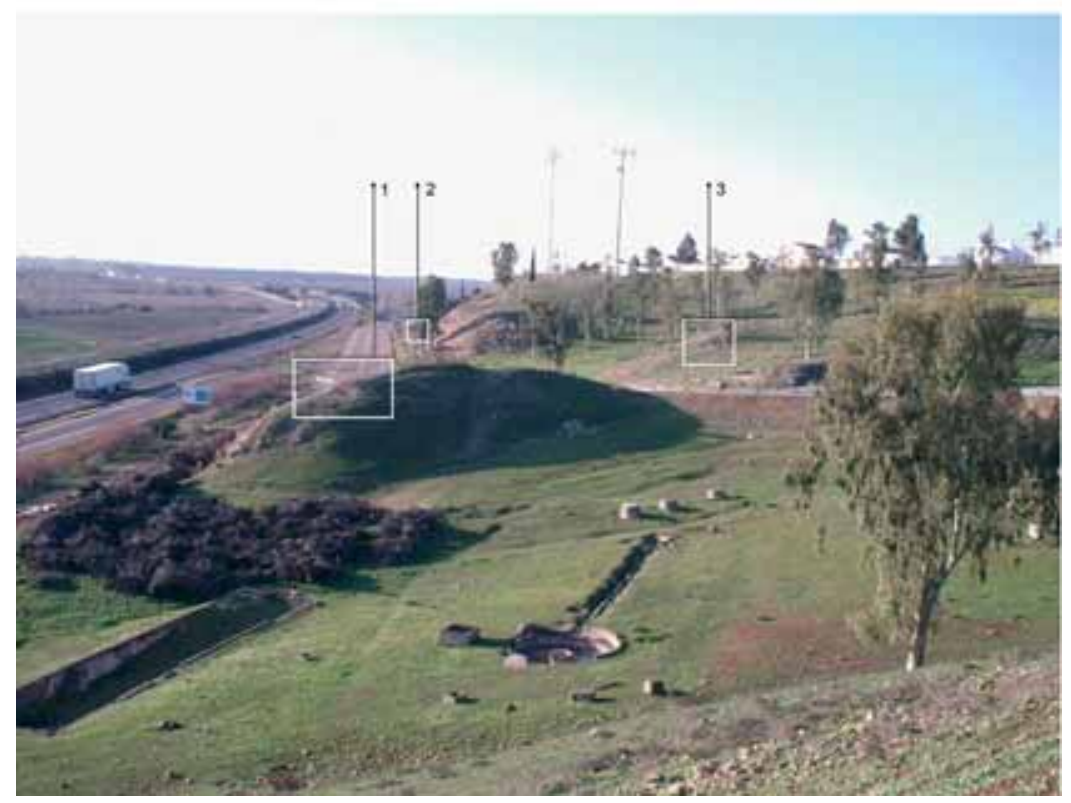

FIG. 8 - Espolón donde se ubica Dipo desde el Sur, con la vaguada que la limita y las tumbas calcolíticas (foto J. M. Jerez Linde). 
Est. V

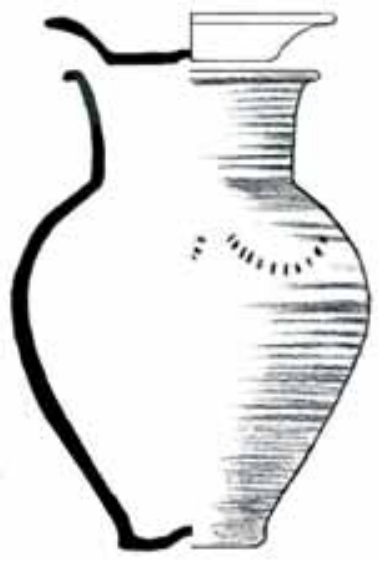

FIg. 9 - Urna turdetana con su tapadera de una tumba aparecida al Sur de Guadajira (según J. M. Jerez Linde).
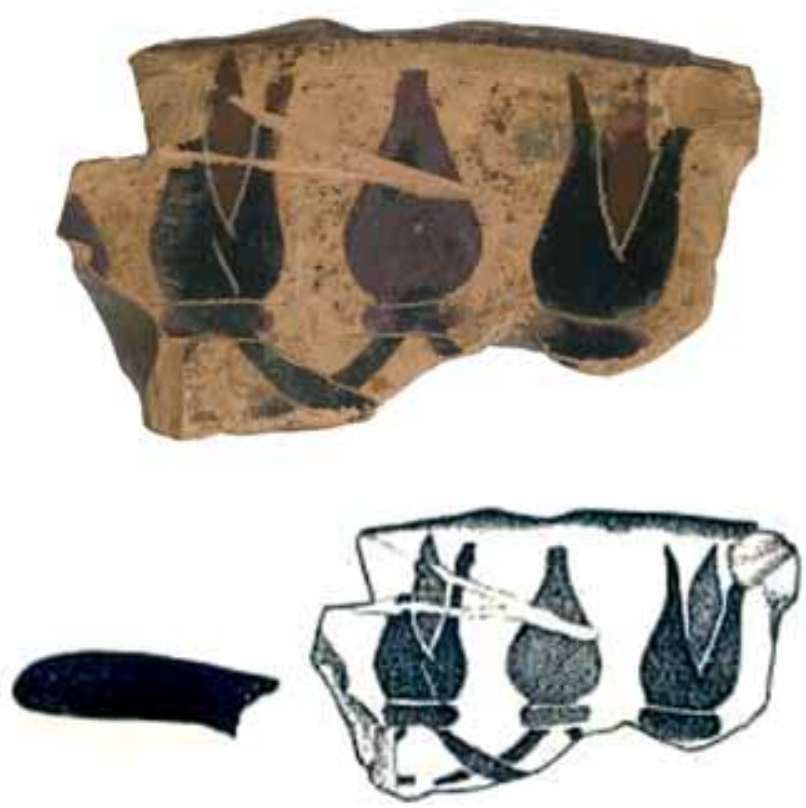

FIg. 10 - Fragmento de plato ático atribuido al Pintor de Londres B-76 hallado en El Cuco (según J. Jiménez Ávila). 
EsT. VI
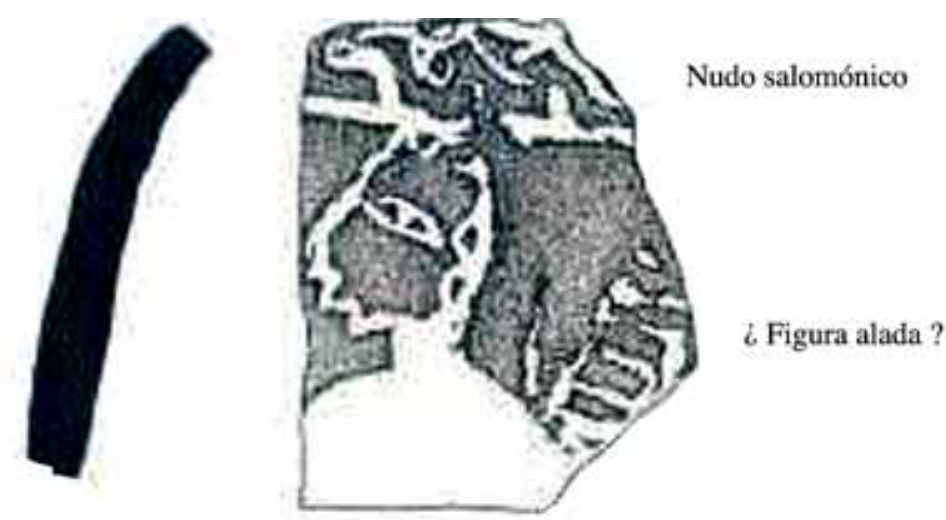

FIG. 11 - Fragmento de cerámica tipo Medellín de El Cuco (según J. M. Jerez Linde).
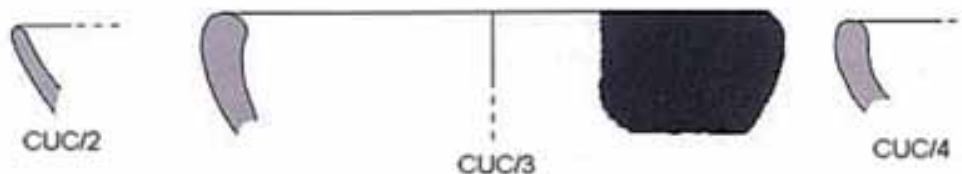

FIG. 12 - Fragmentos áticos de barniz negro hallado en El Cuco (según J. Jiménez Ávila). 

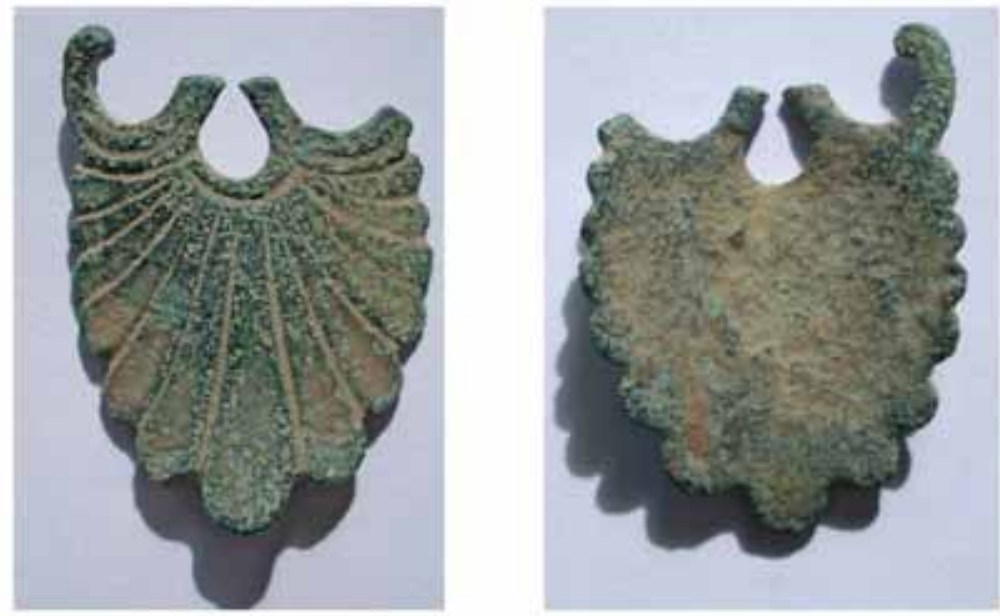

FIG. 13 - Palmeta de bronce de un oinochoe arcaico procedente de El Cuco (foto J. M. Jerez Linde).
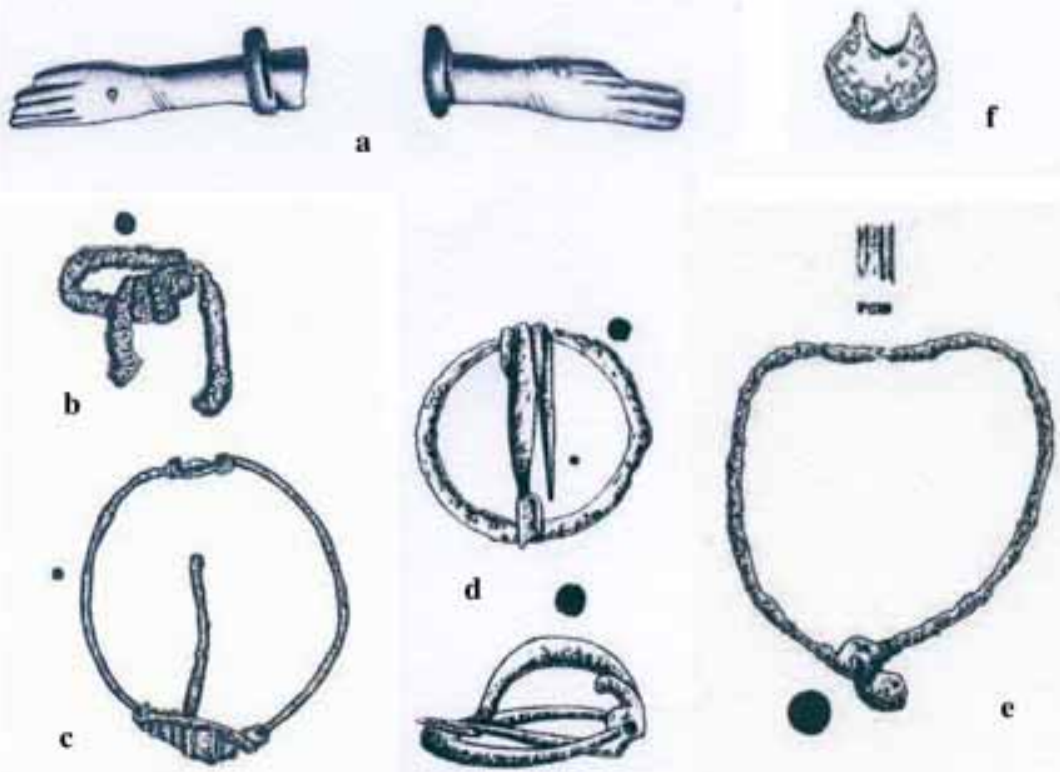

FIG. 14 - Objetos de bronces procedentes de El Cuco (según J. M. Jerez Linde) 
Est. VIII

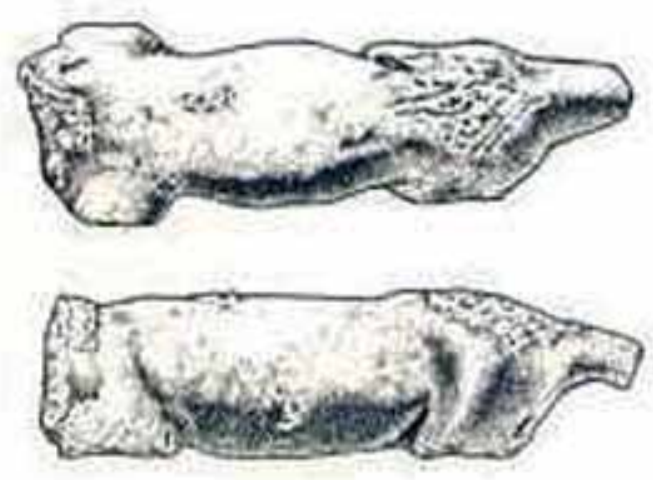

FIG. 15 - Terracota de felino? procedente de El Cuco (según J. M. Jerez Linde).

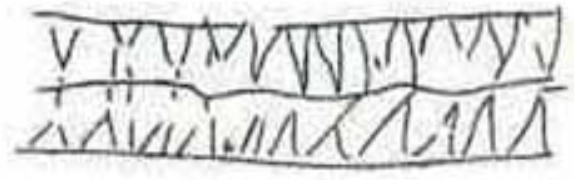

Fusayola
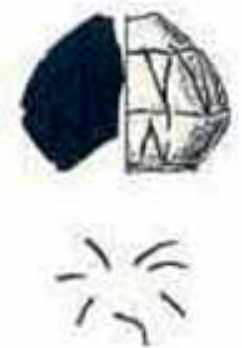

FIg. 16 - Fusayola decorada procedentes de El Cuco (según J. M. Jerez Lindes 
Est. IX
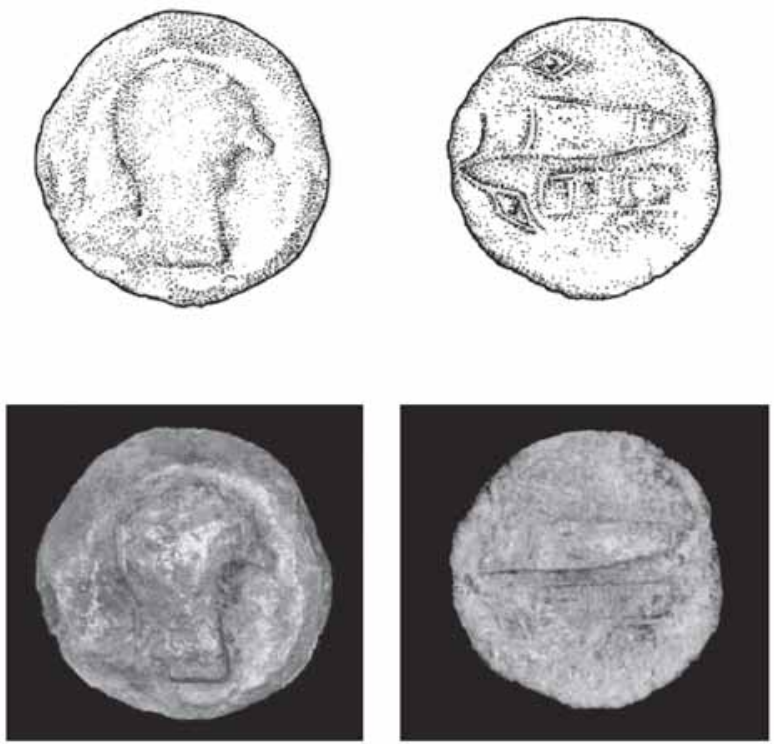

a
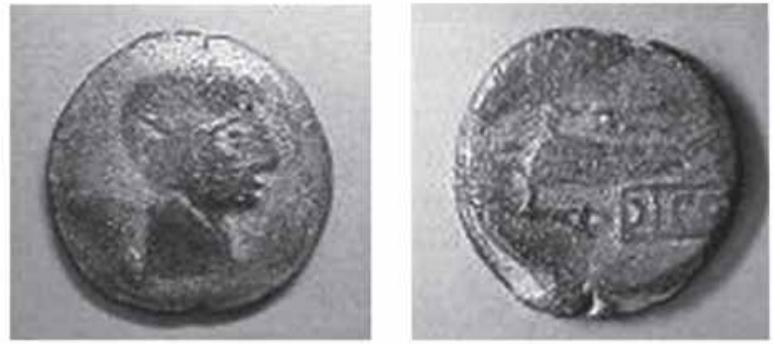

b

Fig. 17 - Monedas de Dipo halladas en Guadajira: a, en la villa romana de Pedro Franco, en la Vega del Guadiana frente a Guadajira (según J. M. Jerez Linde); $b$, sin procedencia concreta (foto Internet). 


\section{Est. X}

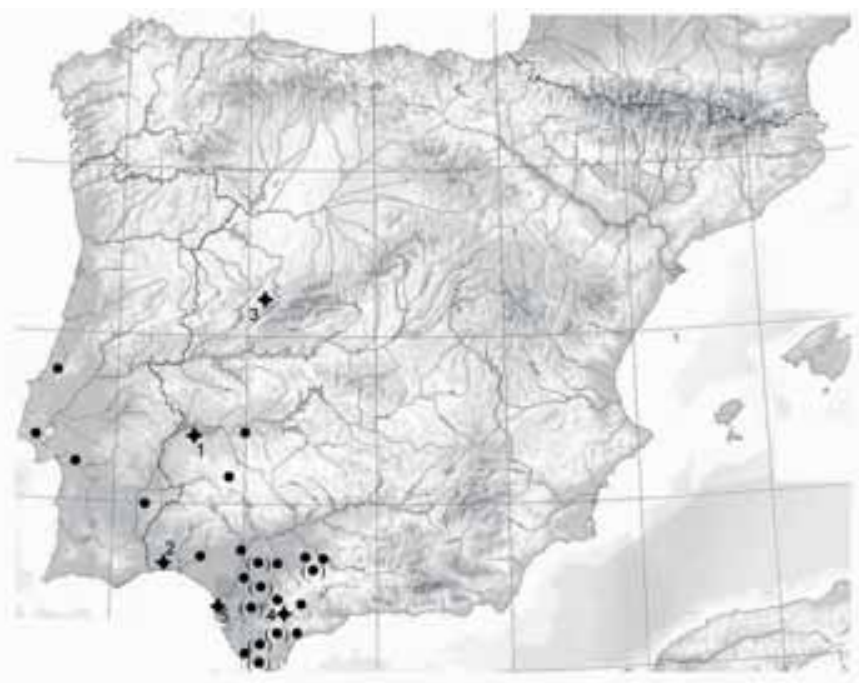

Fig. 18 - Topónimos con -ipo. Las cruces indican los casos con la forma más simple: 1, Dipo; 2, Laepia, Lepe, Huelva; 3, Lippos, Valverde de Valdecasa,

Salamanca; 4, Saepo, Cerro de la Botinera, Algodonales, Cádiz; 5, Aipora, en situación desconocida, quizás en Sanlúcar de Barrameda, Cádiz.

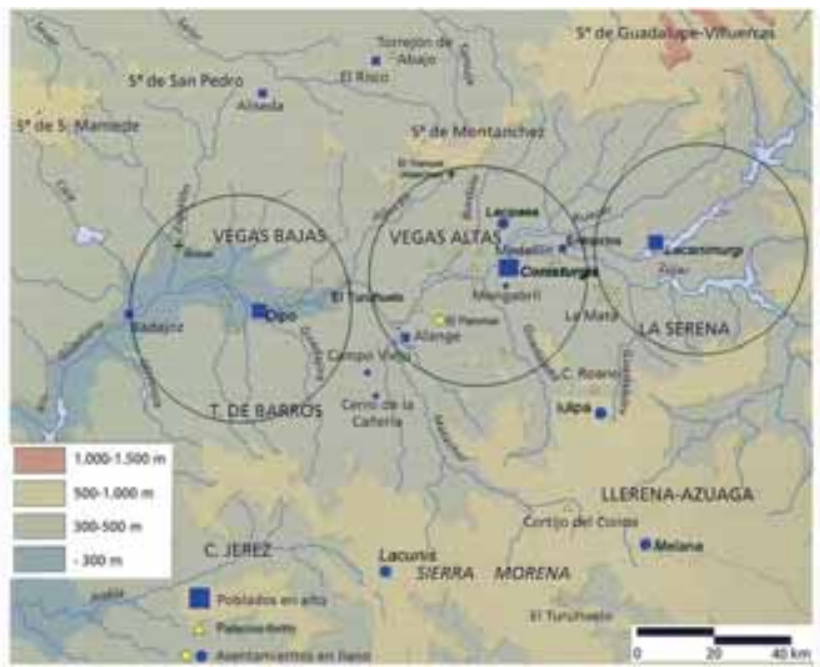

FIG. 19 - Territorios de las ciudades-estado orientalizantes del Valle del Guadiana. 
Est. XI

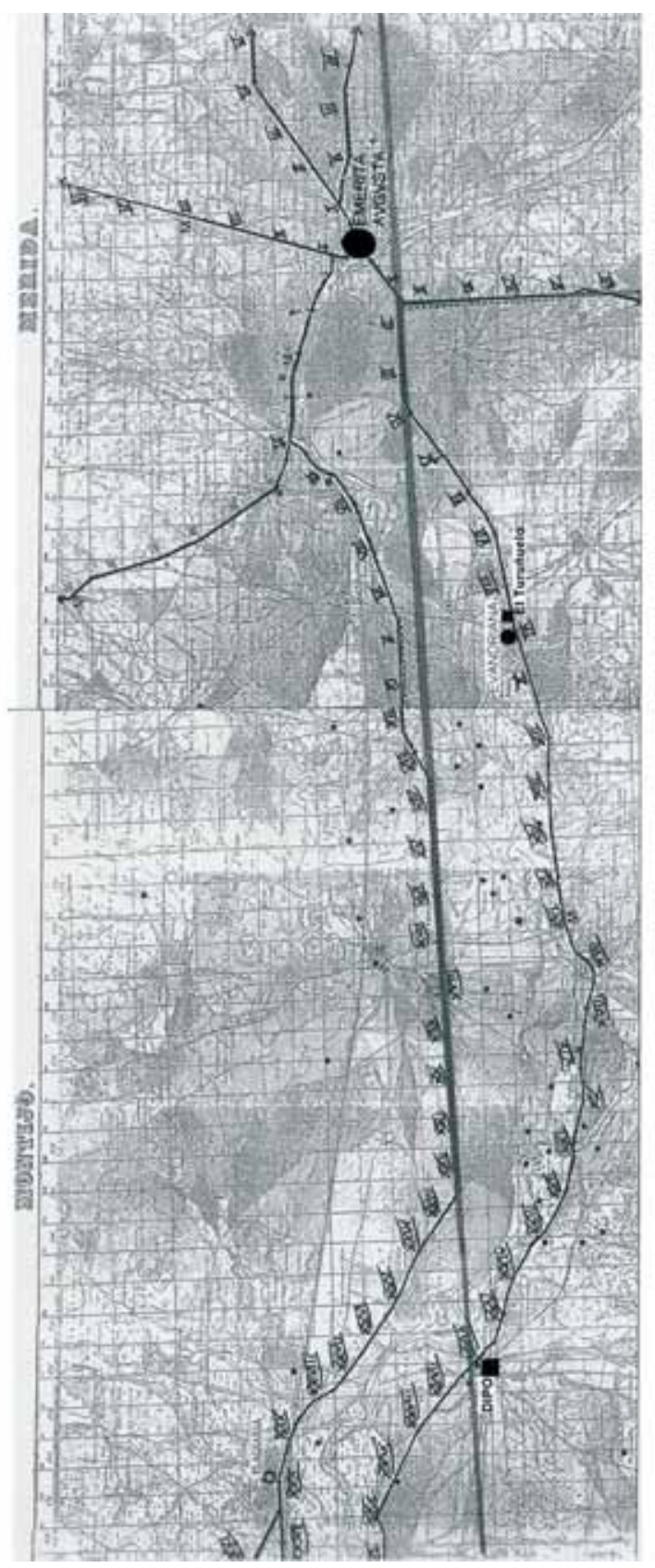

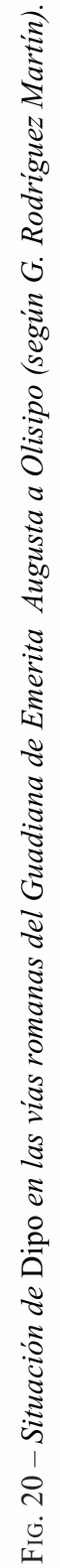


EsT. XII

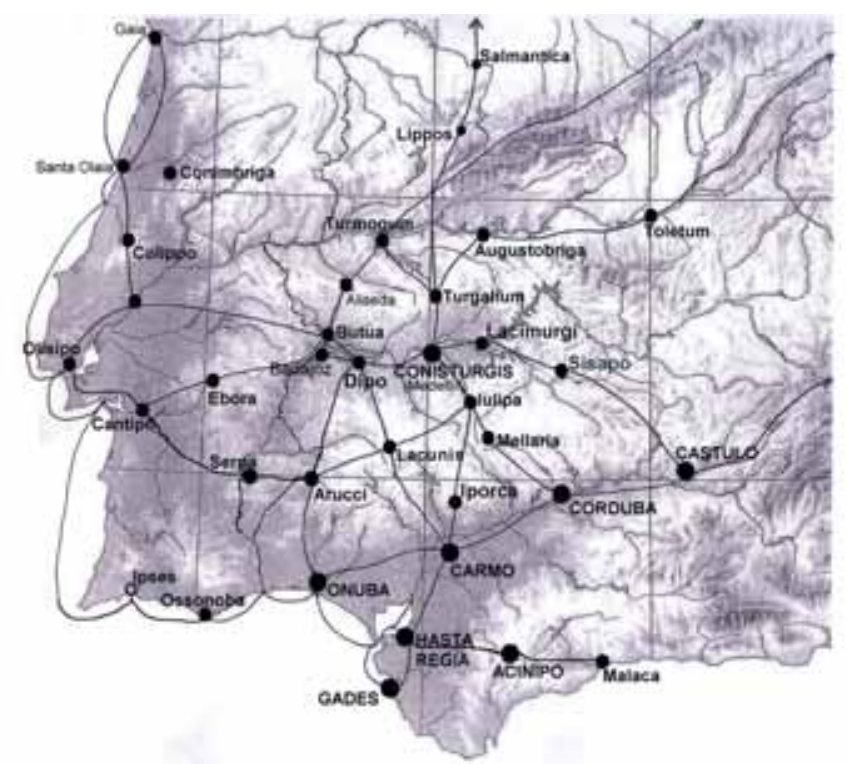

FIg. 21 - Vías de comunicación prerromanas del Suroeste de la Península Ibérica.

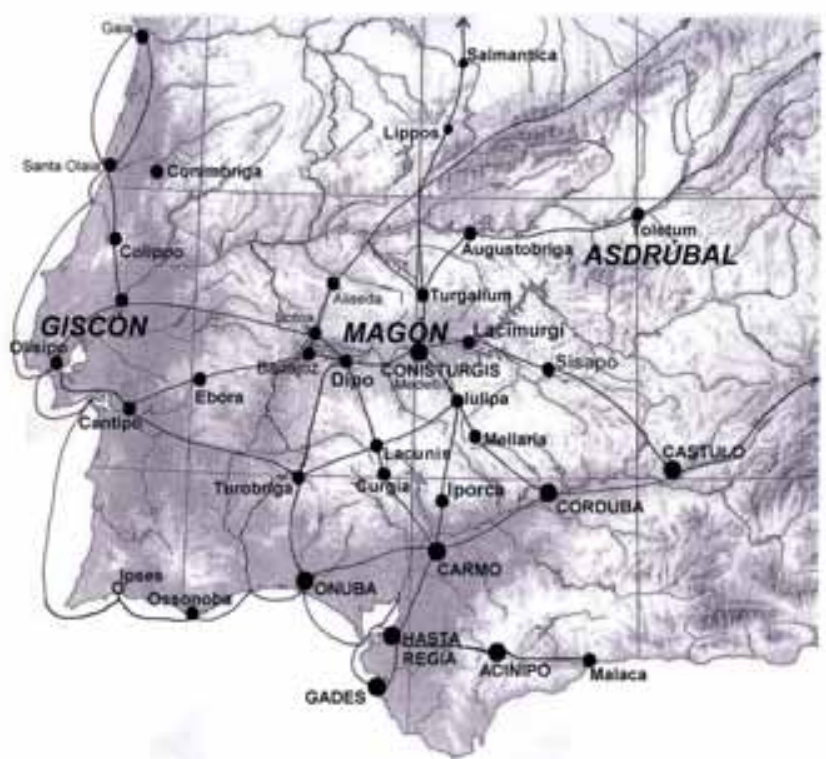

FIG. 22 - Situación de los ejércitos púnicos el 210 a.C. durante la II Guerra Púnica controlando la vía de Olisipo a Toletum que pasaba por Dipo. 


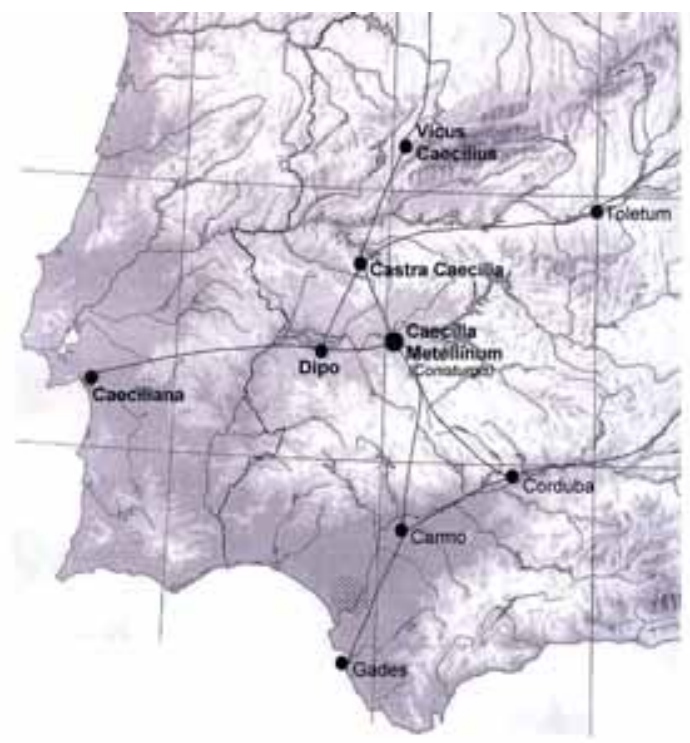

FIG. 23 - Dipo y las vías de comunicación del Guadiana en la Guerra de Sertorio (en negrita, fundaciones y destrucciones de Q. Cecilio Metelo).

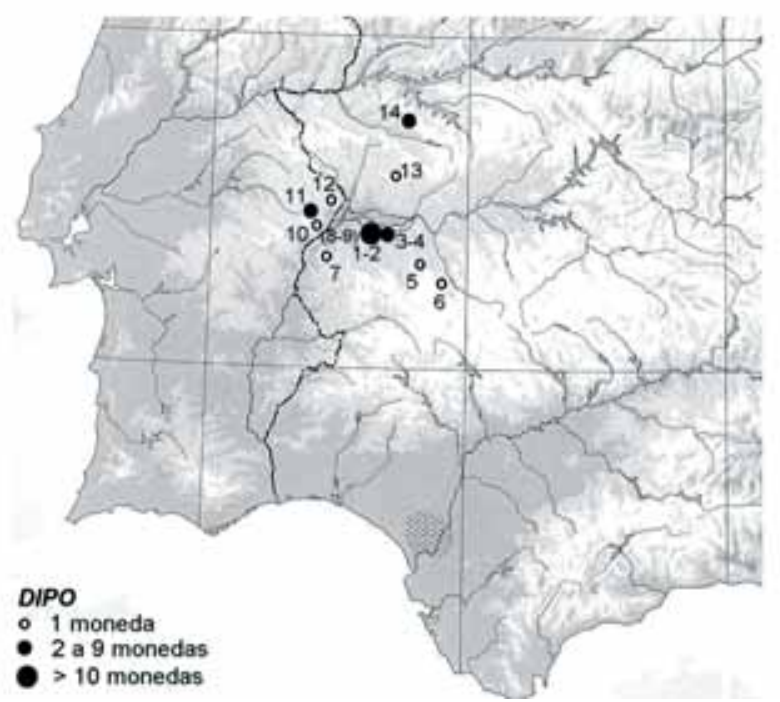

FIG. 24 -Dispersión de los hallazgos de monedas de Dipo (ver texto). 


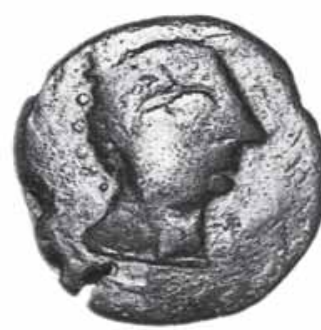

1
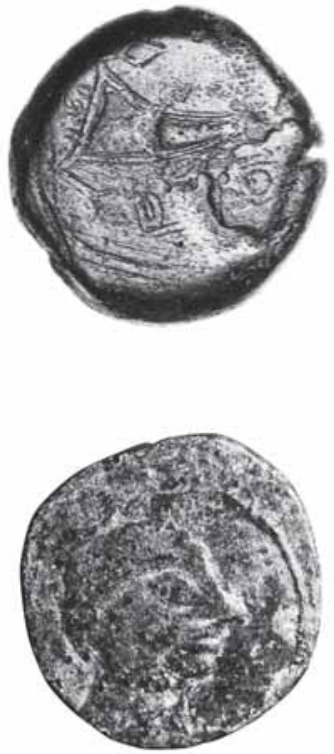

4

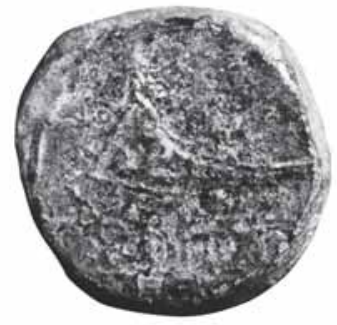

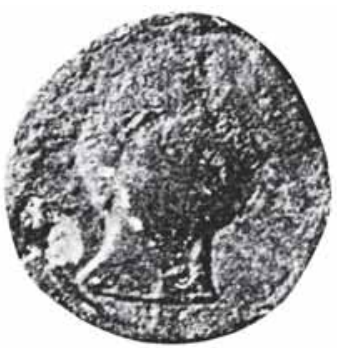

2
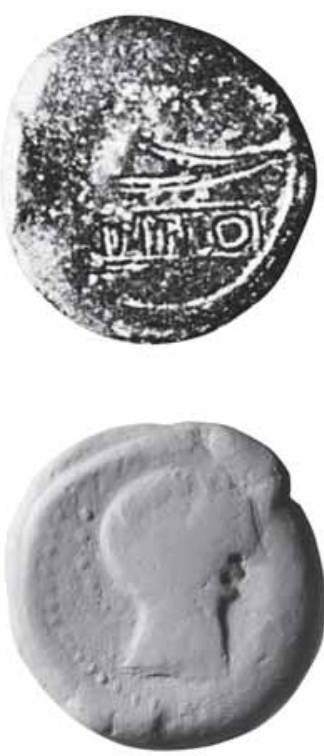

6

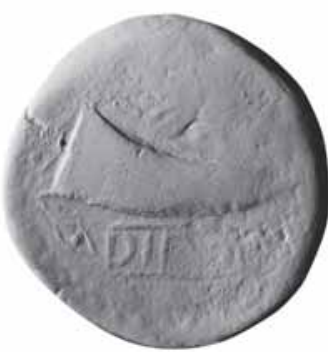

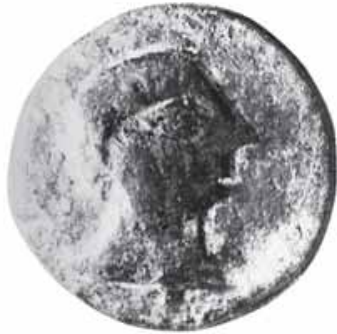

3
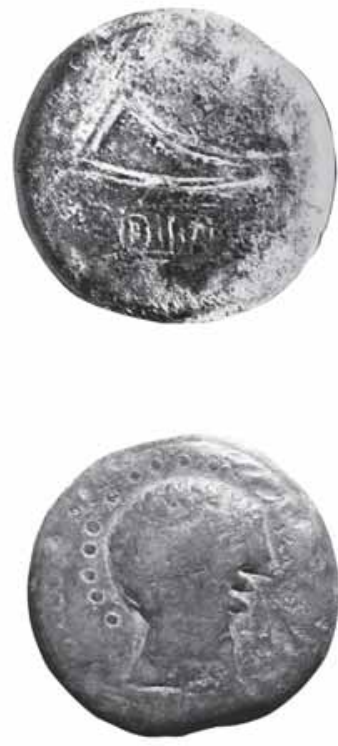

7

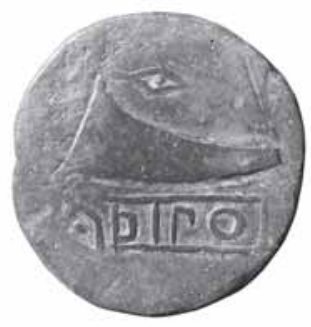

FIG. 25 - Monedas de Dipo (Cat. $\left.n^{o} 1-7\right)$ 
Est. XV

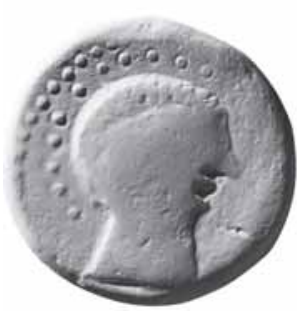

8
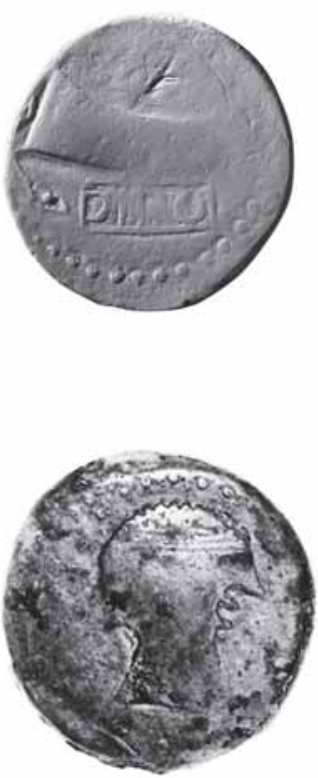

19

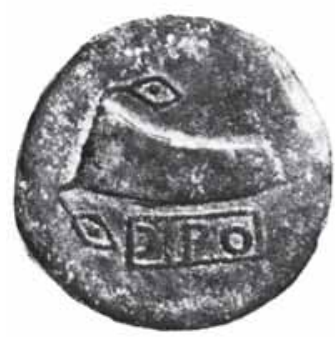

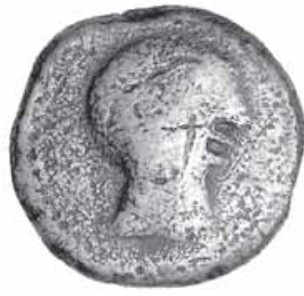

9
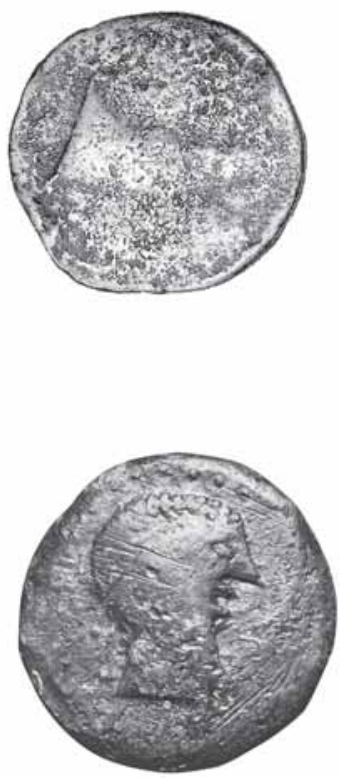

20

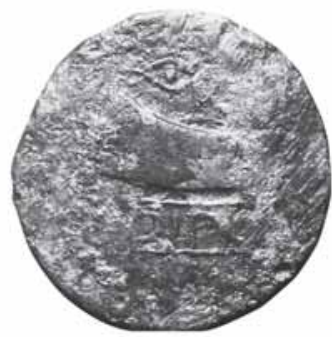

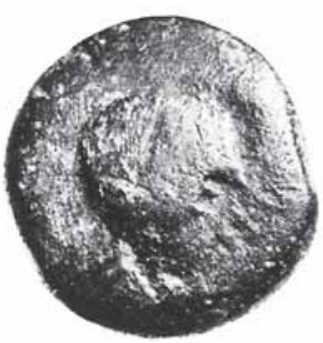

10
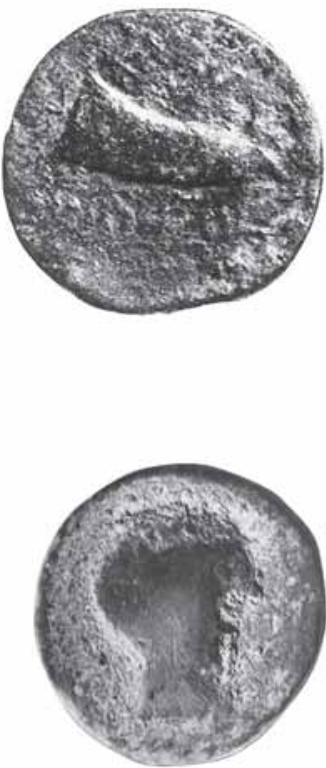

21

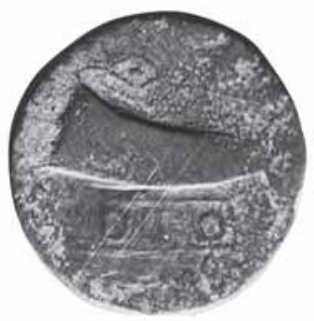

FIG. 26 - Monedas de Dipo (Cat. $\left.n^{o} 8-10,19-21\right)$ 


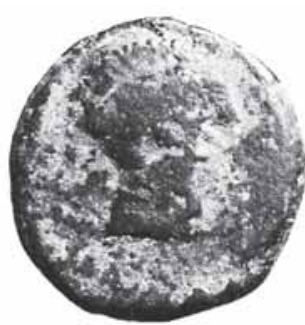

22
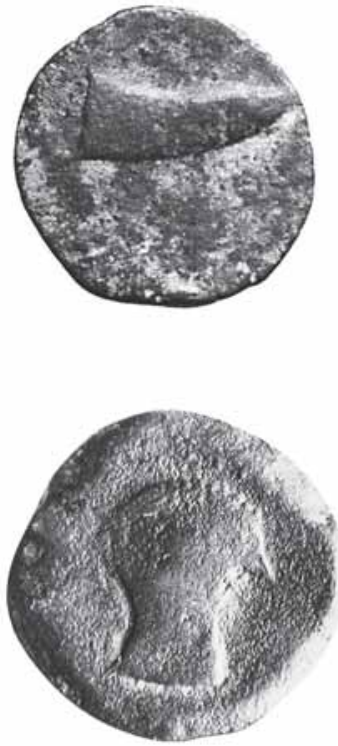

29

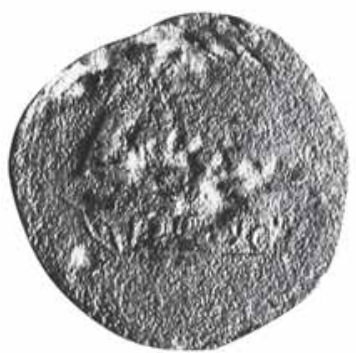

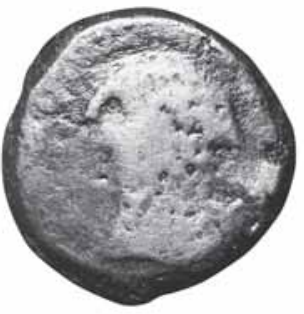

23
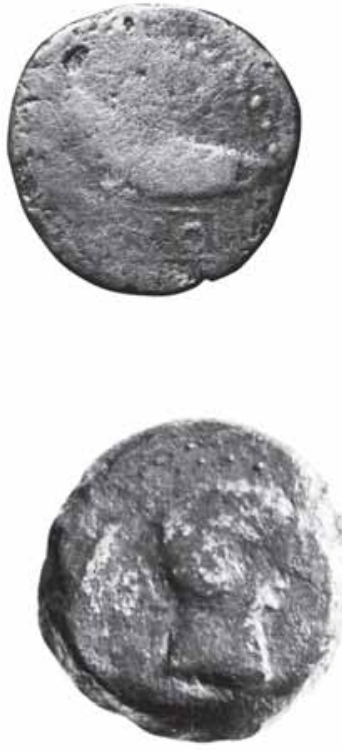

30

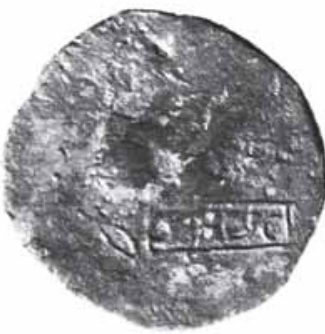

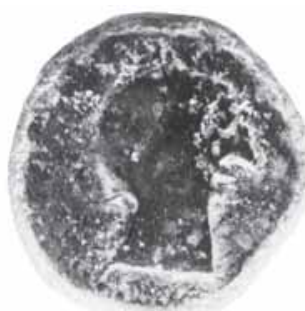

24
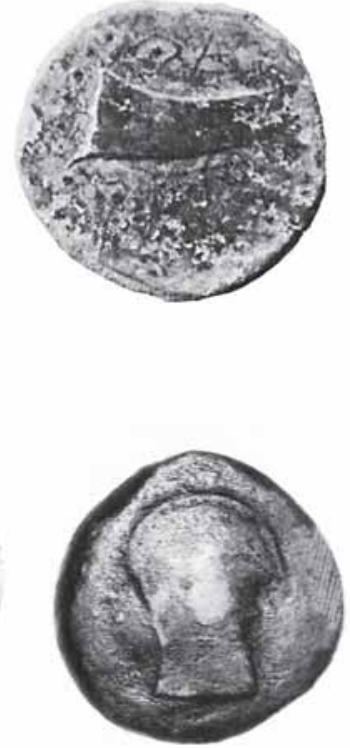

32

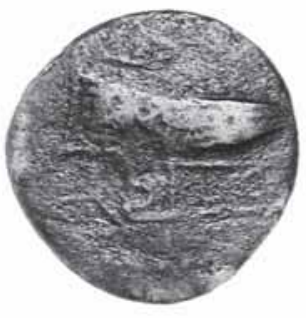

Fig. 27- Monedas de Dipo (Cat. $\left.n^{\circ} 22-24,29-30,32\right)$ 


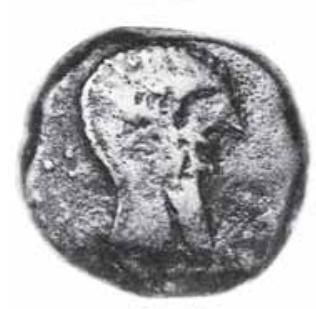

33
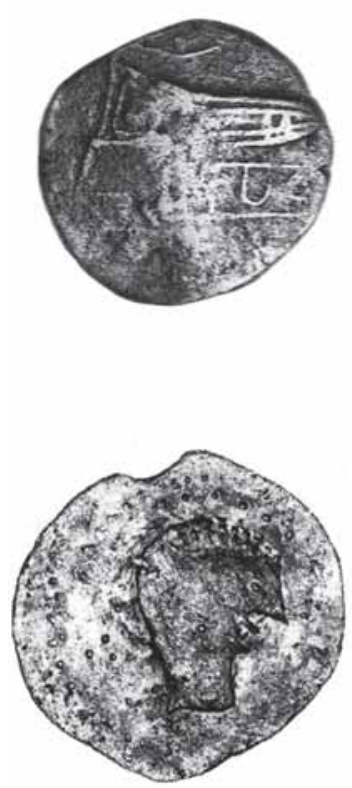

44

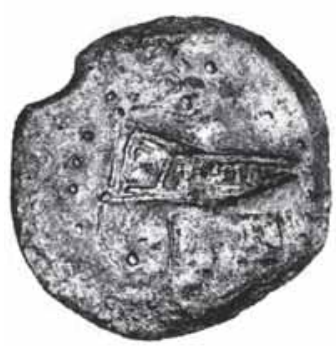

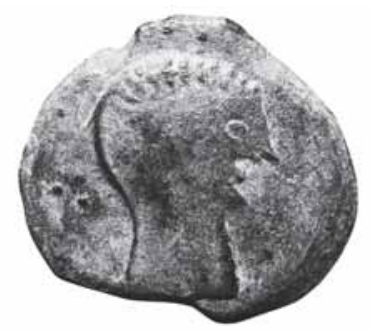

37
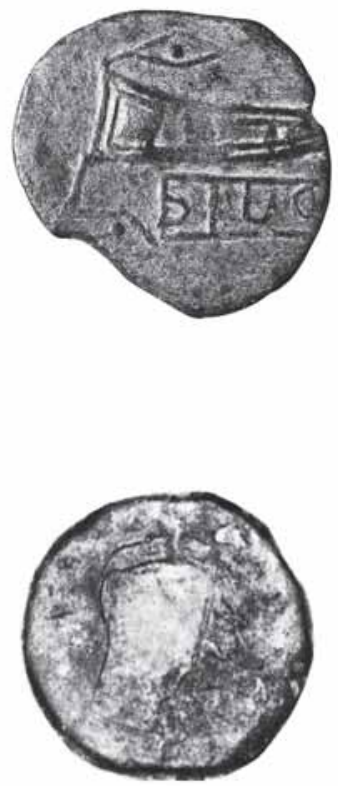

55

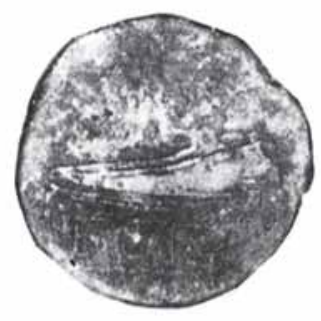

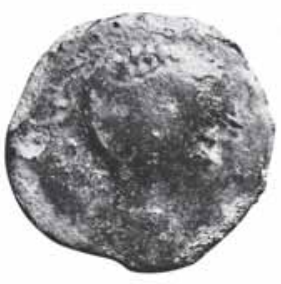

38

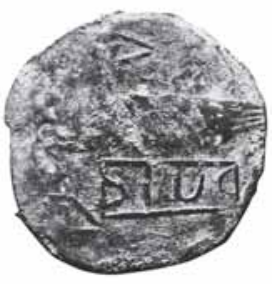

56

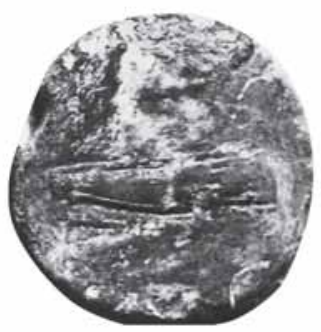

FIG. 28 - Monedas de Dipo (Cat. $\left.n .^{\circ} 33,37-38,44,55-56\right)$ 
Est. XVIII

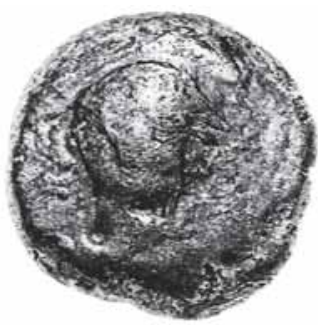

57
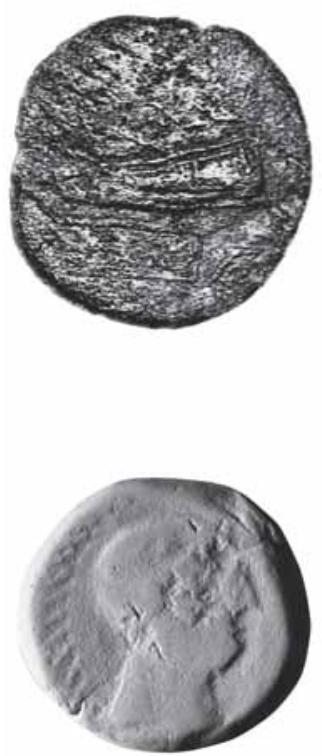

61

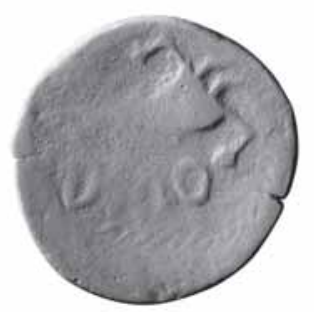

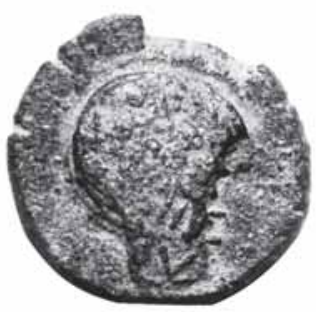

59
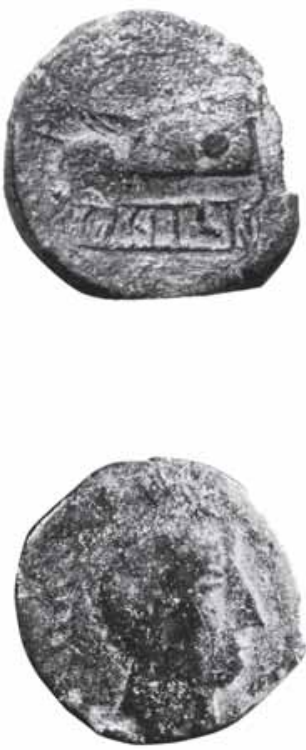

62

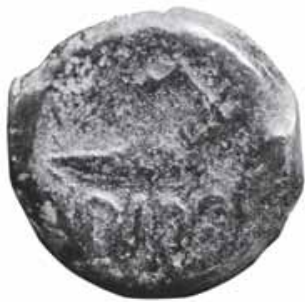

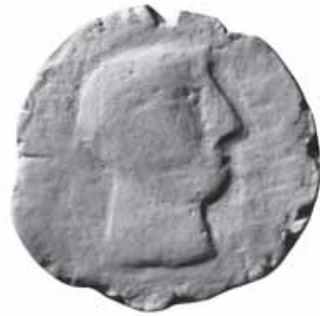

60
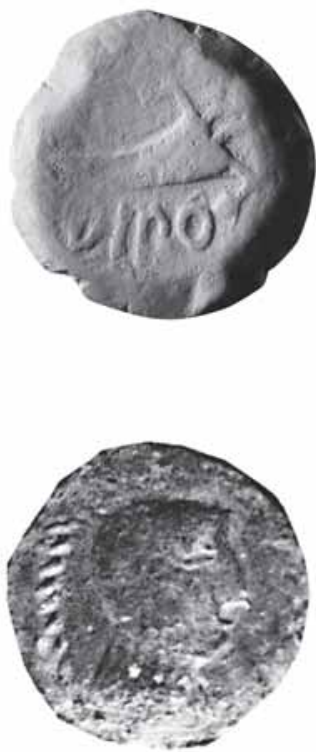

69

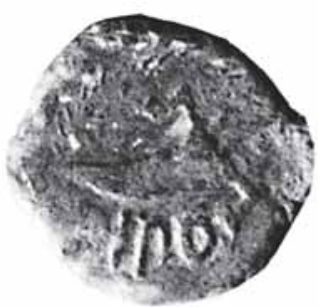

FIG. 29 - Monedas de Dipo (Cat. $n^{\circ}$ 57, 59-60, 61-62, 69) 